Universidad de Lima

Facultad de Ingeniería y Arquitectura

Carrera de Ingeniería Industrial

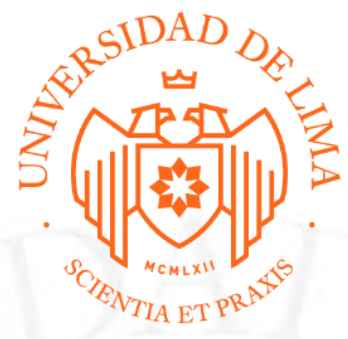

\title{
ESTUDIO DE PRE FACTIBILIDAD PARA LA INSTALACIÓN DE UNA PLANTA PRODUCTORA DE UNA BEBIDA A BASE DE MANZANILLA, MATICO, MUÑA Y ROMERO LISTA PARA TOMAR
}

Trabajo de investigación para optar el Título Profesional de Ingeniero Industrial

Jhairo Alex Cahuana Apolinario

Código 20111620

Asesor

Gustavo Adolfo Luna Victoria León

Lima - Perú

Setiembre de 2019 


\section{PRE FEASIBILITY STUDY FOR THE}

\section{INSTALLATION OF A PRODUCTION PLANT}

OF A BEVERAGE BASED ON CHAMOMILE, MATICO, MUÑA AND ROSEMARY READY TO DRINK 


\section{TABLA DE CONTENIDO}

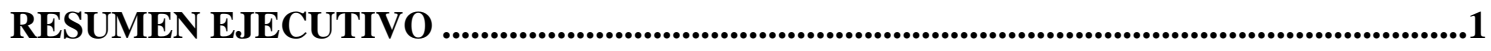

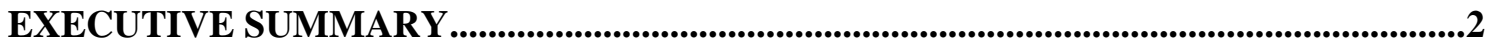

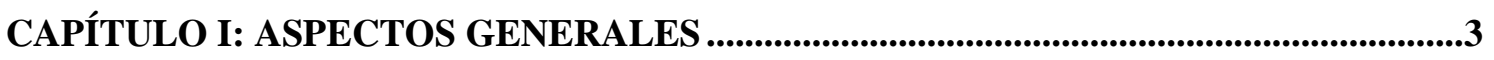

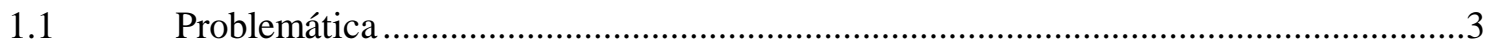

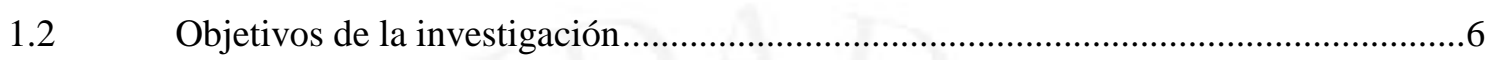

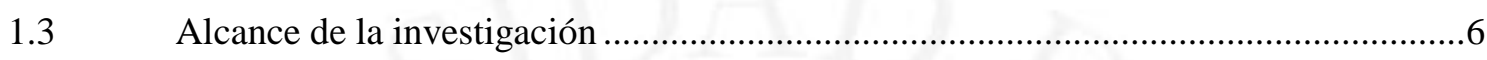

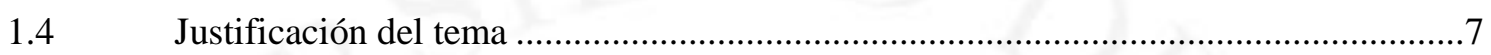

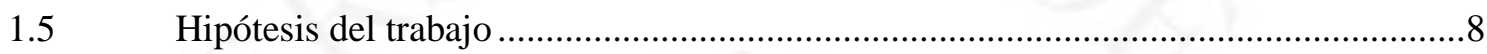

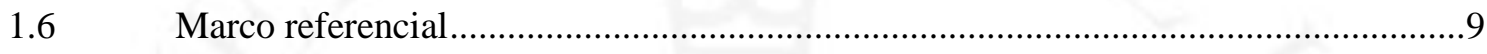

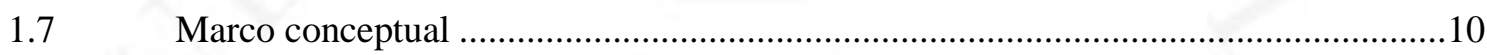

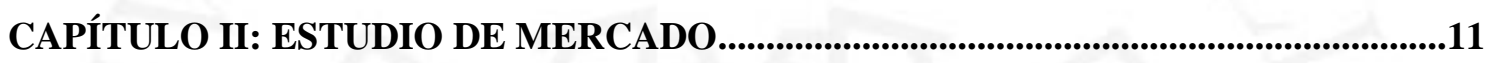

$2.1 \quad$ Aspectos generales del estudio de mercado...............................................................11

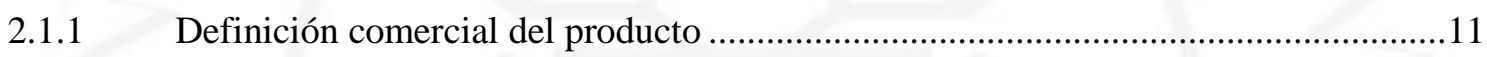

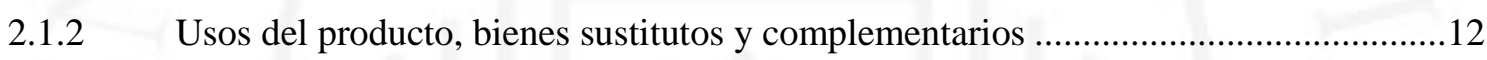

2.1.3 Determinación del área geográfica que abarcará el estudio .......................................14

2.1.4 Análisis del sector industrial (cinco fuerzas de PORTER) ...........................................15

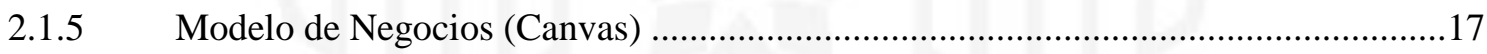

2.2 Metodología a emplear en la investigación de mercado (Uso de fuentes secundarias o primarias, muestreo, método de proyección de la demanda)......................................18

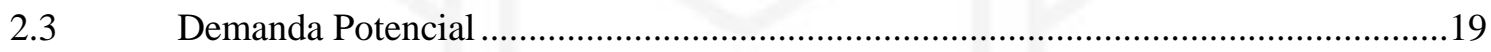

2.3.1 Patrones de consumo: incremento poblacional, estacionalidad, aspectos culturales..19

2.3.2 Determinación de la demanda potencial en base a patrones de consumo similares ...20

2.4 Determinación de la demanda de mercado en base a fuentes secundarias o primarias ....21

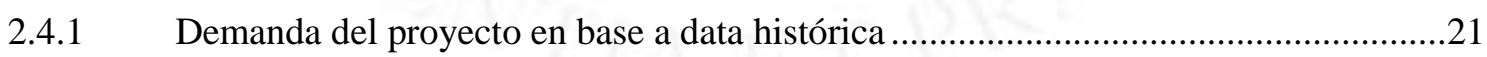

2.4.1.1 Demanda Interna Aparente Histórica tomando como fuente bases de datos de Producción, Importaciones y Exportaciones o las ventas tomando como fuente bases

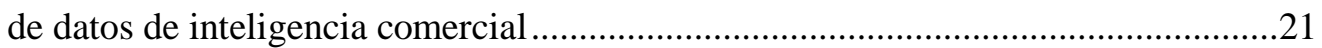

2.4.1.2 Proyección de la demanda (Serie de tiempo o asociativas) ........................................21

2.4.1.3 Definición del mercado objetivo teniendo en cuenta criterios de segmentación.........22

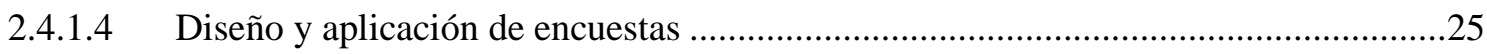

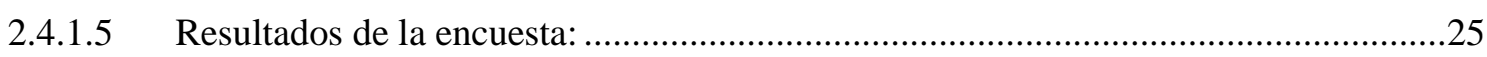

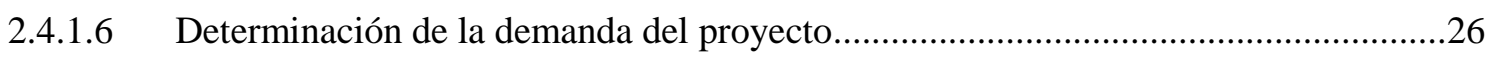




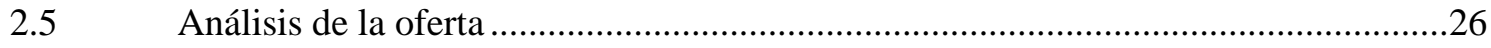

2.5.1 Empresas productoras, importadoras y comercializadoras........................................26

2.5.2 Participación de mercado de los competidores actuales ..............................................27

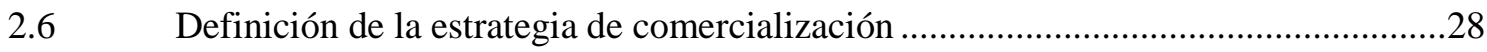

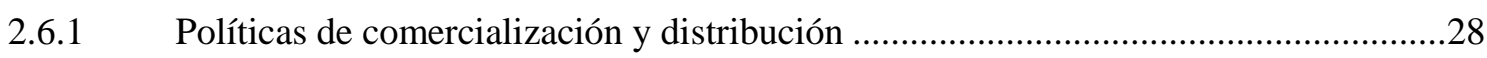

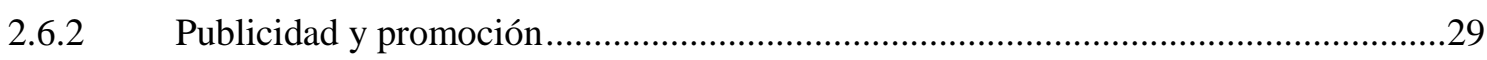

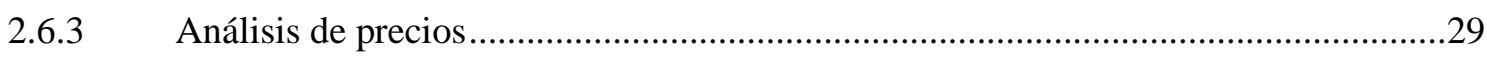

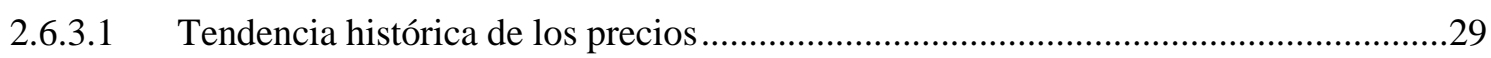

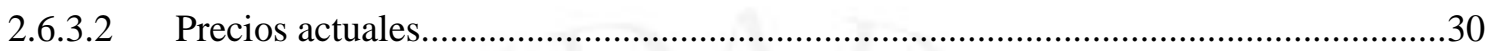

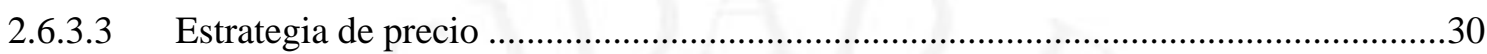

CAPÍTULO III: LOCALIZACIÓN DE PLANTA ...................................................................31

3.1 Identificación y análisis detallado de los factores de localización ................................31

3.2 Identificación y descripción de las alternativas de localización ..................................32

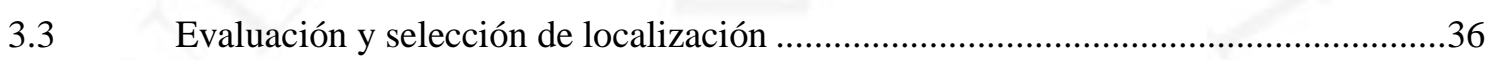

3.3.1 Evaluación y selección de la macro localización........................................................36

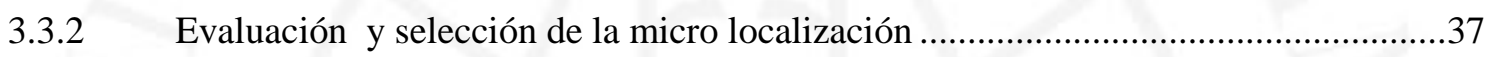

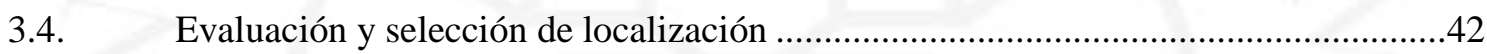

CAPÍTULO IV: TAMAÑO DE PLANTA........................................................................43

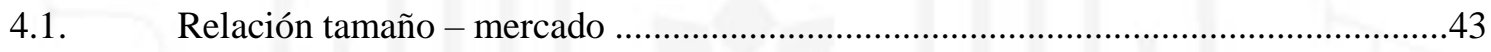

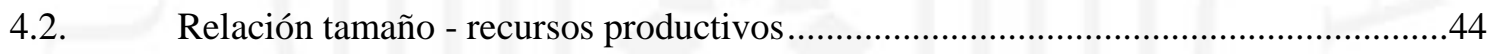

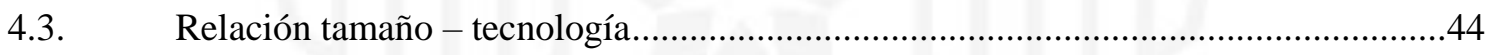

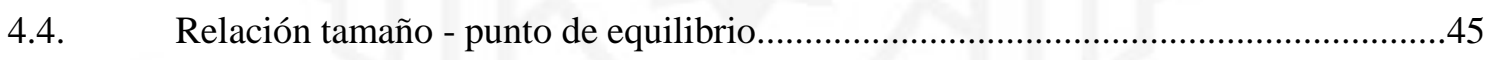

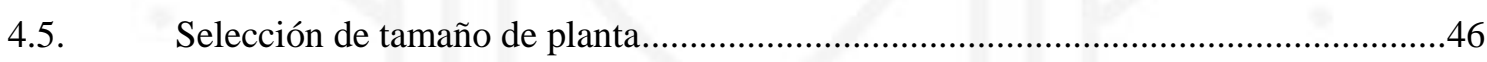

CAPÍTULO V: INGENIERÍA DEL PROYECTO.......................................................................47

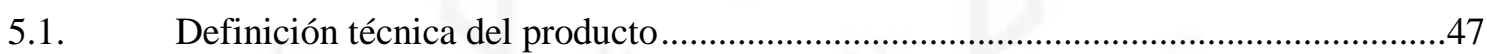

5.1.1. Especificaciones técnicas, composición y diseño del producto.....................................47

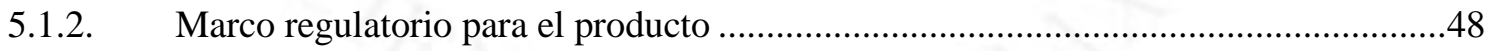

5.2. Tecnologías existentes y procesos de producción ........................................................49

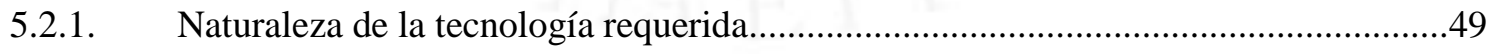

5.2.1.1. Descripción de las tecnologías existentes.................................................................49

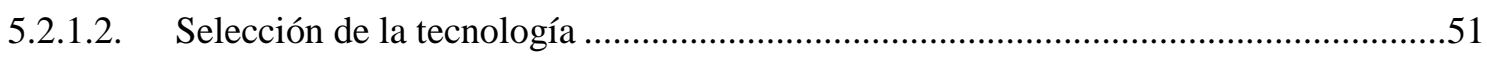

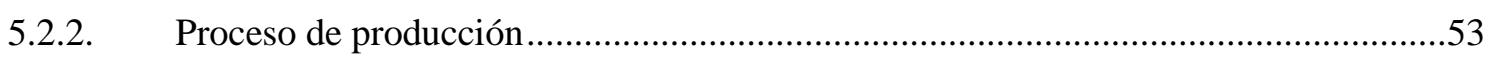

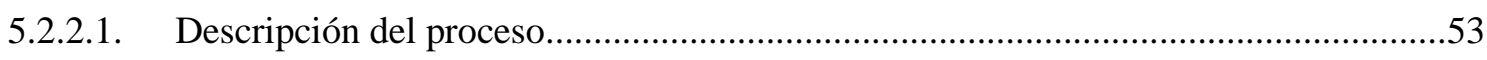

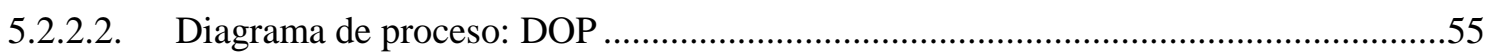

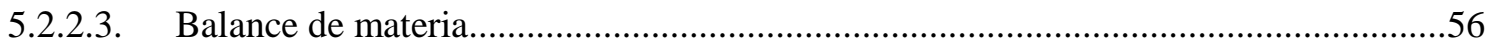

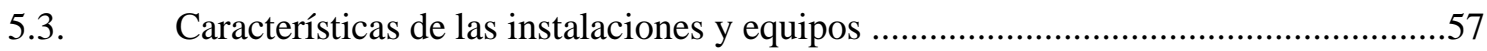




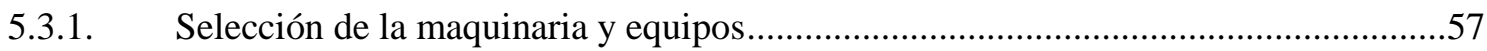

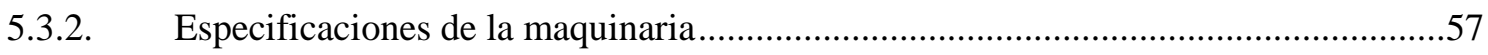

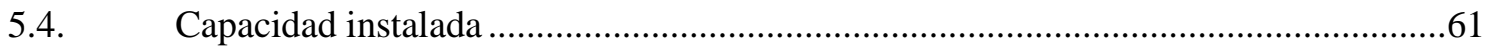

5.4.1. Cálculo detallado del número de máquinas y operarios requeridos ............................61

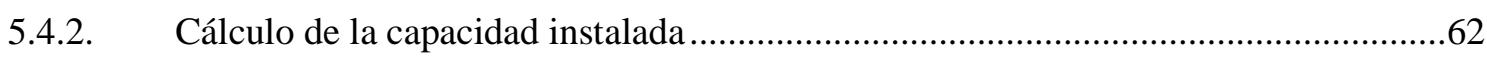

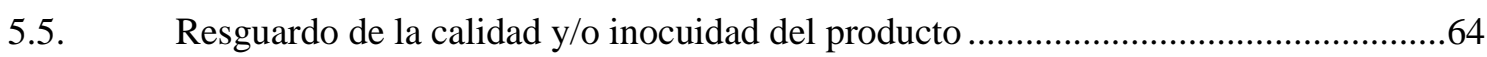

5.5.1. Calidad de la materia prima, de los insumos, del proceso y del producto...................64

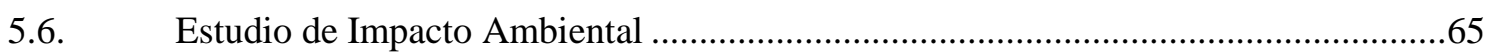

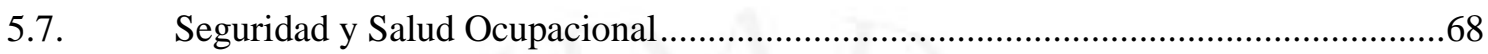

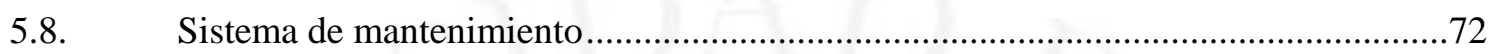

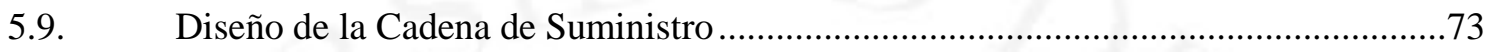

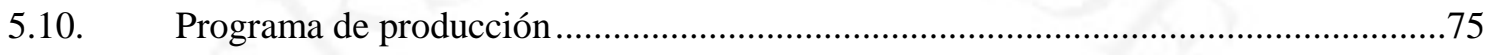

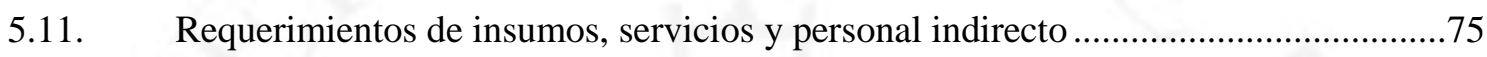

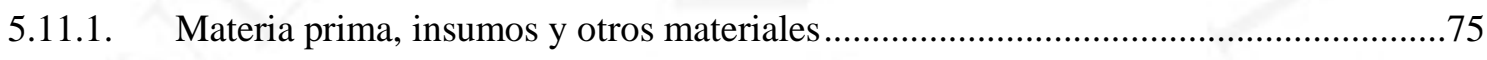

5.11.2. Servicios: energía eléctrica, agua, vapor, combustible, etc. …..................................76

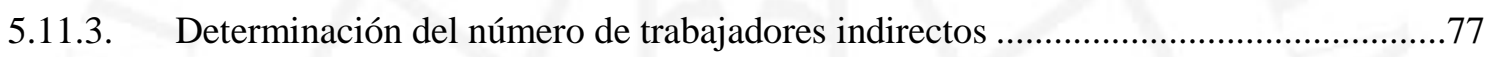

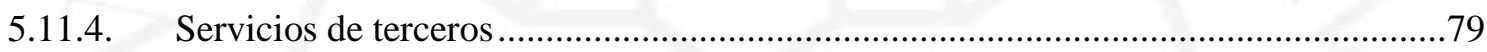

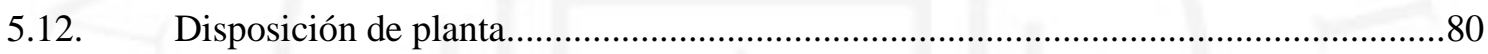

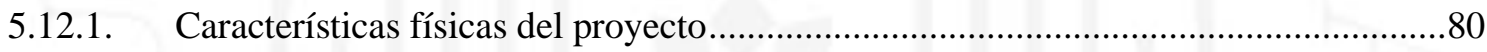

5.12.2. Determinación de las zonas físicas requeridas ......................................................... 82

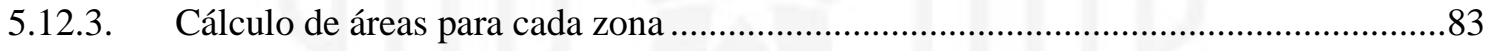

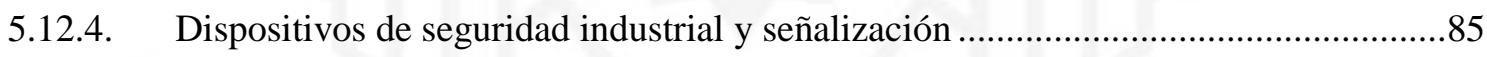

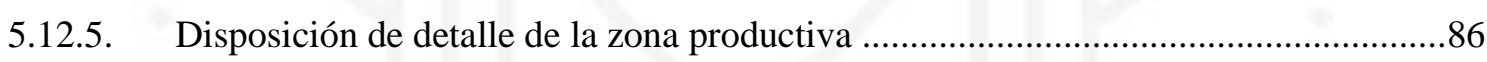

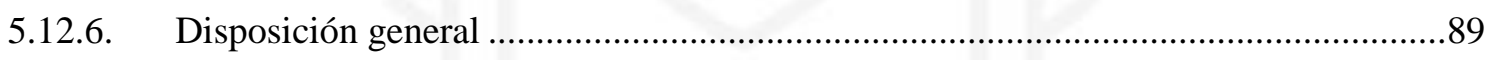

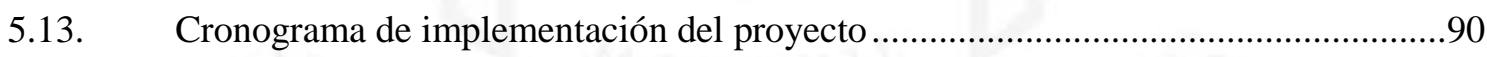

CAPÍTULO VI: ORGANIZACIÓN Y ADMINISTRACIÓN ................................................92

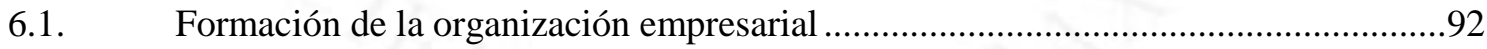

6.2. Requerimientos del personal directivo, administrativo y de servicios; y funciones

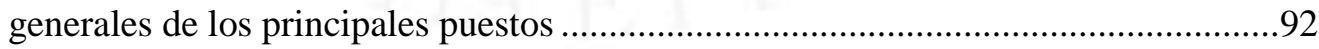

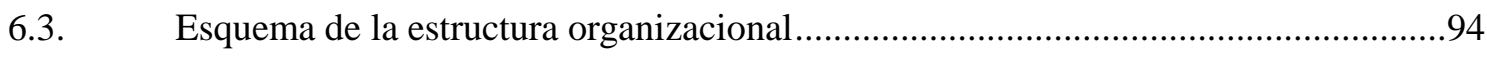

CAPÍTULO VII: PRESUPUESTOS Y EVALUACIÓN DEL PROYECTO ..........................96

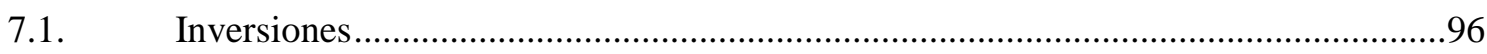

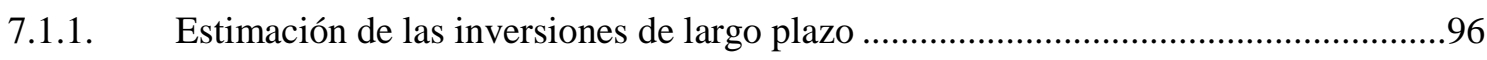

7.1.2. Estimación de las inversiones de corto plazo ...............................................................99

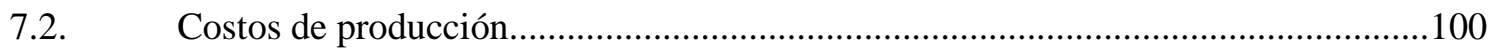

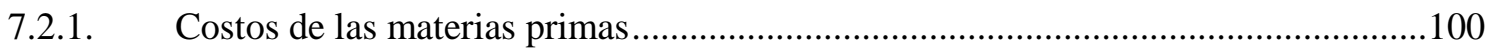




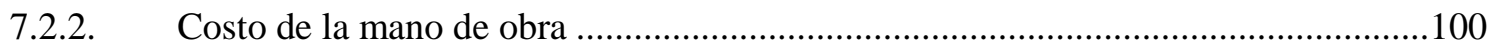

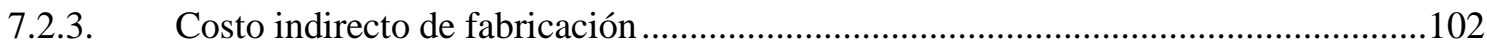

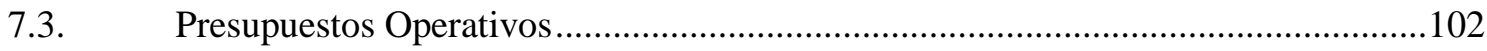

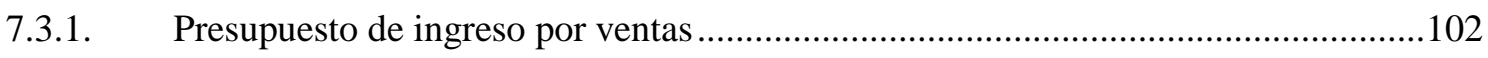

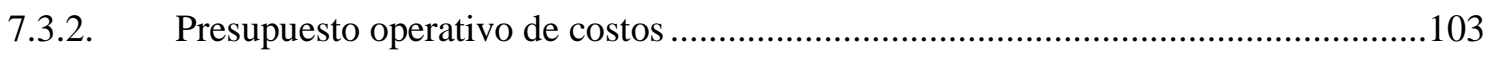

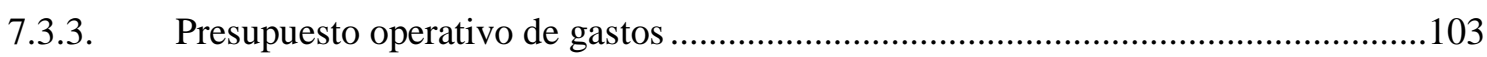

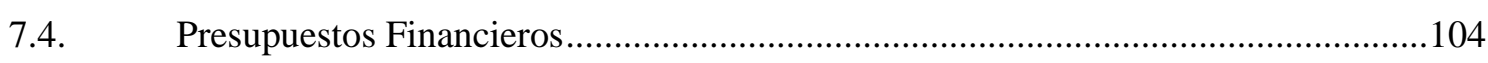

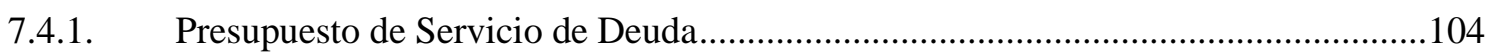

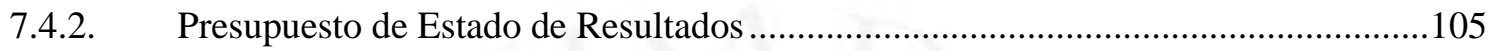

7.4.3. Presupuesto de Estado de Situación Financiera (apertura) .........................................106

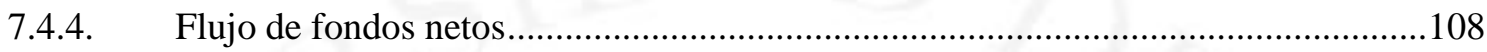

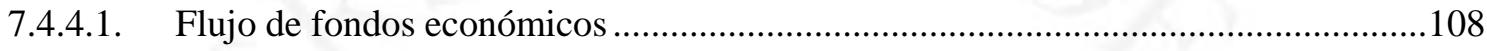

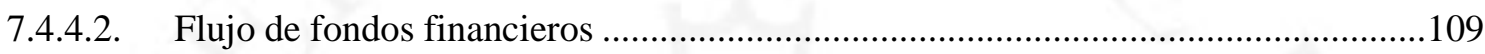

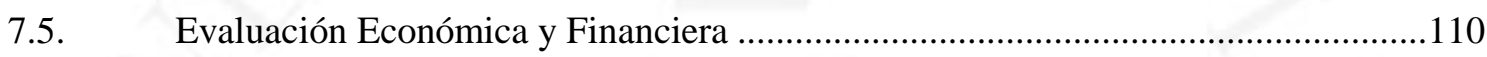

7.5.1. Evaluación económica: VAN, TIR, B/C, PR …....................................................... 110

7.5.2. Evaluación financiera: VAN, TIR, B/C, PR .........................................................111

7.5.3. Análisis de ratios (liquidez, solvencia, rentabilidad) e indicadores económicos y

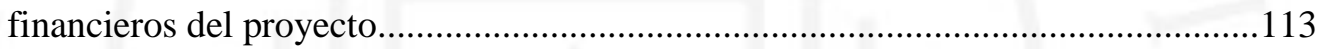

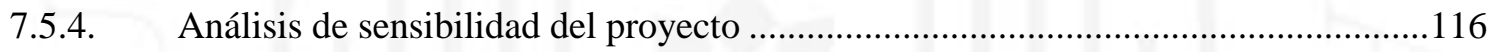

CAPÍTULO VIII: EVALUACIÓN SOCIAL DEL PROYECTO .........................................117

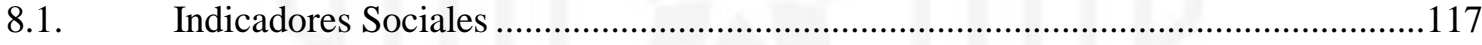

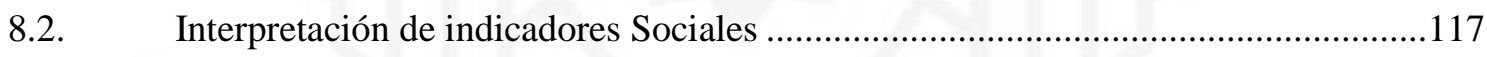

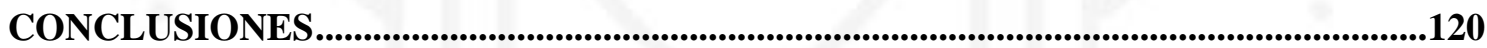

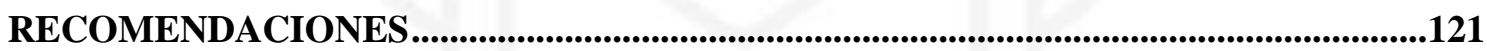

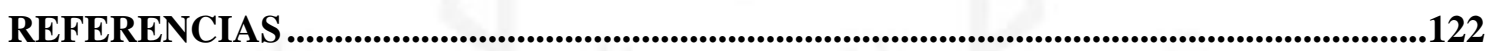

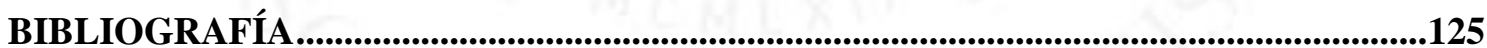

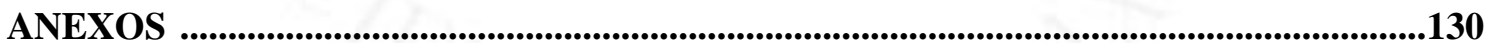




\section{ÍNDICE DE TABLAS}

Tabla 1.1 Consumo bottled water en miles de litros

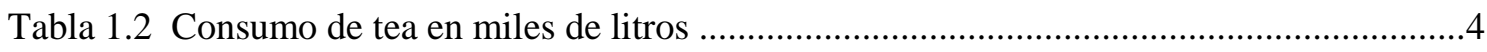

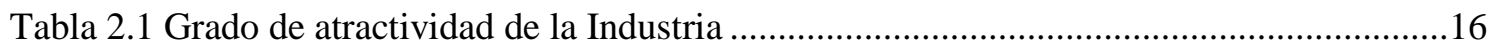

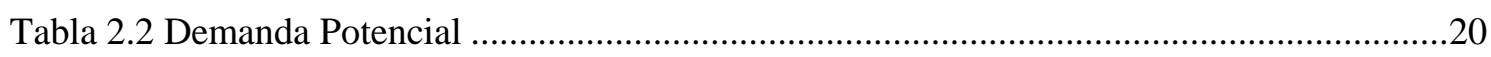

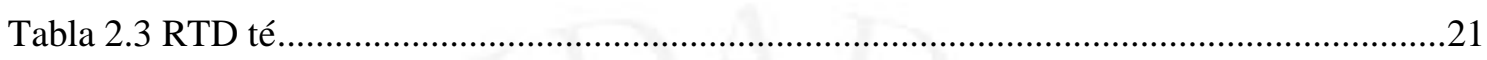

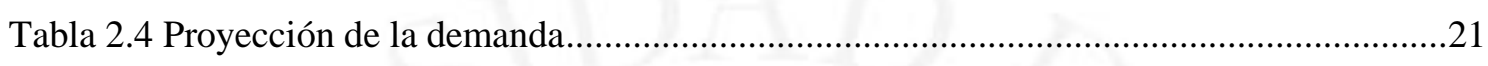

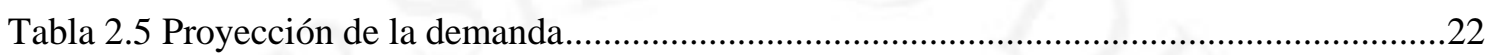

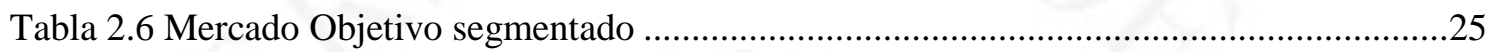

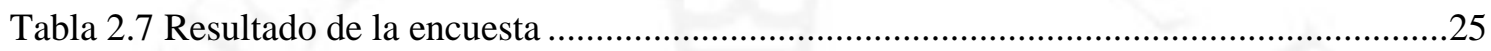

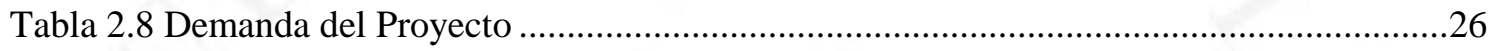

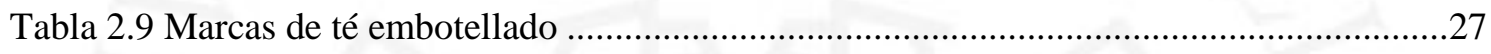

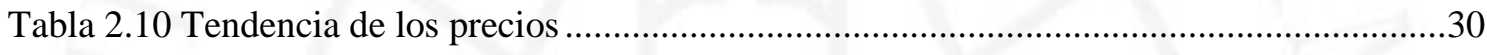

Tabla 3.1 Distancia de los diferentes departamentos a la materia prima ......................................33

Tabla 3.2 Escala de calificación de cercanía a la materia prima .................................................33

Tabla 3.3 Distancia de los diferentes departamentos al departamento de Lima ...........................33

Tabla 3.4 Escala de calificación de cercanía al mercado meta ......................................................34

Tabla 3.5 Escala de calificación de costo de transporte terrestre (Flete) ………….........................34

Tabla 3.6 Escala de calificación de costo de transporte terrestre (Flete) .......................................34

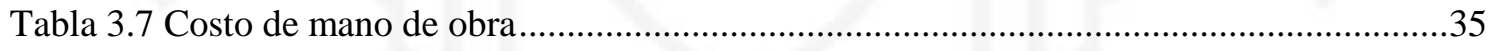

Tabla 3.8 Escala de calificación de costo de mano de obra ............................................................35

Tabla 3.9 Tarifas de las principales empresas por departamento año 2019 .................................35

Tabla 3.10 Escala de calificación de costo de energía año 2019 ................................................36

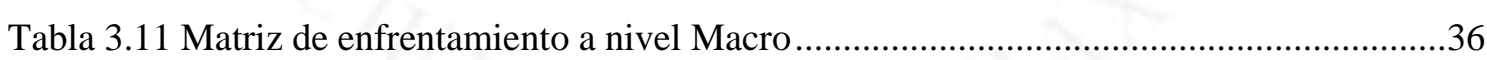

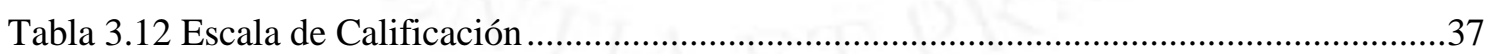

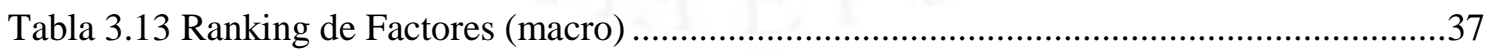

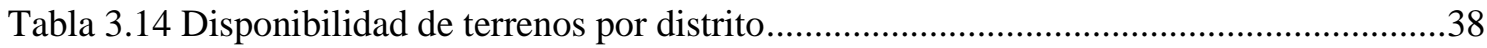

Tabla 3.15 Tabla de calificación de disponibilidad de terrenos .....................................................38

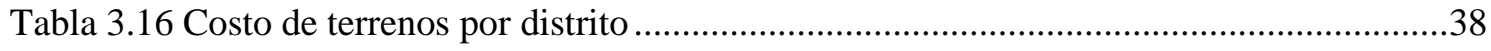

Tabla 3.17 Escala de calificación de Costo de terrenos ...................................................................39

Tabla 3.18 Tabla de calificación de disponibilidad de terrenos ...................................................40

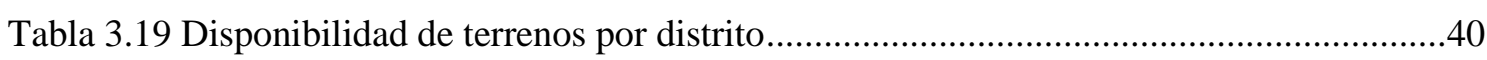

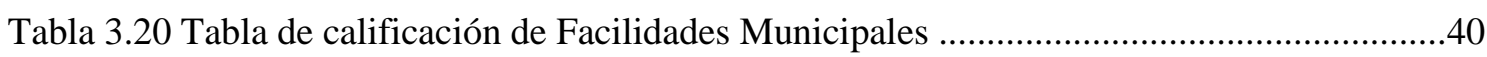


Tabla 3.21 Tabla de habitantes por Policía

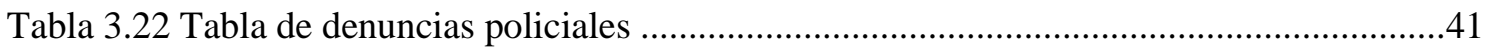

Tabla 3.23 Tabla de calificación de Seguridad ...............................................................................

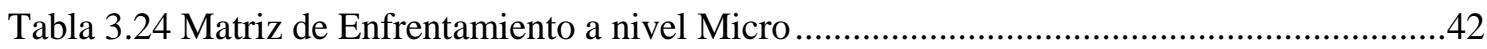

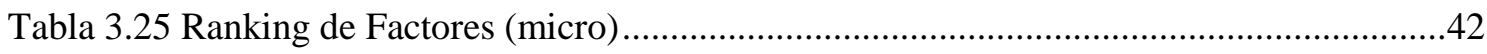

Tabla 4.1 Demanda de bebidas a base de hierbas medicinales embotellada para los próximos seis años. .43

Tabla 4.2 Cantidad de hierbas medicinales necesarias para los próximos seis años. .44

Tabla 4.3 Producción de bebidas a base de hierbas medicinales en Litros y en Botellas .............45

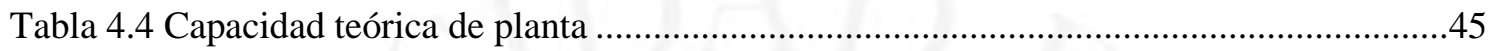

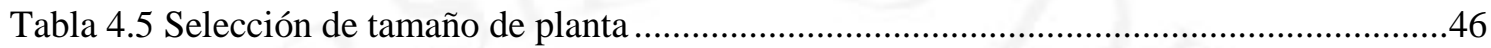

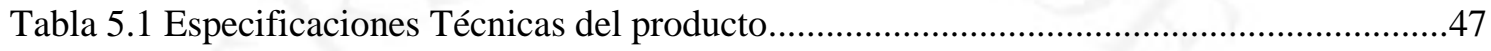

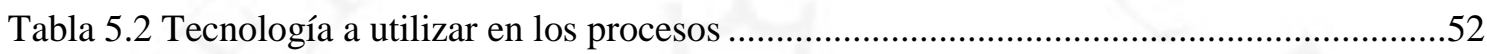

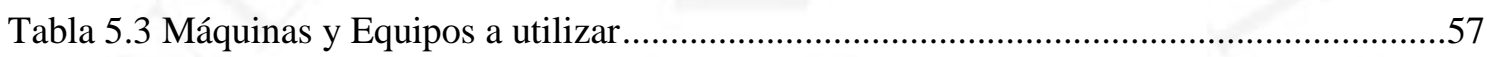

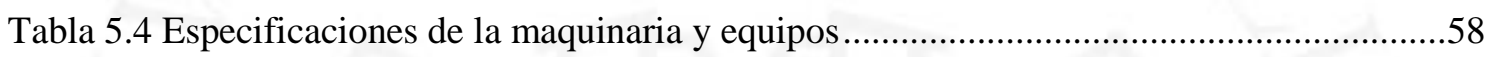

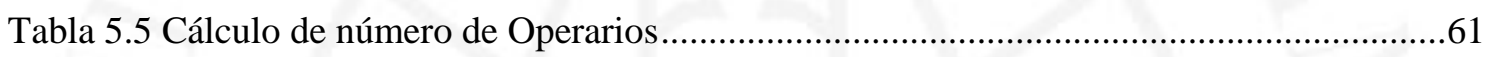

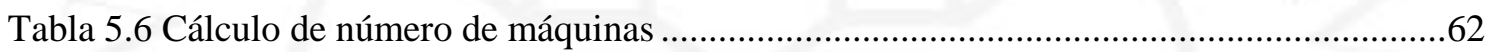

Tabla 5.7 Cálculo de número de máquinas (Proceso de agua).....................................................62

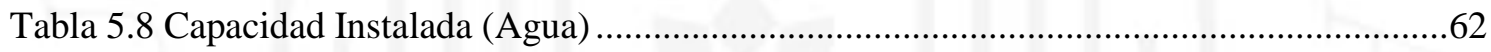

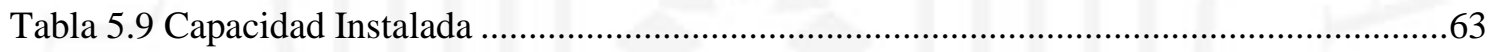

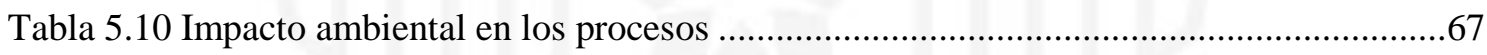

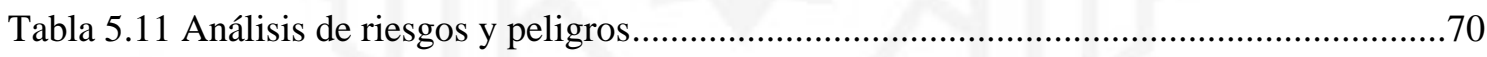

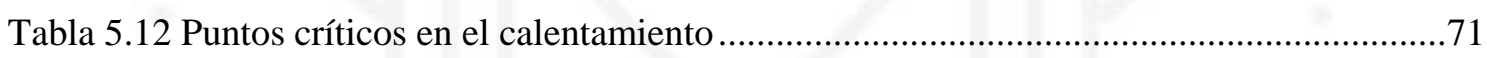

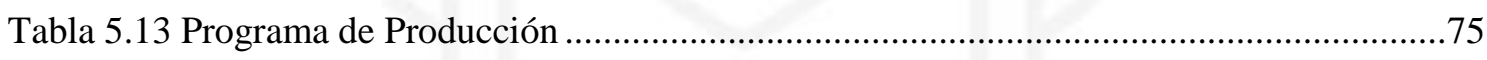

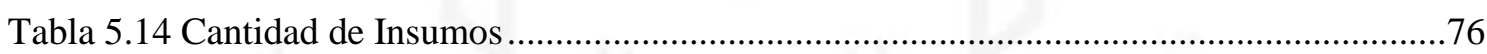

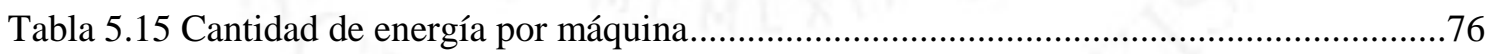

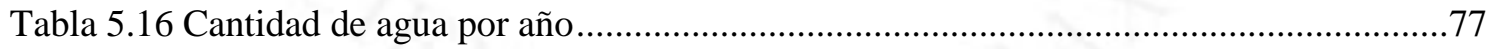

Tabla 5.17 Cantidad de agua de uso administrativo por año ......................................................77

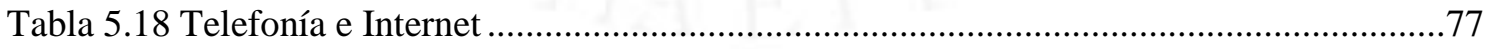

Tabla 5.19 Número de operarios en las operaciones manuales...................................................78

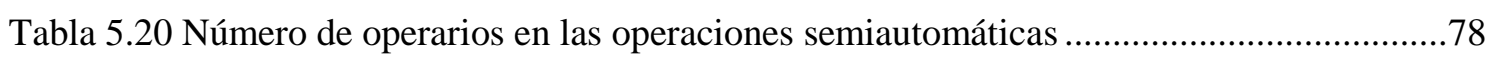

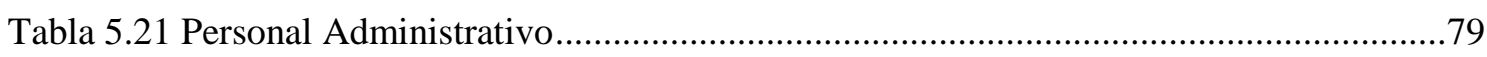

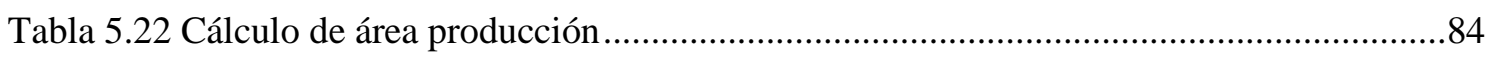

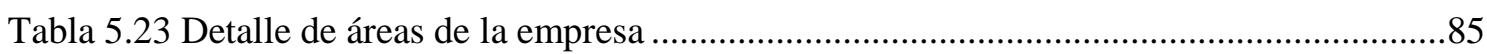

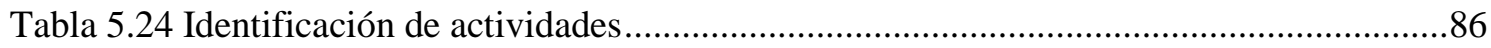

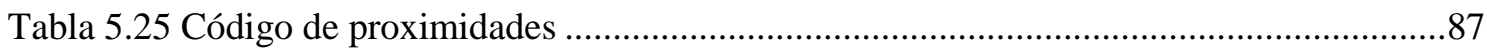


Tabla 5.26 Símbolo de actividades

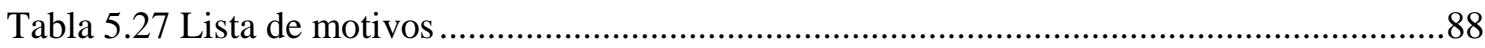

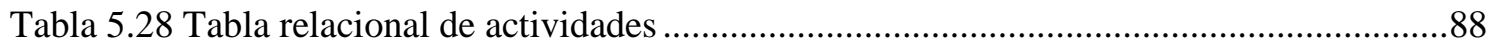

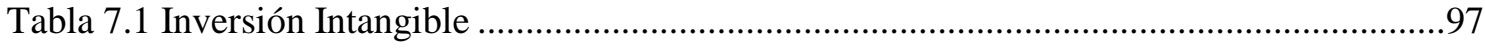

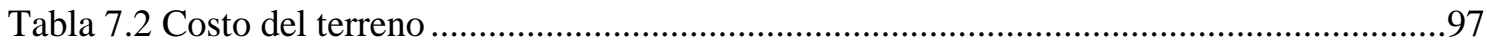

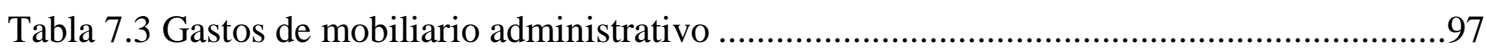

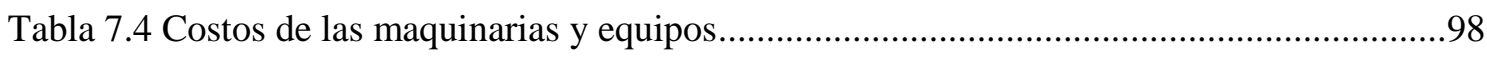

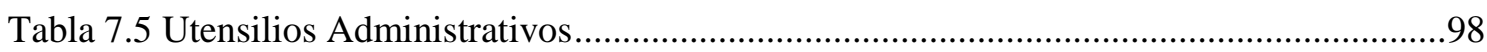

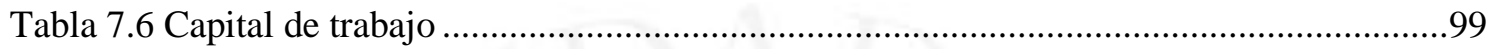

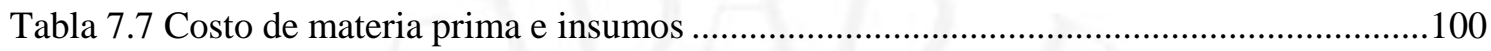

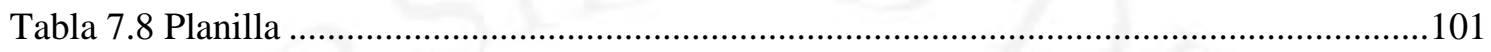

Tabla 7.9 Detalle del costo anual de Mano de obra ...................................................................101

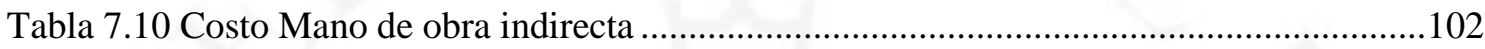

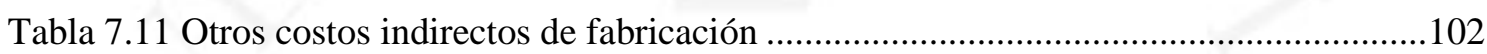

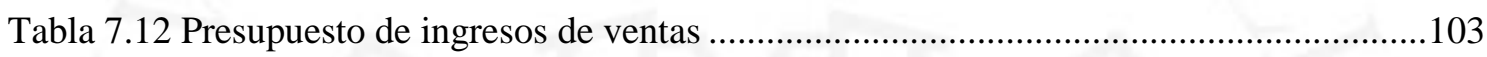

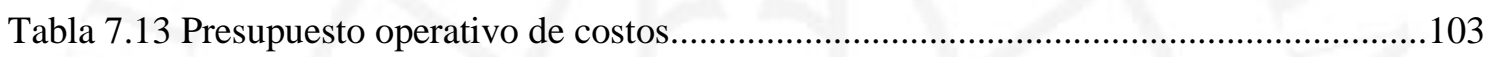

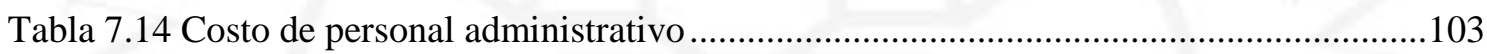

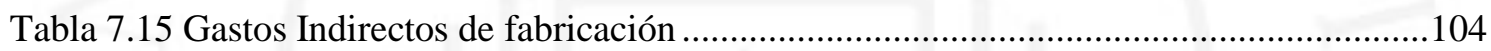

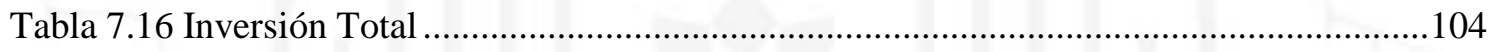

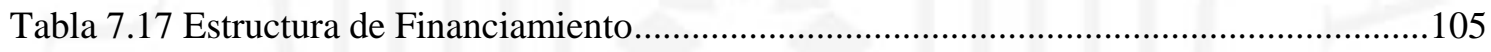

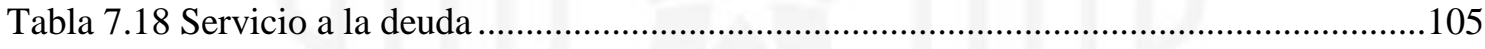

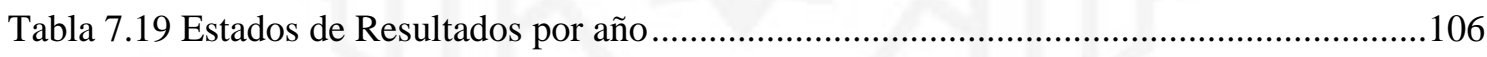

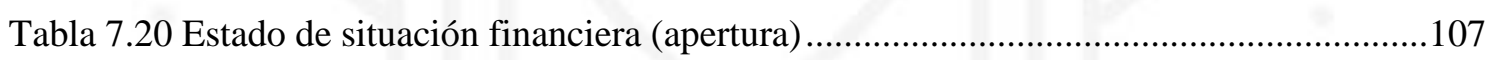

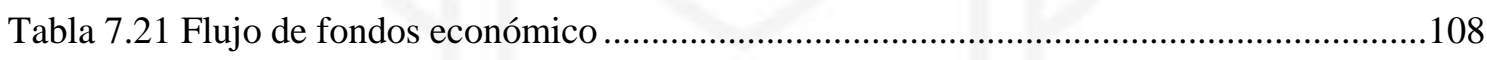

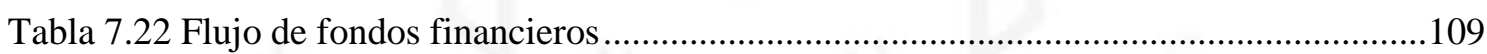

Tabla 7.23 Indicadores de la evaluación económica ...............................................................110

Tabla 7.24 Indicadores de la evaluación financiera .................................................................111

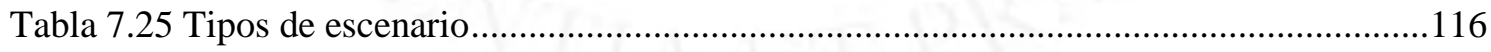

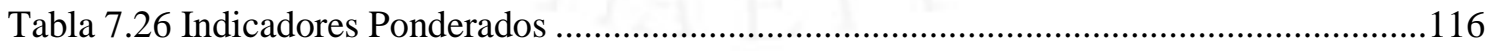

Tabla 8.1 Valor Agregado Opción 1 ...............................................................................117

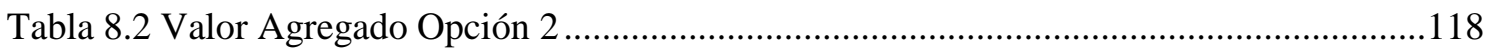




\section{ÍNDICE DE FIGURAS}

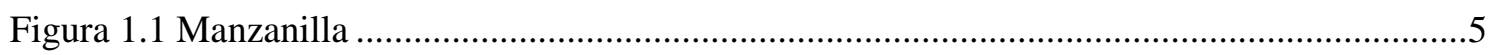

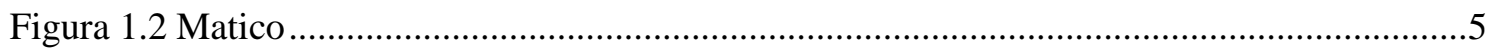

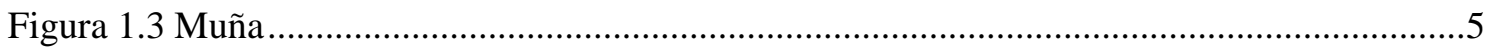

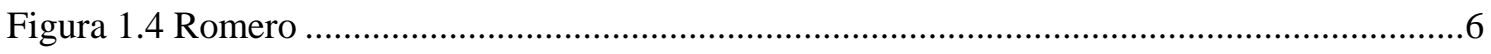

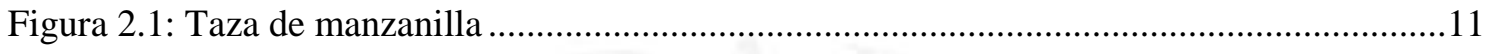

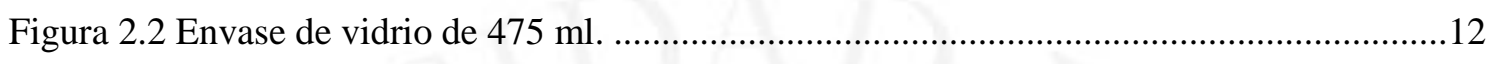

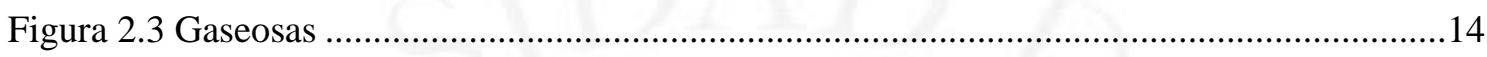

Figura 2.4 Lugar Habitual de compra de productos comestibles ..............................................19

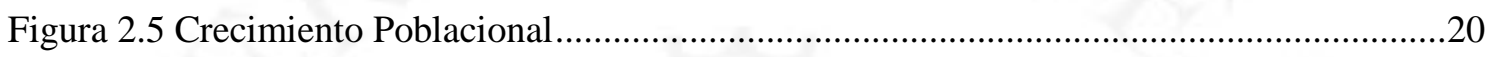

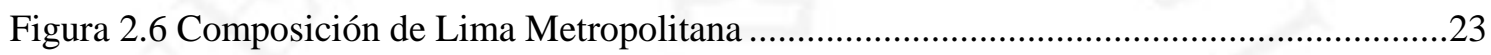

Figura 2.7 Información Demográfica de Lima Metropolitana .....................................................23

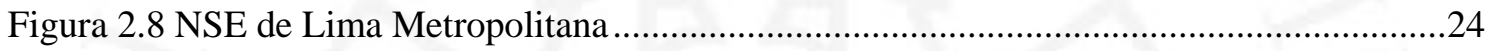

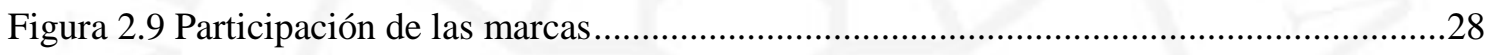

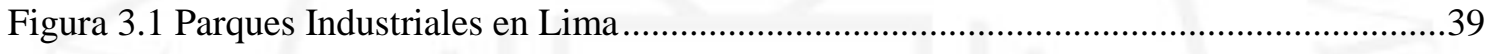

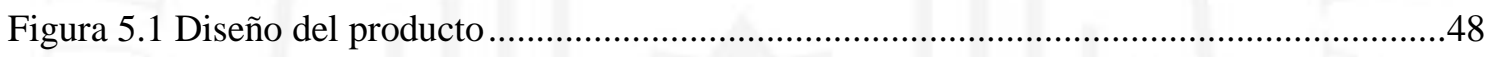

Figura 5.2 Diagrama de operaciones del proceso de la bebida a base de manzanilla ...................55

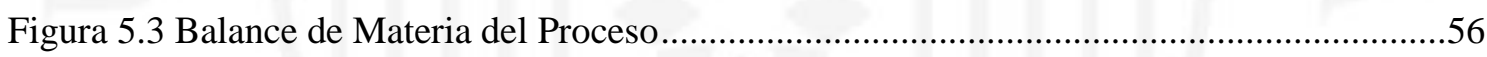

Figura 5.4 Señalización de seguridad y salud en el trabajo .......................................................69

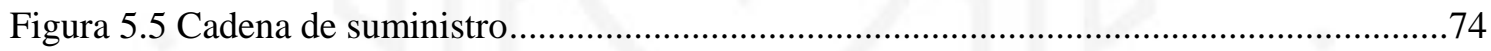

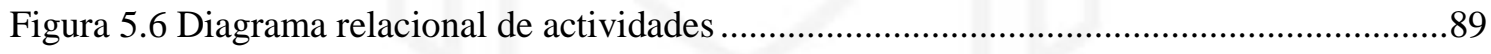

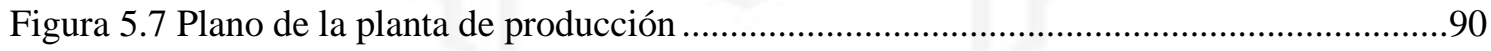

Figura 5.8 Cronograma de implementación del proyecto .............................................................91

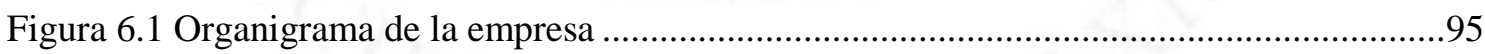




\section{ÍNDICE DE ANEXOS}

Anexo 1: Encuesta

Anexo 2: Resultados de encuesta

Anexo 3: Producción de las materias primas por departamento (2018)

Anexo 4: Muña

Anexo 5: Manzanilla

Anexo 6: Romero

Anexo 7: Matico.

Anexo 8: Las hierbas medicinales listas para mezclarlas

Anexo 9: Las hierbas medicinales en el proceso de cocción 137

Anexo 10: Esencia de las distintas hierbas medicinales 137

Anexo 11: Residuos que se obtienen en el filtrado. 138 


\section{RESUMEN EJECUTIVO}

Actualmente la sociedad está modificando sus hábitos de consumo hacia una alimentación más saludable, cambiando las bebidas gasificadas, con altos contenidos calóricos, por bebidas de frutas, té, agua, etc. Esta modificación en el consumo de las personas permite una oportunidad para satisfacer esta necesidad mediante una bebida a base de hierbas medicinales.

Por ello se desea plasmar un estudio de pre factibilidad de un producto innovador en el mercado peruano, el cual es una bebida a base de hierbas (manzanilla, matico, muña y romero).

Para poder implementar este producto se debe establecer objetivos, metas y el alcance con el fin de poder corroborar al final del trabajo si se han podido lograr las metas propuestas. Se efectuará un estudio de mercado para determinar el área de personas que probablemente puedan consumir el producto, los bienes complementarios y sustitutos y; las fuerzas del entorno competitivo. Adicionalmente, se hallará la demanda objetiva en base a distintos criterios de segmentación que se relacionan al producto.

Luego, se procederá a obtener la localización de planta, tanto en el ambiente macro como micro entorno, el cual dio como resultado que la planta se localizará en el distrito de Lurín y contará con una capacidad marcada por el mercado de 1595893 botellas al año.

Posteriormente, se evaluarán los aspectos relacionados al diseño e ingeniería del proyecto, los cuales estiman que con una inversión en el proyecto de 1193663 soles se puede implementar el proyecto y generar beneficios para los accionistas y la empresa. Los resultados económicos del proyecto arrojan un VAN de 572817 soles y un TIR de $32,29 \%$. Por otro lado, los resultados financieros del proyecto arrojan un VAN de 681 401 soles y un TIR de $42,02 \%$, por lo que se concluye que el proyecto es viable

Debido a todos estos beneficios y ventajas que brindan las bebidas naturales y el proyecto, se propone la instalación de una planta industrial para la elaboración de una planta productora de bebidas a base de hierbas medicinales

Palabras clave: Instalación de planta, bebida, proceso, hierbas. 


\section{EXECUTIVE SUMMARY}

Nowadays society is changing its consumption habits towards a healthier diet, changing carbonated beverages, with high caloric content, for fruit drinks, tea, water, etc. This change in the consumption of people allows an opportunity to satisfy this need through a beverage based on medicinal herbs.

Therefore it is desired create a prefeasibility study of an innovation product in the Peruvian market, which is a beverage based on herbs (chamomile, matico, muña and rosemary)

In order to implement this product is necessary to establish objectives, goals and scope of this work in order to be able to corroborate at the end of this one if these have been achieved. A market study will be carried out in order to examine certain variables that are necessary to understand how the product relates to the market. It will be examined the area covered by the study, the complementariness and substitutes goods and the forces of the competitive environment. In addition, the demand for the project will be found based on different criteria of segmentation that will be appropriated to the product.

Furthermore, it will proceed to obtain the plant location, both in the macroenvironment and micro environment which resulted that the plant will be located in the district of Lurín and will have a capacity marked by the market of 1595893 bottles per year.

Subsequently, the whole plant will be evaluated in the engineering aspect, which estimate that with an investment in the project of 1193663 soles, the project can be implemented and generate benefits for the shareholders and the company. The economic results of the project show a VAN of 572817 soles and a TIR of 32,29\%. On the other hand, the financial results of the project show a VAN of 681401 soles and an TIR of $42,02 \%$, so it is concluded that the project is viable

Due to all these benefits and advantages provided by natural beverages and the project, the installation of an industrial plant is proposed for the production of a plant that produces beverages based on medicinal herbs.

Keywords: Plant installation, beverage, process, herbs. 


\section{CAPÍTULO I: ASPECTOS GENERALES}

\subsection{Problemática}

En los últimos años, teniendo como base de datos a Euromonitor (2018), el mercado mundial de bebidas carbonatadas ha sufrido un gran dinamismo pues no existe una tendencia clara de crecimiento o decrecimiento, por el contrario como se muestra en la tabla 1.1 el consumo humano de bottled wáter ha venido aumentando lo cual indica que cada vez más personas consumen bebidas por ello como se muestra en la tabla 1.2 existe un crecimiento bien marcado en el consumo de bebidas naturales a base de té, por lo cual existe una tendencia clara de que cada vez más personas buscan bebidas saludables y nutritivas. En consecuencia, se ha dado origen a nuevas oportunidades de negocios que tienen como objetivo posicionarse en el mercado de bebidas naturales.

En el Perú no somos ajenos a esta realidad pues según Euromonitor (2018) existe un decrecimiento en el consumo de gaseosas, el cual desde el año 2013 al 2018, refleja una caída del 6,74\% lo cual demuestra que existe una búsqueda de otras bebidas más saludables.

El contexto antes descrito pone en evidencia el cambio en los hábitos de consumo de las personas, los cuales reflejan la preferencia actual hacia las bebidas saludables, además de existir una limitada oferta en cuanto a cantidad, variedad y presentación de estas bebidas es que se aprovechará estos factores actuales para desarrollar una investigación acerca de la Instalación de una planta productora de una bebida a base de manzanilla, matico, muña y romero lista para tomar, la cual se incluirá en la categoría de productos sanos. 
Tabla 1.1

Consumo bottled water en miles de litros

Passport

\begin{tabular}{|c|c|c|c|c|c|c|c|}
\hline \multicolumn{8}{|c|}{ Market Sizes | Historical/Forecast } \\
\hline Geograph $\mathbf{T}$ & Unit - & $2013-$ & $2014-$ & $2015-$ & $2016-$ & $2017-$ & 2018 \\
\hline Brazil & 000 litres & $4.694 .510,9$ & $5.458 .516,6$ & $6.278 .573,7$ & $6.738 .952,3$ & $7.073 .058,3$ & $7.369 .051,8$ \\
\hline Argentina & 000 litres & $4.778 .330,5$ & $4.783 .997,9$ & $4.873 .249,9$ & $4.733 .309,0$ & $4.732 .052,9$ & $4.743 .219,0$ \\
\hline Colombia & 000 litres & $940.556,7$ & $992.671,0$ & $1.064 .936,0$ & $1.114 .242,5$ & $1.128 .324,8$ & $1.193 .353,0$ \\
\hline Peru & 000 litres & $503.185,3$ & $533.346,0$ & $590.866,5$ & $636.913,7$ & $712.555,1$ & $741.482,0$ \\
\hline Chile & 000 litres & $438.207,1$ & $476.606,7$ & $532.200,0$ & $559.310,0$ & $605.090,0$ & $632.700,0$ \\
\hline Ecuador & 000 litres & 568.717 .4 & 631.413 .0 & 705.655 .3 & 709.696 .8 & 726.405 .5 & 741.911 .2 \\
\hline Uruguay & 000 litres & $255.647,3$ & $269.540,2$ & $284.332,0$ & $310.659,4$ & $325.851,7$ & $349.711,5$ \\
\hline Paraguay & 000 litres & $102.194,7$ & $111.998,7$ & $127.829,1$ & $151.861,0$ & $180.653,3$ & $198.983,7$ \\
\hline Bolivia & 000 litres & $79.770,0$ & $97.840,0$ & $106.570,0$ & $119.738,7$ & $140.539,5$ & $161.593,2$ \\
\hline
\end{tabular}

Fuente: Euromonitor, (2018)

Tabla 1.2

Consumo de tea en miles de litros

\section{Passport}

\begin{tabular}{|c|c|c|c|c|c|c|c|c|}
\hline \multicolumn{9}{|c|}{ Market Sizes | Historical/Forecast } \\
\hline Geography $\mathbf{T}$ & Categor] - & Unit - & $2013-$ & $2014-$ & $2015 \nabla$ & $2016 \nabla$ & $2017-\nabla$ & $2018 \quad \nabla$ \\
\hline Brazil & RTD Tea & 000 litres & $115.246,3$ & $125.580,4$ & $119.300,0$ & $122.280,0$ & $125.948,4$ & $130.104,7$ \\
\hline Peru & RTD Tea & 000 litres & $50.062,9$ & $57.753,7$ & $67.070,0$ & $75.730,0$ & $83.003,0$ & $88.060,9$ \\
\hline Colombia & RTD Tea & 000 litres & $71.041,9$ & $79.129,5$ & $87.145,0$ & $77.485,6$ & $54.825,1$ & $44.078,8$ \\
\hline Ecuador & RTD Tea & 000 litres & $64.865,6$ & $70.166,9$ & $62.343,3$ & $52.368,4$ & $44.497,4$ & $39.495,9$ \\
\hline Chile & RTD Tea & 000 litres & $9.264,2$ & $9.761,7$ & $10.437,0$ & $11.580,0$ & $12.519,2$ & $13.260,0$ \\
\hline Bolivia & RTD Tea & 000 litres & 640,0 & $1.190,0$ & $1.693,0$ & $2.024,1$ & $2.581,9$ & $3.349,8$ \\
\hline Argentina & RTD Tea & 000 litres & $2.870,0$ & $3.050,0$ & $2.565,0$ & $2.446,0$ & $1.284,0$ & 479,0 \\
\hline Uruguay & RTD Tea & 000 litres & - & 4,2 & 21,9 & 24,8 & 27,1 & 28,4 \\
\hline
\end{tabular}

Fuente: Euromonitor, (2018)

\section{a) Descripción del producto propuesto para el estudio}

La bebida a base de hierbas medicinales beneficia a la industria de las bebidas pues brinda una nueva alternativa de bebida saludable que proporciona beneficios diferentes a los actuales y un sabor agradable. La bebida natural, sirve para satisfacer la sed de manera agradable y saludable pues presenta el sabor característico y los beneficios de dichas hierbas sobre todo como reguladora estomacal, curar heridas o golpes y para las afecciones oculares; tiene también virtudes tranquilizantes y a menudo es recomendada como complemento de los tratamientos médicos de los catarros y congestiones nasales. 


\section{Figura 1.1}

Manzanilla

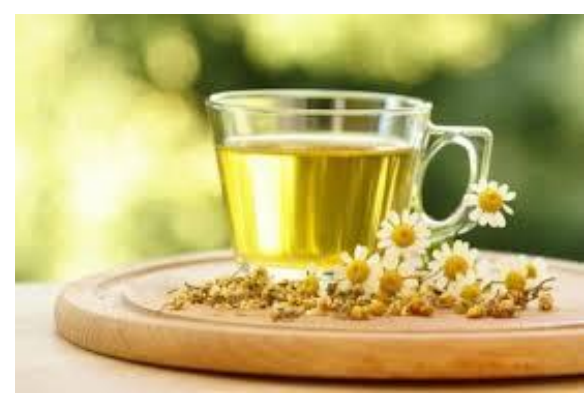

Fuente: Ministerio de agricultura y riego, MINAGRI (2018)

Figura 1.2

Matico

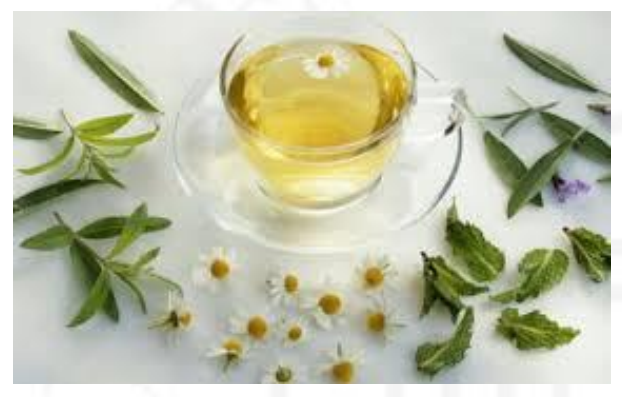

Fuente: Ministerio de agricultura y riego, MINAGRI (2018)

Figura 1.3

Muña

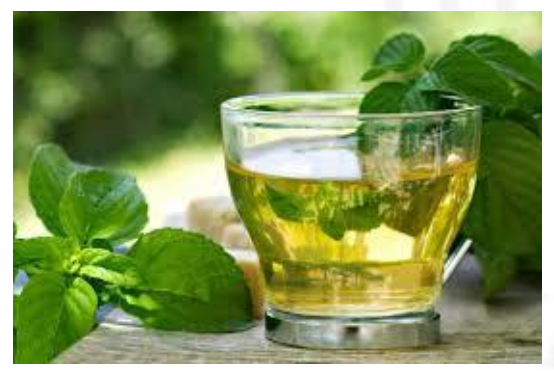

Fuente: Ministerio de agricultura y riego, MINAGRI (2018) 
Figura 1.4

Romero

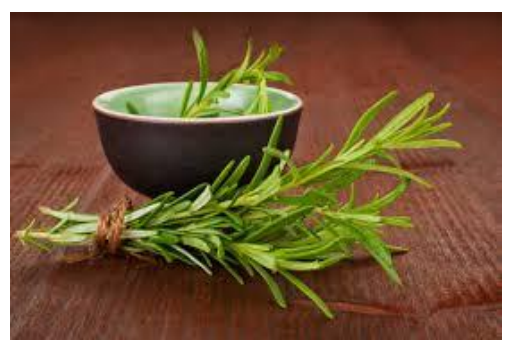

Fuente: Ministerio de agricultura y riego, MINAGRI (2018)

\subsection{Objetivos de la investigación}

\section{a. Objetivo general}

El objetivo general de esta investigación es determinar la viabilidad de mercado, tecnológica, financiera y social para la instalación de una planta de fabricación de una bebida a base de hierbas medicinales embotellada en el Perú para su consumo.

\section{b. Objetivos específicos}

- Elaborar un estudio de mercado que permita definir la viabilidad de producir bebidas a base de hierbas en el mercado limeño.

- Demostrar la viabilidad tecnológica del proyecto

- Determinar si el proyecto es económico y financieramente viable utilizando herramientas para verificar la rentabilidad del mismo

- Demostrar la viabilidad social del proyecto analizando herramientas para conocer el nivel de impacto que se generará en la sociedad

\subsection{Alcance de la investigación}

El presente estudio explora el mercado de Lima Metropolitana para la producción y venta de una bebida a base de hierbas medicinales. La investigación basará su información en base de datos actuales referentes al té, la cual permitirá tener información del tamaño de mercado que podremos abarcar, ya que acerca de bebidas a base de manzanilla, matico, muña y romero no se encuentra mucha información.

Como parte de los alcances se prevé que el producto tenga un impacto en el mercado de Lima dentro de los sectores A y B. 
Por otro lado, dentro de las limitaciones de la investigación que se tendrá en cuenta es para la empresa en marcha, siendo las principales el desarrollo de la demanda del producto, ya que el producto es relativamente nuevo y poco conocido en el medio, también se considera el desarrollo de los proveedores para el óptimo abastecimiento de manzanilla, matico, romero y muña.

\subsection{Justificación del tema}

\section{- Técnica}

Hoy en día la fabricación de bebidas a base de insumos naturales se realiza de manera más eficiente, eficaz y ordenado debido a que se cuenta con nuevas tecnologías que ayudan a aumentar la calidad y productividad de la empresa.

Actualmente existen varias empresas nacionales e internacionales en el mercado de bebidas que fabrican bebidas a base de insumos naturales es por ello que el proyecto se basara en las técnicas de fabricación de las bebidas sustitutas como son el té y a aplicar una metodología de producción similar que nos permita generar productos de buena calidad con un costo bajo, es por ello que el proyecto es técnicamente viable.

Las principales máquinas a utilizar en el proyecto son:

- Máquina para pasteurizar: Sirve para eliminar microorganismos que puedan existir en la bebida

- Máquina para envasar: Sirve para embotellar las bebidas y taparlas

- Máquina para etiquetar: Sirve para colocar etiquetas y rótulos

\section{- Económica}

La puesta en marcha de este proyecto se debe a que se ha comprobado el crecimiento de la industria de bebidas a base de insumos naturales, el cual seguirá por los próximos años. El mercado de bebidas a base de insumos naturales se encuentra en aumento debido a que las personas se inclinan más por el consumo de lo natural, es decir, la tendencia del consumo natural es cada vez mayor pues su consumo es sinónimo de consumir sano y de calidad. Es viable económicamente pues se usará equipos existentes que permitirán incorporarse a un mercado potencial en crecimiento el cual permitirá tener una buena rentabilidad. 
Verificar que existe una gran cantidad de empresas que producen bebidas a base de insumos naturales en el Perú permite darse cuenta que existe un gran mercado nacional de bebidas de insumos naturales y comprobar, como se muestra en la tabla 1.3, que existe una demanda actual de crecimiento en el Perú de bebidas lo cual permitiría garantizar la demanda, lo cual conlleva a ser viables económicamente, es decir, ser rentables.

Tabla 1.3

Consumo bottled water en miles de litros

\section{Passport}

\begin{tabular}{|c|c|c|c|c|c|c|c|}
\hline \multicolumn{8}{|c|}{ Market Sizes | Historical/Forecast } \\
\hline Geograph $\mathbf{T}$ & Unit $>$ & $2013-{ }^{\prime}$ & $2014-1$ & 2015 & $2016-\nabla$ & $2017-$ & 2018 \\
\hline Brazil & 000 litres & $4.694 .510,9$ & $5.458 .516,6$ & $6.278 .573,7$ & $6.738 .952,3$ & $7.073 .058,3$ & $7.369 .051,8$ \\
\hline Argentina & 000 litres & $4.778 .330,5$ & $4.783 .997,9$ & $4.873 .249,9$ & $4.733 .309,0$ & $4.732 .052,9$ & $4.743 .219,0$ \\
\hline Colombia & 000 litres & $940.556,7$ & $992.671,0$ & $1.064 .936,0$ & $1.114 .242,5$ & $1.128 .324,8$ & $1.193 .353,0$ \\
\hline Peru & 000 litres & $503.185,3$ & $533.346,0$ & $590.866,5$ & $636.913,7$ & $712.555,1$ & $741.482,0$ \\
\hline Chile & 000 litres & $438.207,1$ & $476.606,7$ & $532.200,0$ & $559.310,0$ & $605.090,0$ & $632.700,0$ \\
\hline Ecuador & 000 litres & $568.717,4$ & $631.413,0$ & $705.655,3$ & $709.696,8$ & $726.405,5$ & $741.911,2$ \\
\hline Uruguay & 000 litres & $255.647,3$ & $269.540,2$ & $284.332,0$ & $310.659,4$ & $325.851,7$ & $349.711,5$ \\
\hline Paraguay & 000 litres & 102.194 .7 & 111.998 .7 & $127.829,1$ & $151.861,0$ & $180.653,3$ & $198.983,7$ \\
\hline Bolivia & 000 litres & $79.770,0$ & $97.840,0$ & $106.570,0$ & $119.738,7$ & $140.539,5$ & $161.593,2$ \\
\hline
\end{tabular}

Fuente: Euromonitor, (2018)

\section{- Social}

El consumo de este tipo de bebidas ayudará a incrementar el consumo de bebidas naturales de las personas, por lo que se verán beneficiados en mantener una buena salud. Además, se crearán diversos puestos de trabajo en la zona donde se ubique la planta y ayudará a mejorar el estilo de vida de las personas que vivan a los alrededores.

\subsection{Hipótesis del trabajo}

La instalación de una planta de fabricación de bebidas a base de hierbas medicinales embotellada en el Perú es viable a nivel de mercado, técnico, económico y social debido a que se cuenta con un mercado potencial, tecnología apropiada y financiamiento necesario, además de contar con una amplia disposición de la materia prima. 


\subsection{Marco referencial}

- Celiz Castillo, Hernán (1991). "Estudio de pre factibilidad para la Instalación de una fábrica de bolsitas filtrantes de plantas medicinales". Tesis para optar el título de ingeniero industrial. Lima: Universidad de Lima.

Código: HIERBA LUISA-1991 (Tesis).

En cuanto a las similitudes, se usa el mismo insumo (manzanilla) además de encontrar información útil para el desarrollo acerca del uso y beneficios de la manzanilla. En cuanto a las diferencias, el producto final es diferente pues es en bolsitas filtrantes lo cual permite diferenciarlos en distintos mercados.

- Gallardo Barzola, Cynthia (2014). "Estudio de pre factibilidad para la instalación de una planta productora de jugo bebible de verduras". Tesis para optar el título de ingeniero industrial. Lima: Universidad de Lima. Código: BEBIDAS-2014 (Tesis).

En cuanto a las similitudes, ambos tienen amenazas de bienes sustitutos idénticos y por ende el mercado objetivo. Además, se obtuvo información sobre la situación más actualizada del mercado de bebidas naturales. En cuanto a diferencias, dicha planta no usa el mismo insumo lo cual permite obtener un producto con propiedades distintas.

- Saravia Quispe, Diego (2014). "Estudio de pre factibilidad para la producción y comercialización de néctar de ajonjolí en Lima metropolitana". Tesis para optar el título de ingeniero industrial. Lima: Pontificia Universidad Católica del Perú.

En cuanto a similitudes, ambos son bebidas naturales lo cual permite tener una idea acerca de dicho mercado. En cuanto a diferencias, usamos una materia prima distinta la cual ayudará a comparar las distintas propiedades de los productos.

- Aliaga Paredes, Elio (2017). "Estudio de pre factibilidad para la instalación de una planta de producción de bolsas filtrantes de manzanilla común". Tesis de investigación para optar el título de ingeniero industrial. Lima: Universidad de Lima. Código: Tesis electrónica. 
En cuanto a similitudes, ambos tienen como insumo principal a la manzanilla lo cual permite tener una idea acerca de dicha materia prima. En cuanto a diferencias, se usa un producto final distinto el cual permite diferenciarlos en distintos mercados.

- Collazos Acosta, Daniel (2018). "Estudio de pre factibilidad para la implementación de una fábrica para la elaboración de bebida de Aloe Vera”. Tesis de investigación para optar el título de ingeniero industrial. Lima: Universidad de Lima. Código: Tesis electrónica En cuanto a similitudes, ambos son estudios de bebidas a base de insumos naturales lo cual permite tener una idea acerca de los mercados objetivos. En cuanto a diferencias, se usa materias primas distintas el cual permite conocer las propiedades de cada insumo.

\subsection{Marco conceptual}

- Bebidas carbonatadas: La gaseosa (también llamada refresco, bebida carbonatada, soda o cola, dependiendo del país) es una bebida saborizada, efervescente (carbonatada) y sin alcohol. Estas bebidas suelen consumirse frías, para ser más refrescantes y para evitar la pérdida de dióxido de carbono, que le otorga la efervescencia.

- Soft drinks: Se denomina, según la clasificación de Euromonitor, a la compilación de bebidas carbonatadas, jugos de frutas o vegetales, agua embotellada, bebidas funcionales, tés embotellados y cafés embotellados. (Euromonitor, 2017).

- Bebidas funcionales: Clasificación de bebidas que ofrecen beneficios para la salud, pueden tener vitaminas, minerales $u$ otros ingredientes (Naranjo Gómez, 2015).

- Stevia: Pequeño arbusto herbáceo cuyas hojas son dulces y se utilizan para la fabricación de un edulcorante natural (Asociación Española de la Stevia Rebaudiana, 2011).

- Pasteurización: Proceso térmico con el que se minimiza la presencia de agentes como bacterias entre otros con el fin de conservar líquidos (GEA Process Enginnering S.A de C.V., 2009). 


\section{CAPÍTULO II: ESTUDIO DE MERCADO}

\subsection{Aspectos generales del estudio de mercado}

\subsubsection{Definición comercial del producto}

La bebida natural a base de hierbas medicinales, sirve para satisfacer la sed de manera agradable y saludable pues presenta un sabor característico particular y los beneficios de dichas plantas sobre todo como reguladora estomacal, alivia heridas y para las afecciones oculares, tiene también virtudes tranquilizantes, y a menudo es recomendada como complemento de los tratamientos médicos de los catarros y congestiones nasales

\section{a. Producto básico:}

Bebida a base de hierbas medicinales, es un producto obtenido de la combinación de la manzanilla, matico, muña y romero con agua que satisface la sed.

Figura 2.1: Taza de manzanilla

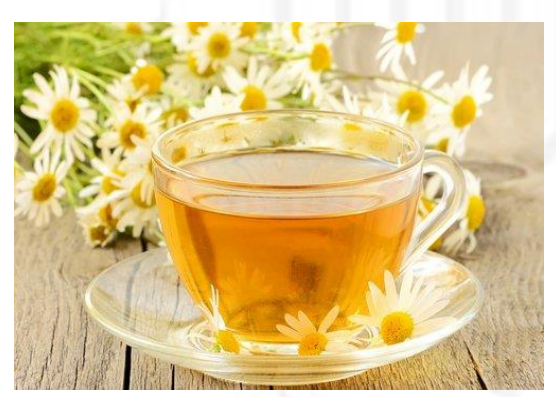

Fuente: Lipton (2018)

\section{b. Producto real:}

El producto está comprometido a cumplir estándares de calidad. Bebida natural de hierbas medicinales en presentación de envases de vidrio de $475 \mathrm{ml}$ fácilmente reconocibles, con etiquetas que posean información como el nombre de la marca "Agua de Chachakuma", fecha de vencimiento, composición del producto; se mencionará los beneficios del mismo e incluirá una tabla de información nutricional, datos de la empresa, etc. Este producto aparte de satisfacer la sed y contar con nutrientes propios de 
cada hierba es un producto práctico que se puede llevar de un lugar a otro gracias a su envase embotellado

Figura 2.2

Envase de vidrio de $475 \mathrm{ml}$.

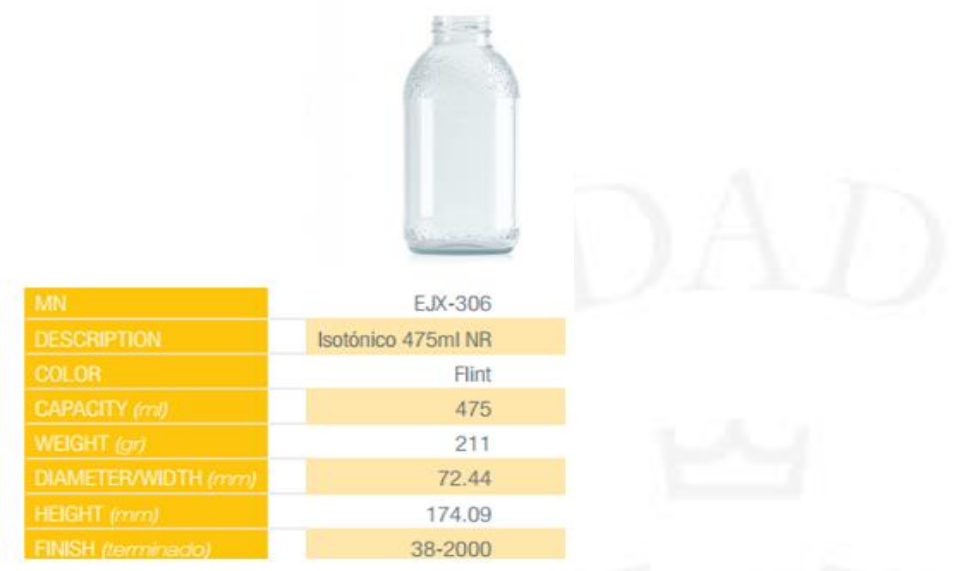

Fuente: Owens Illimois (2018)

\section{c. Producto aumentado:}

En primer lugar, se contará con una página web en la cual se ofrecerá información a los clientes acerca de los beneficios y atributos del producto, así como de la empresa en general. También se tendrá un buzón de sugerencia en la página web y en la propia empresa, la cual atenderá las quejas y sugerencias de los clientes para una mejora continua, logrando la satisfacción de los clientes. Adicionalmente se participará de forma activa en las redes sociales (Facebook, Instagram, Twitter) para poder tener llegada a todo el público y con ello atraer más personas al consumo del producto natural.

\subsubsection{Usos del producto, bienes sustitutos y complementarios}

\section{a. Usos y características del producto}

La manzanilla tiene como característica ser reguladora estomacal, sirve para las afecciones oculares, tiene también virtudes tranquilizantes, y a menudo es recomendada como complemento de los tratamientos médicos de los catarros y congestiones nasales.

El matico es muy efectivo aliviando las náuseas, el dolor de estómago y el vómito. Incluso se recomienda su ingesta cuando se tienen gases intestinales, el efecto 
será rápido. También pone su grano de arena en el alivio de resfríos, tos además de emplearse contra hemorragias internas y externas que calman rápidamente, también en caso de heridas, caídas y golpes.

La muña cuenta con diversas propiedades, se encarga de eliminar los parásitos intestinales que pueda tener una persona, disminuye la aparición de problemas visuales, tales como cataratas y miopía, descongestiona las vías respiratorias causadas por diversos factores, además las hojas de esta planta sirven de gran ayuda para la curación de fracturas y tumores ocasionados por golpes y favorece a una excelente digestión de los alimentos, evitando así la formación de gases.

El romero favorece a la recuperación en las enfermedades respiratorias y del aparato digestivo pues evita la hinchazón y la acidez estomacal.

En cuanto a la clasificación CIIU, este tiene el código 15546: Elaboración de bebidas no alcohólicas.

Además, se pudo conocer que la partida arancelaria es 2202.91.00.00. Esta pertenece al grupo de las demás aguas y bebidas no alcohólicas, azucaradas y no gaseadas.

- Industria de alimentos y bebidas:

Se emplea en la fabricación de filtrantes y bebidas como por ejemplo filtrantes de manzanilla o muña de la marca Mc Collin's, HERBI o ZURIT.

- Industria de insumos de relajación:

Se podría emplear el agua de la manzanilla en la industria de masajes y relajación pues es un producto que presenta virtudes tranquilizantes.

\section{b. Bienes sustitutos y complementarios}

\section{- Bienes sustitutos:}

Agua:

El agua es un producto sustituto pues satisface las necesidades básicas de las personas.

\section{Jugos:}

Los jugos son productos sustitutos pues cubren algunas necesidades similares a las bebidas naturales a base de hierbas. 
Los jugos pertenecen a la misma industria de bebidas, pero son distintos pues nuestro producto es una bebida con otros tipos de características.

\section{Bebidas Carbonatadas:}

Las bebidas carbonatadas o comúnmente llamadas gaseosas son bebidas que en su composición no aporta ventajas nutritivas y por el contrario puede significar una amenaza para la salud pues la gaseosa puede causar obesidad y diabetes.

Figura 2.3

\section{Gaseosas}

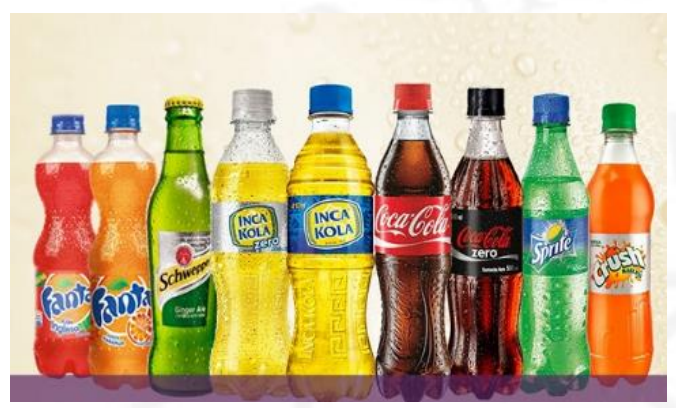

Fuente: Lindley (2018)

- Bienes complementarios:

$\checkmark$ Sorbetes: Ayudan a ingerir el producto de una manera más fácil para algunas personas.

$\checkmark$ Galletas: Ayudan a acompañar a la bebida.

$\checkmark$ Pan: Ayuda a acompañar a la bebida por ejemplo en un lonche.

\subsubsection{Determinación del área geográfica que abarcará el estudio}

El sector de bebidas naturales envasadas a base de insumos naturales se desarrolla principalmente en Lima, entonces se pretende abarcar inicialmente al mercado de lima metropolitana perteneciente al nivel socioeconómico A y B y al mercado nacional posteriormente. 


\subsubsection{Análisis del sector industrial (cinco fuerzas de PORTER)}

\section{a. Amenaza de nuevos ingresos}

La amenaza de nuevos ingresos es alta debido a que existe un incremento en el consumo de las bebidas a base de insumos naturales y es por ello que se busca nuevas alternativas de bebidas naturales que puedan satisfacer al mercado. Por otro lado, existen barreras de entrada medias debido a que es un nuevo producto, pero ya existen marcas consolidadas con economías de escala; una ventaja de las bebidas a base de hierbas medicinales es la diferenciación que presentan en el mercado la cual se basa en las propiedades que presentan dichas materias primas.

\section{b. Poder de Negociación de los clientes}

El poder de negociación de los clientes es medio debido a que tienen una oferta de bebidas amplia, los principales productos ofertados son las bebidas carbonatadas que hoy en día abarcan la mayoría del mercado debido a que brindan un producto que satisface las necesidades básicas de las personas.

Por otro lado, las bebidas a base de insumos naturales están en pleno desarrollo, es decir, cada vez se busca tener otras opciones de bebidas naturales lo cual lleva a tener una alta competencia en el mercado.

Un indicador de que las bebidas carbonatadas abarcan gran parte del mercado es la gran cantidad de bebidas que se produce en Perú.

\section{c. Poder de Negociación de los Proveedores}

El poder de negociación de los Proveedores es bajo pues los productores tienen pocas oportunidades de vender su producto, es decir, podrían exportar, venderlo como insumo para filtrantes o para el uso en bebidas además de que los proveedores no disponen de muchas empresas que utilicen la manzanilla, matico, muña o romero como insumo o producto. 


\section{d. Amenaza de productos sustitutos}

La amenaza de los productos sustitutos es medio, pues tanto las bebidas carbonatadas, agua, jugos y nuevas bebidas naturales captan un gran porcentaje de clientes pues satisfacen sus necesidades básicas.

Las gaseosas, el agua y los jugos son los sustitutos más vendidos en el mercado, debido a que satisfacen las necesidades pero presentan una tendencia de ventas descendente y en caso del agua se venden a un precio menor.

\section{e. Rivalidad entre competidores existentes}

La rivalidad entre competidores existentes de bebidas es medio pues aquellos que producen bebidas carbonatadas son los que dominan el mercado, lo cual les permite tener mayores ingresos. Por otro lado, aquellos que producen bebidas a base de insumos naturales se ubican en un mercado donde la situación actual va mejorando, es decir, existe una inclinación por el consumo de lo natural pero hoy en dia ya existe marcas consolidadas en cuanto a bebidas a base de insumos naturales lo cual nos indica que existen barreras de entrada a dicho mercado.

\section{Tabla 2.1}

Grado de atractividad de la Industria

\begin{tabular}{|c|c|c|c|c|c|}
\hline Grado de atractividad de la Industria & 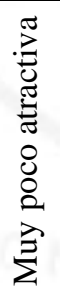 & 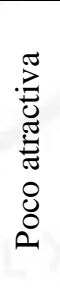 & 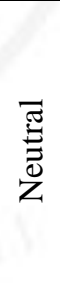 & 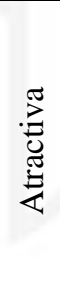 & 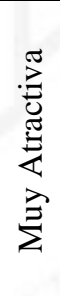 \\
\hline Amenaza de nuevos ingresos & & 2 & & & \\
\hline Poder de negociación de clientes & & & 3 & & \\
\hline Poder de negociación de proveedores & & & & 4 & \\
\hline Amenaza de productos sustitutos & & & 3 & & \\
\hline Rivalidad entre competidores existentes & & & 3 & & \\
\hline Evaluación Global & & & 3 & & \\
\hline
\end{tabular}

Elaboración propia 


\subsubsection{Modelo de Negocios (Canvas)}

A continuación se presenta el modelo de canvas en el cual se detallará el modelo de negocio

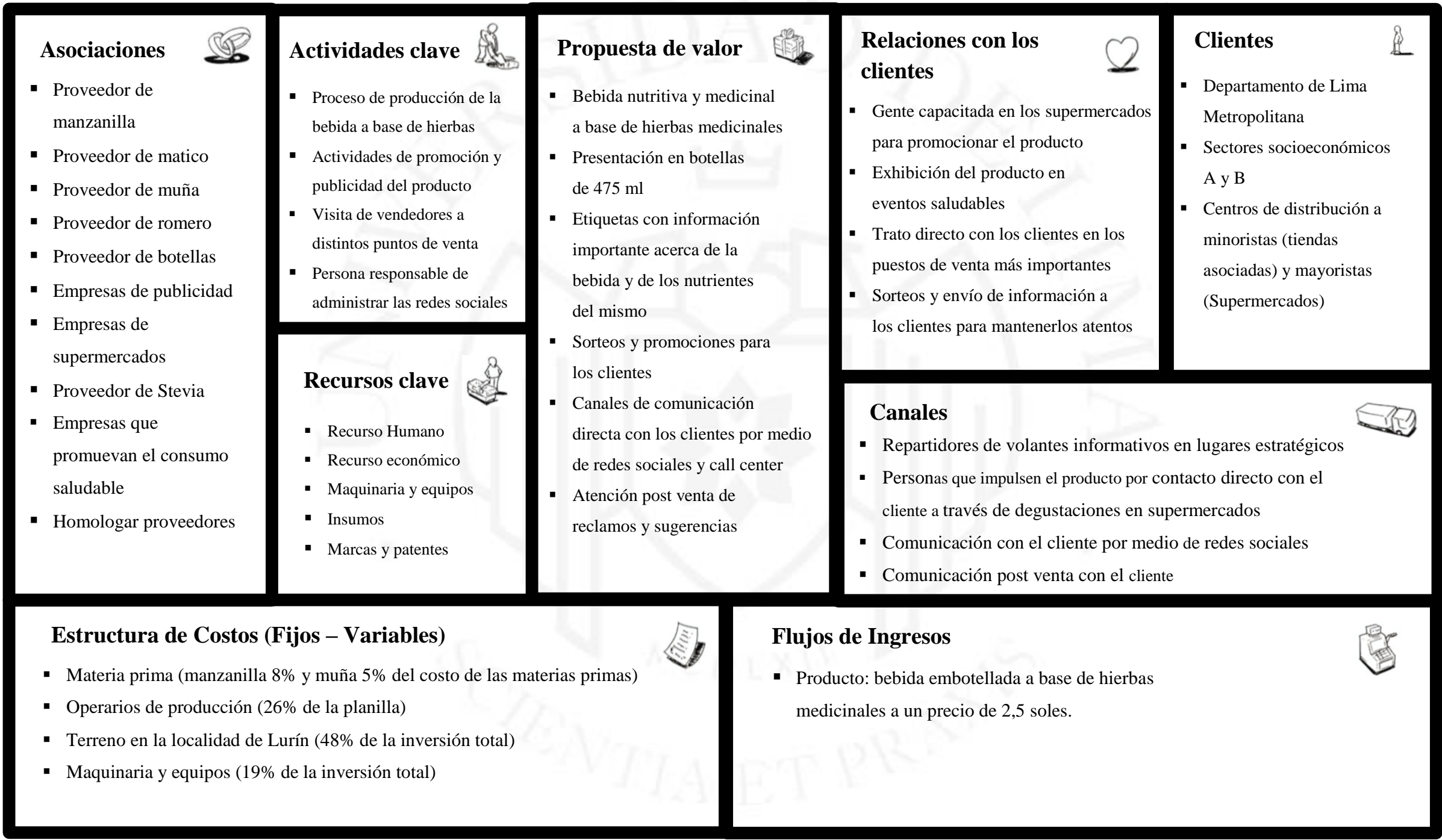




\subsection{Metodología a emplear en la investigación de mercado (Uso de fuentes}

secundarias o primarias, muestreo, método de proyección de la demanda)

\section{a. Fuentes Primarias}

Para el presente estudio se considera llevar a cabo una encuesta que nos permita identificar cierta intención de consumo y de opinión al público objetivo para poder conocer la intención de compra, los precios que estarían dispuestos a pagar por el producto y su opinión sobre las bebidas a base de insumos naturales que se ofrecen actualmente en el mercado.

\section{b. Fuentes Secundarias}

Se utilizará como fuentes secundarias principalmente las tesis consideradas en el marco referencial, además, se utilizarán bases de datos como Euromonitor, Perú compendio estadístico y Veritrade para obtener valores de producción, consumo, etc.

\section{c. Fuentes Terciarias}

Se consultará principalmente páginas web con el fin de obtener información de las tendencias globales de la industria de bebidas naturales. También se buscará revistas virtuales de consumo masivo para conocer más sobre el manejo de las ventas de este tipo de productos.

\section{d. Técnicas de Ingeniería}

La técnica principal que se utilizará en la investigación de mercados será el uso de estimaciones lineales, con el fin de analizar las proyecciones futuras de la demanda del proyecto. 


\subsection{Demanda Potencial}

2.3.1 Patrones de consumo: incremento poblacional, estacionalidad, aspectos culturales

En un estudio que se realizó en el año 2017, se dio a conocer que esta nueva clase de bebidas tienen una baja penetración. Justamente fue el único año donde Ipsos Apoyo en su estudio anual de productos de consumo masivo dio a conocer que el té embotellado tenía un $12 \%$ de penetración.

La lealtad hacia una marca en este tipo de productos es relativamente media, tal como lo indica el mismo estudio, donde el $65 \%$ de entrevistados son fieles a la marca que consumen.

El lugar frecuente de compra son los Markets y Small Grocers (Bodega), tal como lo indica la figura 2.4 .

Figura 2.4

Lugar Habitual de compra de productos comestibles

\section{Lugar habitual de compra}

\begin{tabular}{|c|c|c|c|c|c|c|c|}
\hline \multirow{5}{*}{ 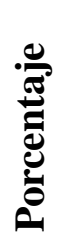 } & & \multirow{5}{*}{\multicolumn{2}{|c|}{ - }} & & & \multirow{5}{*}{-} & \multirow{5}{*}{-} \\
\hline & & & & & & & \\
\hline & \multirow{4}{*}{$\begin{array}{r}60.0 \\
50.0 \\
40.0 \\
30.0 \\
20.0 \\
10.0 \\
0.0\end{array}$} & & & & & & \\
\hline & & & & & & & \\
\hline & & & & & & & \\
\hline & & 2013 & 2014 & 2015 & 2016 & 2017 & 2018 \\
\hline \multicolumn{2}{|c|}{ markets } & 16.0 & 16.0 & 15.6 & 15.4 & 15.0 & 14.9 \\
\hline \multicolumn{2}{|c|}{ 口TD Tea Supermarkets } & 20.1 & 20.3 & 19.8 & 19.9 & 19.7 & 19.6 \\
\hline \multicolumn{2}{|c|}{ RTD Tea Small Grocers } & 50.4 & 50.0 & 50.5 & 50.1 & 50.0 & 49.8 \\
\hline \multicolumn{2}{|c|}{ RTD Tea Other } & 13.5 & 13.7 & 14.1 & 14.6 & 15.3 & 15.7 \\
\hline
\end{tabular}

Fuente: Euromonitor (2018)

Con respecto al crecimiento poblacional, existe una tendencia de crecimiento que se muestra en la siguiente figura 2.5 . 
Figura 2.5

Crecimiento Poblacional

\section{Crecimiento Poblacional}

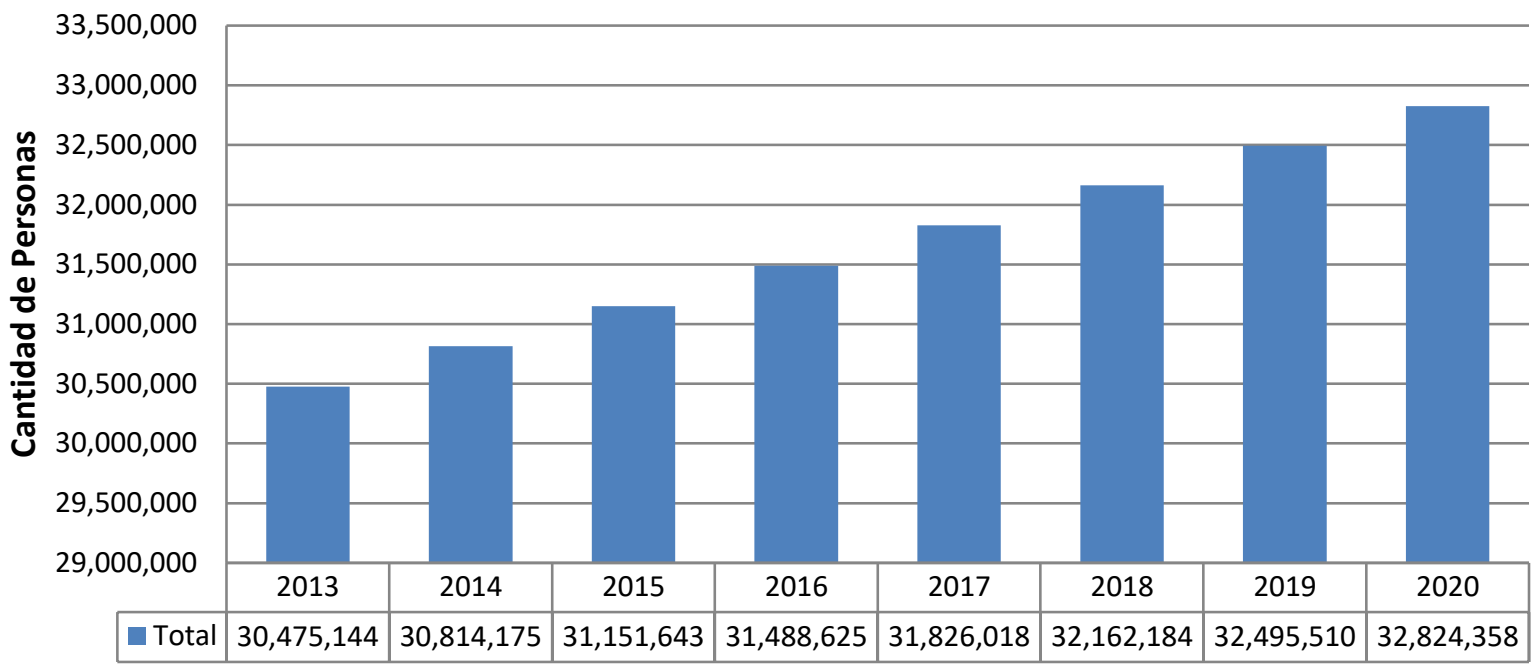

Fuente: Instituto Nacional de estadística e Informática (2018)

\subsubsection{Determinación de la demanda potencial en base a patrones de consumo} similares

La demanda potencial de este estudio será determinada a partir de la población actual en el país, el cual es 32162184 según INEI y el consumo per cápita de un país vecino que tenga un consumo mayor con el fin de saber hasta dónde sería la meta a alcanzar en las ventas. El país que se evaluará es Brasil, cuyo CPC para el 2019 sería 4,41908 litros por habitante, se tomará como referencia a Brasil por ser un país Latinoamericano y cultura similar.

Tabla 2.2

Demanda Potencial

\begin{tabular}{cccc}
\hline Año & Población & $\begin{array}{c}\text { CPC } \\
\text { (L./habitante) }\end{array}$ & $\begin{array}{c}\text { Demanda } \\
\text { Potencial } \\
\text { (L./año) }\end{array}$ \\
\hline 2019 & 32162184 & 4,41908 & 142127264 \\
\hline
\end{tabular}

Elaboración propia 
2.4 Determinación de la demanda de mercado en base a fuentes secundarias o primarias

\subsubsection{Demanda del proyecto en base a data histórica}

2.4.1.1 Demanda Interna Aparente Histórica tomando como fuente bases de datos de Producción, Importaciones y Exportaciones o las ventas tomando como fuente bases de datos de inteligencia comercial

Para la demanda del proyecto se tendrá en cuenta la base de datos en base al consumo de té embotellado en el Perú, por ello en la tabla 2.3 se muestra el consumo anual de té embotellado por litros.

Tabla 2.3

RTD té

\begin{tabular}{cc}
\hline Año & DIA (Litros) \\
\hline 2013 & 50062900 \\
2014 & 57753700 \\
2015 & 67070000 \\
2016 & 75730000 \\
2017 & 83003000 \\
2018 & 88060900 \\
\hline
\end{tabular}

Fuente: Euromonitor (2018)

\subsubsection{Proyección de la demanda (Serie de tiempo o asociativas)}

Para hallar la proyección de la demanda se realizó la siguiente ecuación de regresión:

$y=6000000 x+50000000$

$\mathrm{R}^{2}=0,9841$

Tabla 2.4

Proyección de la demanda

\begin{tabular}{cc}
\hline Año & DIA (Litros) \\
\hline 2019 & 93158800 \\
2020 & 98282200 \\
2021 & 103417000 \\
2022 & 108550000 \\
2023 & 113668300 \\
2024 & 122000000 \\
\hline
\end{tabular}

Elaboración propia 
Tabla 2.5

Proyección de la demanda

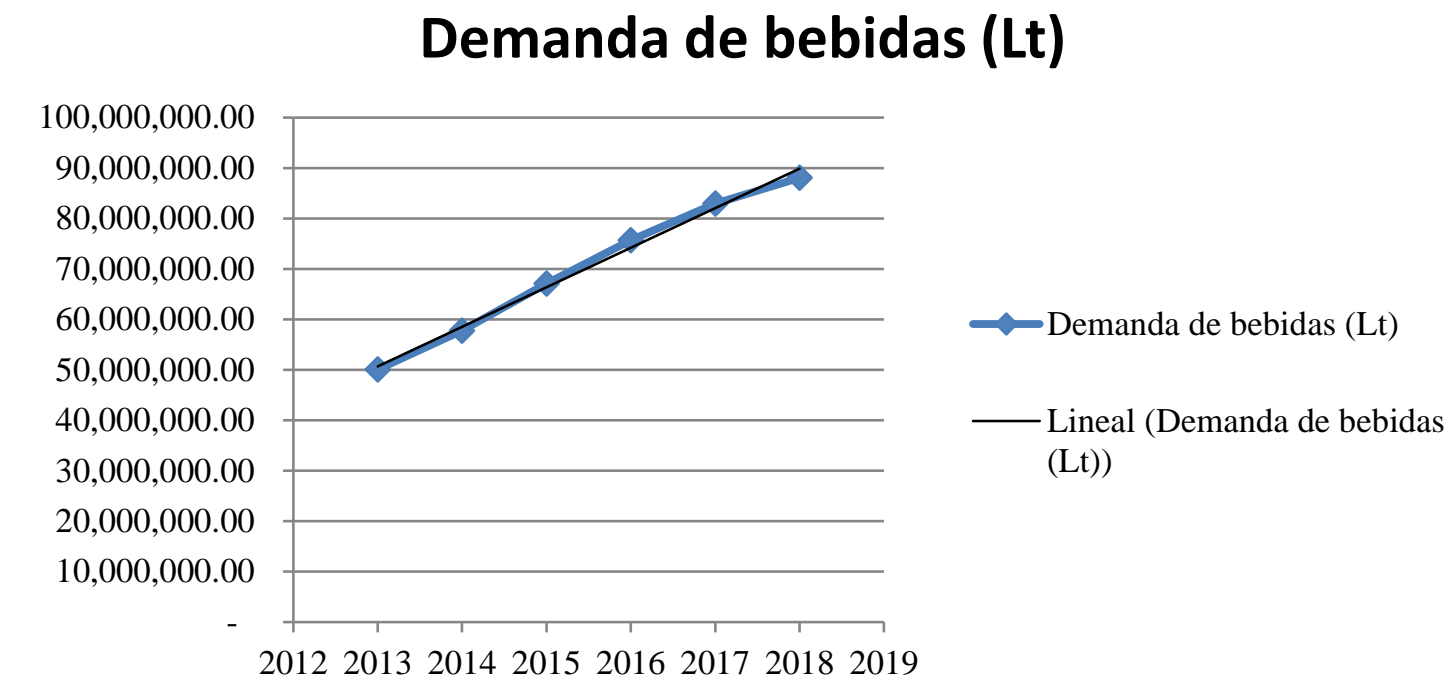

Elaboración propia

\subsubsection{Definición del mercado objetivo teniendo en cuenta criterios de} segmentación

a. Segmentación del mercado

Mediante la segmentación de mercado se busca definir el grupo de consumidores que tiene una necesidad o preferencia por la compra del producto en estudio y se encuentra determinado por:

- Geográfica: Los puntos de venta del producto se encontrarán en Lima Metropolitana, el cual se encuentra segmentando en seis zonas geográficas, las cuáles son: Callao, Lima Centro, Lima Moderna, Lima Norte, Lima Este y Lima Sur. 
Figura 2.6

Composición de Lima Metropolitana

Lima Metropolitana

Distritos que componen cada zona geográfica
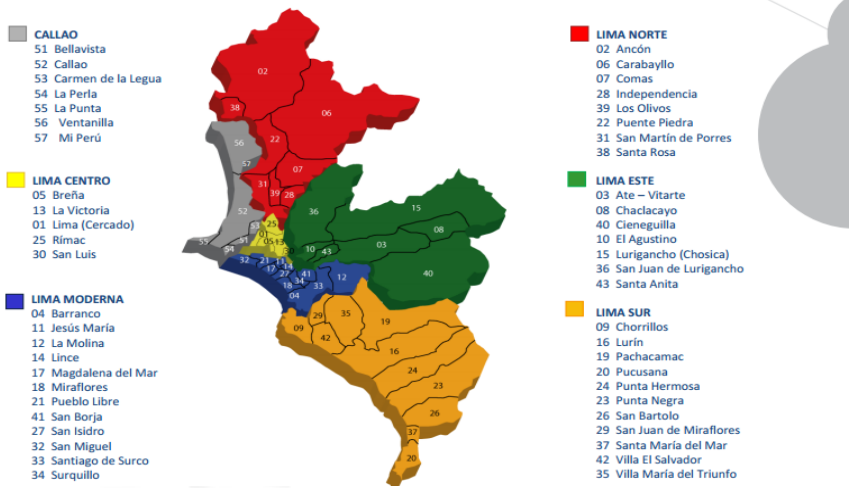

Fuente: Ipsos Apoyo (2018)

- Demográfica: En la figura 2.7 se muestra la composición de los habitantes por cada zona geográfica donde habita, en el cual predomina un mayor número de mujeres en Lima Metropolitana y que la mayoría de la población es relativamente joven, ya que el mayor rango de edad está entre los 21 y 59 años.

Figura 2.7

Información Demográfica de Lima Metropolitana

Lima Metropolitana

Información demográfica

\begin{tabular}{|c|c|c|c|c|c|c|c|}
\hline $\begin{array}{l}\text { Habitantes, hogares, viviendas y } \\
\text { manzanas }\end{array}$ & $\begin{array}{l}\text { Lima } \\
\text { Metropolitana }\end{array}$ & Lima Norte & Lima Este & Lima Centro & Lima Moderna & Lima Sur & Callao \\
\hline Total de habitantes $^{(1)}$ & 9893,245 & $2 ` 519,656$ & 24450,397 & 742,029 & 12273,377 & $1 ' 893,851$ & $1^{10} 013,935$ \\
\hline$\%$ respecto al total de habitantes & $100.0 \%$ & $25.5 \%$ & $24.8 \%$ & $7.5 \%$ & $12.9 \%$ & $19.1 \%$ & $10.2 \%$ \\
\hline Total de hogares (1) & $2^{\prime} 422,122$ & 573,342 & 545,892 & 244,083 & 378,156 & 431,329 & 249,160 \\
\hline Total de viviendas ocupadas ${ }^{(1)}$ & $2 ' 414,023$ & 551,342 & 540,109 & 255,886 & 404,108 & 417,331 & 245,247 \\
\hline Total de manzanas de viviendas (1) & 82,916 & 20,992 & 21,631 & 4,809 & 8,837 & 17,631 & 9,016 \\
\hline \% respecto al total de manzanas & $100.0 \%$ & $25.3 \%$ & $26.1 \%$ & $5.8 \%$ & $10.7 \%$ & $21.3 \%$ & $10.9 \%$ \\
\hline Género (1) & $\begin{array}{l}\text { Lima } \\
\text { Metropolitana }\end{array}$ & Lima Norte & Lima Este & Lima Centro & Lima Moderna & Lima Sur & Callao \\
\hline Masculino & $4,858,186$ & $1,255,905$ & $1,210,745$ & 364,373 & 590,002 & 934,424 & 502,738 \\
\hline Femenino & $5,035,059$ & $1,263,751$ & $1,239,653$ & 377,656 & 683,375 & 959,427 & 511,197 \\
\hline Total & 98993,245 & 2'519,656 & 24450,397 & 742,029 & 1273,377 & $1 ' 893,851$ & $1^{\prime} 013,935$ \\
\hline Edad (1) & $\begin{array}{c}\text { Lima } \\
\text { Metropolitana }\end{array}$ & Lima Norte & Lima Este & Lima Centro & Lima Moderna & Lima Sur & Callao \\
\hline Menos de 7 & 912,416 & 231,344 & 236,364 & 64,747 & 79,949 & 191,904 & 108,107 \\
\hline De 7 a 12 & 932,998 & 253,341 & 235,819 & 61,390 & 82,166 & 206,448 & 93,834 \\
\hline De 13 a 20 & $1,397,978$ & 373,641 & 354,154 & 91,896 & 154,798 & 271,241 & 152,249 \\
\hline De 21 a 35 & $2,301,787$ & 583,652 & 610,339 & 167,776 & 279,983 & 436,422 & 223,615 \\
\hline De 36 a 59 & $2,906,225$ & 712,894 & 711,832 & 214,821 & 404,574 & 563,950 & 298,154 \\
\hline De 60 a más & $1,441,841$ & 364,784 & 301,889 & 141,398 & 271,907 & 223,888 & 137,976 \\
\hline Total & $9 \cdot 893,245$ & $2 \div 519,656$ & 24450,397 & 742,029 & 1273,377 & 1893,851 & 1'013,935 \\
\hline
\end{tabular}

Fuente: Ipsos Apoyo (2018) 
- Psicográfica: En la figura 2.8 se puede observar las variaciones porcentuales de acuerdo a los niveles socioeconómicos de Lima Metropolitana, en el cual el sector $\mathrm{C}$ sigue siendo el de mayor presencia en la capital.

Figura 2.8

NSE de Lima Metropolitana

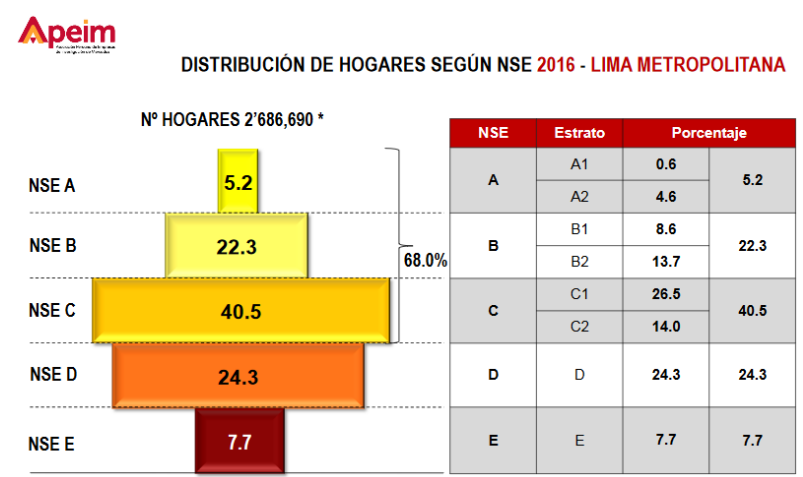

Fuente: Apeim (2016)

b. Selección del mercado meta

De acuerdo a los tipos de segmentación mencionados en el punto anterior, se detallará la segmentación para el mercado meta.

- Geográfico: Se escogerá para el proyecto en primer lugar la zona de Lima Metropolitana, que representa el 35,6\% y de esta manera se medirá la aceptación en este sector para luego evaluar su inclusión en otras zonas del país.

- Psicográfico: Este producto va ir dirigido principalmente para personas de los sectores socioeconómicos A y B, ya que son las de mayor poder adquisitivo y tienden a cuidar mejor su salud comprando productos de buena calidad. Representan un 27,5\% de toda Lima Metropolitana. 
Tabla 2.6

Mercado Objetivo segmentado

\begin{tabular}{cccc}
\hline Año & $\begin{array}{c}\text { DIA estimada } \\
\text { (Litros) }\end{array}$ & $\begin{array}{c}\text { Lima } \\
\text { Metropolitana (L) } \\
\mathbf{3 5 . 6 \%}\end{array}$ & $\begin{array}{c}\text { Nivel Socioeconómico } \\
\text { A y B (L) 27,5\% }\end{array}$ \\
\hline 2019 & 93158800 & 33164533 & 9120247 \\
2020 & 98282200 & 34988463 & 9621827 \\
2021 & 103417000 & 36816452 & 10124524 \\
2022 & 108550000 & 38643800 & 10627045 \\
2023 & 113668300 & 40465915 & 11128127 \\
2024 & 122000000 & 43432000 & 11943800 \\
\hline
\end{tabular}

Elaboración: Propia

\subsubsection{Diseño y aplicación de encuestas}

En relación a esta evaluación se realizaron encuestas a 384 personas.

La encuesta realizada sirve para determinar la intención e intensidad de compra del producto en estudio. Cabe mencionar que la encuesta se realizó a personas del entorno lo que significa que el resultado es referencial.

El diseño de la encuesta (ver anexo 1) fue realizado con el objetivo de conocer el mercado, la intensión, la intensidad y sus requerimientos.

\subsubsection{Resultados de la encuesta:}

Los resultados principales que se utilizarán en la determinación del mercado son la intención e intensidad de compra. Los resultados (ver anexo 2) en porcentajes son los siguientes:

Tabla 2.7

Resultado de la encuesta

\begin{tabular}{ccc}
$\begin{array}{c}\text { Número de } \\
\text { encuestados }\end{array}$ & $\begin{array}{c}\text { Intención de } \\
\text { compra }\end{array}$ & $\begin{array}{c}\text { Intención x Intensidad } \\
\text { de compra }\end{array}$ \\
\hline 384 & $90,36 \%$ & $52,89 \%$ \\
\hline
\end{tabular}

Fuente: Encuestas (2018) 


\subsubsection{Determinación de la demanda del proyecto}

Con los diferentes tipos de segmentación escogida y de acuerdo a los datos proporcionados por los estudios de Ipsos Apoyo más una ambición en participación del $12 \%$ debido a que el mercado de bebidas saludables se encuentra en crecimiento y al ambicionar llegar a tener un participación ponderada de las marcas relativamente nuevas, la demanda proyectada del proyecto es la siguiente:

Tabla 2.8

Demanda del Proyecto

\begin{tabular}{lccccc}
\hline Año & $\begin{array}{c}\text { DIA } \\
\text { estimada (L) }\end{array}$ & $\begin{array}{c}\text { Lima } \\
\text { Metropolitana (L) } \\
\mathbf{3 5 . 6 \%}\end{array}$ & $\begin{array}{c}\text { Nivel } \\
\text { Socioeconómico A } \\
\text { y B (L) 27,5\% }\end{array}$ & $\begin{array}{c}\text { Encuesta (L) } \\
\mathbf{5 2 . 8 9 \%}\end{array}$ & $\begin{array}{c}\text { Participación } \\
\text { (Ambición)(L) } \\
\mathbf{1 2 . 0 0 \%}\end{array}$ \\
\hline 2019 & 93158800 & 33164533 & 9120247 & 4823698 & 578844 \\
2020 & 98282200 & 34988463 & 9621827 & 5088985 & 610678 \\
2021 & 103417000 & 36816452 & 10124524 & 5354861 & 642583 \\
2022 & 108550000 & 38643800 & 10627045 & 5620644 & 674477 \\
2023 & 113668300 & 40465915 & 11128127 & 5885666 & 706280 \\
2024 & 122000000 & 43432000 & 11943800 & 6317076 & 758049 \\
\hline
\end{tabular}

Elaboración propia

\subsection{Análisis de la oferta}

\subsubsection{Empresas productoras, importadoras y comercializadoras}

Las empresas que comercializan una bebida a base de una infusión, que en su mayoría son a base de té, son Aje, Unilever, P\&D Andina Alimentos, Gloria, Corporación JPM y Eko Business SAC; siendo Free Tea, de la empresa Aje, la que es más vendida en el país y que con las inversiones que vienen realizando en su planta de producción se espera realizar potenciar su portafolio de bebidas y además exportar a mercados como el boliviano. 
Tabla 2.9

Marcas de té embotellado

\begin{tabular}{|c|c|c|}
\hline Marca & $\begin{array}{c}\text { Empresa que lo } \\
\text { comercializa }\end{array}$ & Logo \\
\hline Free Tea & Aje Group S.A. & \\
\hline Lipton & Unilever Andina S.A. & \\
\hline Leaf Tea & Gloria S.A. & \\
\hline Vida & Corporación JMP & \\
\hline Beberash & $\begin{array}{c}\text { La Cosecha Peruana } \\
\text { S.A.C }\end{array}$ & \\
\hline 4Tea & $\begin{array}{l}\text { P\&D Andina } \\
\text { Alimentos S.A. }\end{array}$ & \\
\hline
\end{tabular}

Elaboración propia

\subsubsection{Participación de mercado de los competidores actuales}

De acuerdo a las marcas mencionadas anteriormente, se pudo conocer la participación que tiene cada marca de té embotellado. Además, cabe mencionar que Free Tea sigue liderando el mercado, su participación ha aumentado considerablemente, ya que del 2017 al 2018 sufrió un crecimiento de participación 2.44\%. 
Figura 2.9

Participación de las marcas

\title{
Participación 2018
}

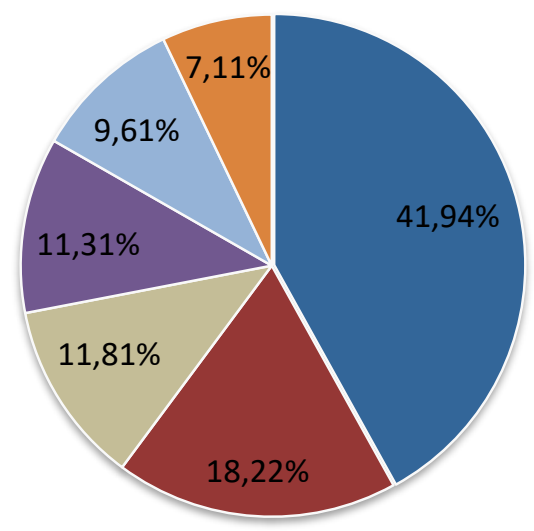

\author{
- Free Tea (Aje Group) \\ - Lipton (Unilever Group) \\ - Leaf Tea (Gloria SA, Grupo) \\ - Vida (Embotelladora Don Jorge SA) \\ Beberash (La Cosecha Peruana SAC) \\ - Others
}

Fuente: Euromonitor (2018)

\subsection{Definición de la estrategia de comercialización}

\subsubsection{Políticas de comercialización y distribución}

Para establecer las políticas es necesario identificar tres aspectos: canales de distribución, transporte y almacenaje.

La distribución de los productos se realizará de forma indirecta en autoservicios y bodegas, ya que se venderá a terceros por medio de la estrategia push para impulsar el producto al mercado en grandes volúmenes pero la estrategia inicial será la estrategia pull pues se busca dar a conocer el producto y la marca para generar atracción en los consumidores finales.

Se sabe que la mayoría de personas adquiere sus productos en las bodegas cercanas a sus hogares, autoservicios y supermercados, por lo que se pondrá énfasis en promocionar mediante estos canales.

El almacenamiento de los productos terminados se efectuará en ambientes destinados exclusivamente para este fin. Para ello se destinará un espacio adecuado para los envases del producto con el fin de que pueda cumplir con las diferentes medidas de seguridad y además contar con pasillos amplios para un adecuado traslado de los productos. 
Con respecto al transporte, se realizará de manera cuidadosa con la finalidad que prevenga los envases y evite daños a estos. Por ello es bueno contar con vehículos acondicionados y provistos de medios suficientes para proteger el producto de cualquier daño que pueda ocurrir.

\subsubsection{Publicidad y promoción}

El proyecto se centrará en diferenciar el producto como uno que cuida mejor la salud de las personas.

El objetivo de las campañas publicitarias de lanzamiento es dar a conocer al cliente el producto y brindarle la información necesaria de este con el fin de que pueda sentirse atraído con el producto.

Al principio se tendrá un fuerte trabajo en campo con el fin de reforzar los canales y que el consumidor conozca mejor del producto, de las cualidades que tiene y los beneficios que aporta la bebida, para ello se usará la estrategia pull pues se busca dar a conocer el producto y la marca para generar atracción en los consumidores finales, también se usará una estrategia push para poder impulsar el producto al mercado en grandes volúmenes.

También se planea que la marca esté presente en todas las redes sociales, la cual es un medio muy satisfactorio para ganar más popularidad. En dichas páginas se pueden colocar beneficios que aporta la manzanilla, matico, muña y romero, promociones, eventos de confraternidad entre otros; todo ello con el fin de fidelizar a los clientes.

Las promociones del producto irán de acuerdo a la cantidad que adquiera cada cliente y a la fidelidad que tengan hacia el producto. De acuerdo con esto se lo podrá otorgar descuentos, mayores facilidades de pago, ofrecerle algunos regalos, entre otras opciones.

\subsubsection{Análisis de precios}

\subsubsection{Tendencia histórica de los precios}

Se pudo investigar los precios de los años anteriores de un producto sustituto, el cual viene a ser el té embotellado. Básicamente el precio del producto estudiado debe asemejarse con el fin que pueda competir y sea al alcance del cliente. 
Tabla 2.10

Tendencia de los precios

\begin{tabular}{ccc}
\hline \multirow{2}{*}{ Marca } & \multicolumn{2}{c}{ Precio (S/.) } \\
& $\mathbf{2 0 1 8}$ & $\mathbf{2 0 1 9}$ \\
\hline Beberash Té Verde & 4,00 & 4,00 \\
Free Tea Light & 2,20 & 2,50 \\
Gloria Leaf Tea & 1,90 & 2,00 \\
Ice Tea Vida & 1,40 & 1,50 \\
Lipton Green Tea & 2,40 & 2,50 \\
\hline
\end{tabular}

Fuente: Euromonitor (2018)

\subsubsection{Precios actuales}

La bebida va a ser enfocada para los NSE A y B y buscará una constante lucha por adquirir mayores consumidores mediante una diferenciación en el producto por los beneficios y agradable sabor que posee. Tomando como referencia los tés embotellados y la encuesta realizada, se pretende salir al mercado con un precio de venta de S/.2.50, el cual es un precio muy atractivo para los nuevos consumidores.

\subsubsection{Estrategia de precio}

Para definir una estrategia del precio del producto estudiado, primero se debe considerar que es un producto nuevo en el mercado y que competirá directamente con las bebidas a base de productos naturales.

Actualmente estas tienen un precio entre 1.5 y 4 nuevos soles, el cual indica que el precio inicial con el que saldrá al mercado debe estar en ese rango.

También es bueno analizar los costos que tomaría fabricar este producto, por lo que se buscará reducirlos lo más que se pueda, pero sin dejar de lado la calidad que debe tener la materia prima a escoger y el proceso de fabricación.

Si durante la etapa inicial se nota un bajo volumen de ventas, se tomará la decisión de aplicar promociones o reducir un poco el precio de venta. 


\section{CAPÍTULO III: LOCALIZACIÓN DE PLANTA}

\subsection{Identificación y análisis detallado de los factores de localización}

Inicialmente se determinarán las posibles ubicaciones de la planta a nivel macro localización, es decir se analizará diferentes departamentos tomando como factores de importancia la Proximidad a la materia prima, cercanía al mercado, disponibilidad de mano de obra, abastecimiento de servicios y disponibilidad de terrenos.

De esta manera se busca tomar la mejor decisión de ubicación a base de ventajas y desventajas de cada departamento y con ello satisfacer al mercado objetivo con un costo menor y maximización de beneficios del proyecto.

\section{a. Proximidad a la materia prima}

La manzanilla, matico, muña y romero crecen de manera natural en Junín y Ancash lo cual es muy favorable pues se encuentra cerca a Lima, lo cual permite cuidar la materia prima pues estas son muy frágiles y tiende a dañarse en el transporte. Este factor es de gran importancia pues mientras más alejado se encuentren los proveedores de materia prima se incurrirá en mayores costos de transporte.

\section{b. Cercanía al mercado}

El proyecto pretende abastecer al mercado nacional para los sectores socioeconómicos A y B por lo que se tendrá como principal ingreso a la región de Lima metropolitana, por ello es conveniente que la planta se ubique cerca al mercado limeño pues de esta manera se ahorran costos, sobre todo de transporte, y se puede colocar el producto en los puntos de venta con mayor rapidez.

\section{c. Costo de transporte terrestre}

La comunicación terrestre por carreteras se debe de tomar en cuenta para poder atender con facilidad al mercado meta (Lima Metropolitana)

\section{d. Costo de mano de obra}

Para instalar la planta se debe evaluar la disponibilidad de mano de obra pues es un factor importante pues la planta debe estar ubicada en lugares poblados donde la mano de obra se encuentre disponible y a un buen precio. 


\section{e. Costo de Energía eléctrica}

La energía eléctrica es de suma importancia para la maquinaria y equipos, tanto para la parte operativa como para la parte administrativa. El costo de energía eléctrica varía según cada región.

\section{f. Disponibilidad de terrenos}

Para la ubicación de la planta se debe buscar una buena disponibilidad de terrenos amplios y precios bajos, el cual permita implementar el proyecto de manera óptima.

\section{g. Costo de Terreno}

Se analizará el costo de terreno en cada distrito para la ubicación de la planta se debe buscar una buena disponibilidad de terrenos amplios y precios bajos, el cual permita implementar el proyecto de manera óptima.

\section{h. Existencia de Parques Industriales}

Para la ubicación de la planta se debe buscar lugares apropiados para la operación, por lo tanto, se analizará distritos que cuente con cercanía a Parques Industriales.

\section{i. Facilidades Municipales}

Se analizará los costos y días que brindan cada Municipalidad para poder ubicar de forma óptima la planta.

\section{j. Seguridad distrital}

Se tendrá en cuenta la seguridad de cada distrito, en base a denuncias y policías por persona, para poder prevenir futuros inconvenientes de hurtos.

\subsection{Identificación y descripción de las alternativas de localización}

A continuación, se detallarán factores para la descripción de la localización

\section{a. Proximidad a la materia prima}

Junín es el mayor productor de manzanilla, matico y muña a nivel nacional además de ubicarse cerca a Lima (ver anexo 3). 
El romero es una hierba que crece mayormente en Ancash pero también se cultiva en Junín lo cual permite traer todos los insumos de una misma localidad y ahorrar en costos de transporte.

Tabla 3.1

Distancia de los diferentes departamentos a la materia prima

\begin{tabular}{c|ccc}
\hline Región & $\begin{array}{c}\text { Distancia } \\
(\mathbf{K m})\end{array}$ & $\begin{array}{c}\text { Tiempo } \\
\text { (Horas) }\end{array}$ & Escala \\
\hline Junín & 40 & 1,00 & 10,00 \\
Lima & 328 & 7,00 & 6,00 \\
Ancash & 740 & 14,00 & 2,00 \\
\hline
\end{tabular}

Fuente: Google Map (2019)

Tabla 3.2

Escala de calificación de cercanía a la materia prima

\begin{tabular}{ccc}
\hline Criterio & Rango & Escala \\
\hline Excelente & {$[0-148]$} & 10,00 \\
Muy bueno & {$[148-296]$} & 8,00 \\
Bueno & {$[296-444]$} & 6,00 \\
Regular & {$[444-592]$} & 4,00 \\
Deficiente & {$[592-$ más $]$} & 2,00 \\
\hline
\end{tabular}

Elaboración propia

\section{b. Cercanía al mercado}

Para desarrollar el análisis se tomó como base los departamentos en donde se puede conseguir manzanilla, matico, muña y romero además que estén cercanos a Lima, es por ello que se evaluaron las distancias de estos al mercado objetivo. Como indica la Tabla 3.3; sería conveniente que la planta se ubique en Lima por la cercanía al mercado objetivo, seguidamente de Junín y finalmente Ancash.

\section{Tabla 3.3}

Distancia de los diferentes departamentos al departamento de Lima

\begin{tabular}{c|ccc}
\hline Región & $\begin{array}{c}\text { Distancia } \\
(\mathbf{K m})\end{array}$ & $\begin{array}{c}\text { Tiempo } \\
\text { (Horas) }\end{array}$ & Escala \\
\hline Lima & 40 & 1,00 & 10,00 \\
Junín & 328 & 7,00 & 4 \\
Ancash & 430 & 8,00 & 2 \\
\hline
\end{tabular}

Fuente: Google Map (2019) 
Tabla 3.4

Escala de calificación de cercanía al mercado meta

\begin{tabular}{ccc}
\hline Criterio & Rango & Escala \\
\hline Excelente & {$[0-86]$} & 10,00 \\
Muy bueno & {$[86-172]$} & 8,00 \\
Bueno & {$[172-258]$} & 6,00 \\
Regular & {$[258-344]$} & 4,00 \\
Deficiente & {$[344-$ más $]$} & 2,00 \\
\hline
\end{tabular}

Elaboración propia

\section{c. Costo de transporte terrestre}

El flete de transporte por carretera entre las posibles ubicaciones y Lima Metropolitana es mostrado en la Tabla 3.5, además en la Tabla 3.6 se muestra su escala de calificación.

\section{Tabla 3.5}

Escala de calificación de costo de transporte terrestre (Flete)

\begin{tabular}{c|ccc}
\hline Región & Destino & S/. (Incluido IGV) & Escala \\
\hline Lima & Lima & 1100 & 10,00 \\
Junín & metropolitana & 2100 & 4,00 \\
Ancash & & 2300 & 2,00 \\
\hline
\end{tabular}

Fuente: Transhuamali EIRL (2019)

Tabla 3.6

Escala de calificación de costo de transporte terrestre (Flete)

\begin{tabular}{ccc}
\hline Criterio & Rango & Escala \\
\hline Excelente & {$[930-1200]$} & 10,00 \\
Muy bueno & {$[1200-1470]$} & 8,00 \\
Bueno & {$[1470-1740]$} & 6,00 \\
Regular & {$[1740-2100]$} & 4,00 \\
Deficiente & {$[2100-$ más $]$} & 2,00 \\
\hline
\end{tabular}

Elaboración propia

\section{d. Costo de mano de obra}

Para instalar la planta se necesita mano de obra capacitada, la cual debe tener conocimiento sobre el proceso productivo. Además, se necesitará de la mano de obra de 
operarios a quienes se les brindará la capacitación necesaria para el trabajo por lo cual se analizará los costos.

Tabla 3.7

Costo de mano de obra

\begin{tabular}{c|cc}
\hline Región & $\begin{array}{c}\text { Nivel de ingresos } \\
\text { (S/.) }\end{array}$ & Escala \\
\hline Lima & 1526 & 2,00 \\
Junín & 1050 & 8,00 \\
Ancash & 1050 & 8,00 \\
\hline
\end{tabular}

Fuente: Ministerio de Trabajo (2018)

Tabla 3.8

Escala de calificación de costo de mano de obra

\begin{tabular}{|c|c|c|}
\hline Criterio & Rango & Escala \\
\hline Excelente & {$[930-1046]$} & 10,00 \\
\hline Muy bueno & {$\left[\begin{array}{lllll}1 & 046 & -1 & 165\end{array}\right]$} & 8,00 \\
\hline Bueno & {$\left[\begin{array}{llll}1 & 165 & -1 & 284\end{array}\right]$} & 6,00 \\
\hline Regular & {$\left[\begin{array}{lllll}1 & 284 & -1 & 403\end{array}\right]$} & 4,00 \\
\hline Deficiente & [1 403 - más] & 2,00 \\
\hline
\end{tabular}

Elaboración propia

\section{e. Costo de Energía eléctrica}

A continuación, en la tabla 3.9, se muestra el costo mensual de energía eléctrica en las tres regiones a evaluar teniendo en cuenta que el máximo consumo de energía eléctrica anual para la producción es de 73 931,52 kwh. Adicionalmente en la tabla 3.10 se muestra la escala de calificación de costo de energía eléctrica

Tabla 3.9

Tarifas de las principales empresas por departamento año 2019

\begin{tabular}{c|cccc}
\hline Región & S/./ Kwh & Kwh/año & S/. / mes & Escala \\
\hline Lima & 0,29 & 73931,52 & 1786,68 & 2,00 \\
Junín & 0,27 & 73931,52 & 1663,46 & 4,00 \\
Ancash & 0,26 & 73931,52 & 1601,85 & 4,00 \\
\hline
\end{tabular}

Elaboración propia 
Tabla 3.10

Escala de calificación de costo de energía año 2019

\begin{tabular}{|c|c|c|}
\hline Criterio & Rango & Escala \\
\hline Excelente & {$\left[\begin{array}{llll}1 & 200 & -1 & 319\end{array}\right]$} & 10,00 \\
\hline Muy bueno & {$\left[\begin{array}{lllll}1 & 319 & -1 & 438\end{array}\right]$} & 8,00 \\
\hline Bueno & [1 $438-1556]$ & 6,00 \\
\hline Regular & {$\left[\begin{array}{llll}1 & 556 & -1 & 675\end{array}\right]$} & 4,00 \\
\hline Deficiente & [1 675 - más] & 2,00 \\
\hline
\end{tabular}

Elaboración propia

\subsection{Evaluación y selección de localización}

\subsubsection{Evaluación y selección de la macro localización}

Para determinar la Macro Localización de la planta se utilizará el método Ranking de factores, tomando en consideración los siguientes factores:

- $\quad$ Proximidad a la materia prima $=1$

- $\quad$ Cercanía al mercado = 2

- $\quad$ Costo de transporte terrestre $=3$

- $\quad$ Costo de mano de obra $=4$

- $\quad$ Costo de energía eléctrica $=5$

Tabla 3.11

Matriz de enfrentamiento a nivel Macro

\begin{tabular}{c|lccccccc}
\hline $\mathbf{N}^{\mathbf{0}}$ & \multicolumn{1}{|c}{ Factor } & $\mathbf{1}$ & $\mathbf{2}$ & $\mathbf{3}$ & $\mathbf{4}$ & $\mathbf{5}$ & Conteo & Ponderación \\
\hline 1 & Proximidad a las materia prima & & 0 & 0 & 1 & 1 & 2,00 & $18,18 \%$ \\
2 & Cercanía al mercado & 1 & & 1 & 1 & 1 & 4,00 & $36,36 \%$ \\
3 & Costo de Transporte terrestre & 1 & 0 & & 1 & 1 & 3,00 & $27,27 \%$ \\
4 & Costo de mano de obra & 0 & 0 & 0 & & 1 & 1,00 & $9,09 \%$ \\
5 & Costos de Energía Eléctrica & 0 & 0 & 0 & 1 & & 1,00 & $9,09 \%$ \\
\hline
\end{tabular}

Elaboración propia

Adicionalmente en la siguiente tabla 3.12 se define la escala de calificación para más adelante poder realizar un Ranking de factores. 
Tabla 3.12

Escala de Calificación

\begin{tabular}{cc}
\hline Criterio & Calificación \\
\hline Excelente & 10,00 \\
Muy bueno & 8,00 \\
Bueno & 6,00 \\
Regular & 4,00 \\
Deficiente & 2,00 \\
\hline
\end{tabular}

Elaboración propia

Tabla 3.13

Ranking de Factores (macro)

\begin{tabular}{|c|c|c|c|c|c|c|c|}
\hline \multicolumn{2}{|l|}{ Ciudad } & \multicolumn{2}{|c|}{ Junín } & \multicolumn{2}{|c|}{ Lima } & \multicolumn{2}{|c|}{ Ancash } \\
\hline Factor & Peso & Calificación & Puntos & Calificación & Puntos & Calificación & Puntos \\
\hline Proximidad a la materia prima & $18,18 \%$ & 10 & 1,82 & 6 & 1,09 & 2 & 0,36 \\
\hline Cercanía al mercado & $36,36 \%$ & 4 & 1,45 & 10 & 3,64 & 2 & 0,73 \\
\hline Costo de Transporte terrestre & $27,27 \%$ & 4 & 1,09 & 10 & 2,73 & 2 & 0,55 \\
\hline Costo de mano de obra & $9,09 \%$ & 8 & 0,73 & 2 & 0,18 & 8 & 0,73 \\
\hline Costos de Energía Eléctrica & $9,09 \%$ & 4 & 0,36 & 2 & 0,18 & 8 & 4,00 \\
\hline & & & 5,45 & & 7,82 & & 6,36 \\
\hline
\end{tabular}

Elaboración propia

\subsubsection{Evaluación y selección de la micro localización}

Para determinar la Micro Localización de la planta se han tomado en consideración tres distritos de Lima: Ate, Lurín y Villa el Salvador. Para ello se utilizará el método Ranking de factores, tomando en consideración los siguientes factores:

\section{a. Disponibilidad de terrenos}

Para poder analizar la disponibilidad de terrenos en la tabla 3.14 se muestra la oferta existente de terreno e inventario industrial $\left(\mathrm{m}^{2}\right)$. Adicionalmente, en la tabla 3.15 se muestra la escala de calificación de disponibilidad de terreno. 
Tabla 3.14

Disponibilidad de terrenos por distrito

\begin{tabular}{c|cc}
\hline Zona & $\begin{array}{c}\text { Oferta } \\
\text { existente }(\%)\end{array}$ & $\begin{array}{c}\text { Inventario } \\
\left.\text { Industrial } \mathbf{( m}^{2}\right)\end{array}$ \\
\hline Lima Sur & $35 \%$ & 16612568 \\
Lima Centro & $4 \%$ & 3004638 \\
Callao & $27 \%$ & 8544968 \\
Lima Norte & $31 \%$ & 5706333 \\
Lima Este & $3 \%$ & 36595945 \\
\hline
\end{tabular}

Fuente: Colliers International (2017)

Tabla 3.15

Tabla de calificación de disponibilidad de terrenos

\begin{tabular}{c|c}
\hline Distrito & Escala \\
\hline Ate & 2,00 \\
Lurín & 4,00 \\
Villa el Salvador & 4,00 \\
\hline
\end{tabular}

Elaboración propia

\section{b. Costo de terrenos}

A continuación, en la tabla 3.16 se muestra el costo de terrenos por metro cuadrado en los tres distritos a evaluar. Adicionalmente, en la tabla 3.17 se muestra la escala de calificación de costo de terrenos. Lurín sería el distrito con menores precios por $\mathrm{m}^{2}$ respecto a los otros distritos.

Tabla 3.16

Costo de terrenos por distrito

\begin{tabular}{c|cc}
\hline Zona & $\begin{array}{c}\text { Precio de terreno } \\
\left(\mathbf{U S D} / \mathbf{m}^{2}\right)\end{array}$ & Escala \\
\hline Ate & 400 & 6,00 \\
Lurín & 300 & 8,00 \\
Villa el Salvador & 380 & 6,00 \\
\hline
\end{tabular}

Fuente: Colliers International (2017) 
Tabla 3.17

Escala de calificación de Costo de terrenos

\begin{tabular}{ccc}
\hline Criterio & Rango & Escala \\
\hline Excelente & {$[0-180]$} & 10,00 \\
Muy bueno & {$[180-360]$} & 8,00 \\
Bueno & {$[360-540]$} & 6,00 \\
Regular & {$[540-720]$} & 4,00 \\
Deficiente & {$[720-$ más $]$} & 2,00 \\
\hline
\end{tabular}

Elaboración propia

\section{c. Existencia de parques Industriales}

Aparte de lo mostrado en la figura 3.1 se debe tener en consideración las siguientes zonas industriales en Lurín (Praderas de Lurín, Macropolis, Los Eucaliptos), Pachacamac (Quebrada Retamal), Villa el Salvador (Villa el Salvador), Chilca (Sector $62)$.

Figura 3.1

Parques Industriales en Lima

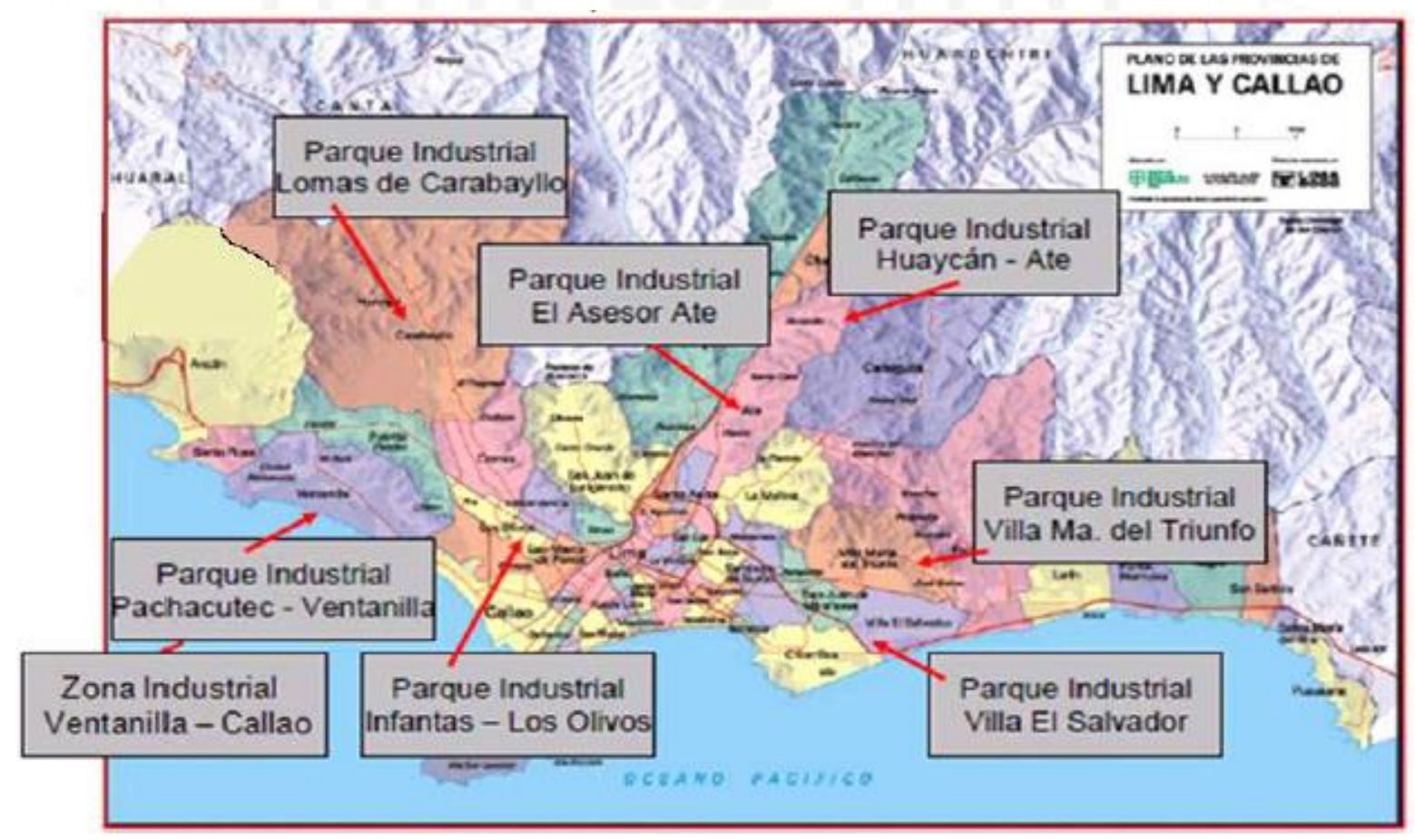

Fuente: Esteves, C. (2008) 
Tabla 3.18

Tabla de calificación de disponibilidad de terrenos

\begin{tabular}{lc}
\hline \multicolumn{1}{c}{ Zona } & Escala \\
\hline Ate & 6,00 \\
Lurín & 8,00 \\
Villa el Salvador & 6,00 \\
\hline
\end{tabular}

Elaboración propia

\section{d. Facilidades Municipales}

Las Diferentes Municipalidades brindan los diferentes servicios legales en periodos de tiempo distintos, en este caso Lurín es el distrito que brinda mayor rapidez en cuanto a realizar trámites legales por estar establecida como zona industrial.

Tabla 3.19

Disponibilidad de terrenos por distrito

\begin{tabular}{|c|c|c|c|}
\hline & Villa el Salvador & Ate & Lurín \\
\hline $\begin{array}{l}\text { Facilidades } \\
\text { Municipales }\end{array}$ & $\begin{array}{l}\text { El procedimiento para } \\
\text { realizar los trámites es } \\
\text { similar al de Lurín. } \\
\text { Costo por licencia de } \\
\text { funcionamiento S/. } 367,30 \\
\text { y demora } 15 \text { días. }\end{array}$ & $\begin{array}{c}\text { El procedimiento a seguir } \\
\text { para los trámites es el más } \\
\text { corto. } \\
\text { Costo por licencia de } \\
\text { funcionamiento es de } \\
\text { S/. } 343,35 \text { y demora } 12 \\
\text { días. }\end{array}$ & $\begin{array}{c}\text { El procedimiento para } \\
\text { realizar los trámites es } \\
\text { similar a V.E.S. } \\
\text { Costo por licencia de } \\
\text { funcionamiento es de } \\
\text { S/. 393,90 y demora } 15 \\
\text { días. }\end{array}$ \\
\hline
\end{tabular}

Elaboración propia

Tabla 3.20

Tabla de calificación de Facilidades Municipales

\begin{tabular}{cc}
\hline Zona & Escala \\
\hline Ate & 8,00 \\
Lurín & 6,00 \\
Villa el Salvador & 6,00 \\
\hline
\end{tabular}

Elaboración propia 


\section{e. Seguridad distrital}

Se selecciona al distrito que presente un menor índice de inseguridad ciudadana para con ello prevenir probables pérdidas de materiales y daños personales. Para la evaluación de este factor se tomaron en cuenta los habitantes por policía y denuncias realizadas en cada distrito.

Tabla 3.21

Tabla de habitantes por Policía

\begin{tabular}{cc}
\hline Distrito & $\begin{array}{c}\text { Habitantes } \\
\text { por policía }\end{array}$ \\
\hline Ate & 2123 \\
Lurín & 838 \\
Villa el Salvador & 1699 \\
\hline
\end{tabular}

Fuente: Araujo, Franco (2017)

Tabla 3.22

Tabla de denuncias policiales

\begin{tabular}{ccc}
\hline Distrito & $\begin{array}{c}\text { Denuncias } \\
\text { Totales }\end{array}$ & $\begin{array}{c}\text { Denuncias por } \\
\text { habitantes }\end{array}$ \\
\hline Ate & 14573 & 0,023 \\
Lurín & 1142 & 0,013 \\
Villa el Salvador & 7693 & 0,017 \\
\hline
\end{tabular}

Fuente: Araujo, Franco (2017)

Tabla 3.23

Tabla de calificación de Seguridad

\begin{tabular}{cc}
\hline Zona & Escala \\
\hline Ate & 8,00 \\
Lurín & 6,00 \\
Villa el Salvador & 6,00 \\
\hline
\end{tabular}

Elaboración propia 
Tabla 3.24

Matriz de Enfrentamiento a nivel Micro

\begin{tabular}{c|lccccccc}
\hline $\mathrm{N}^{\mathbf{0}}$ & \multicolumn{1}{|c}{ Factor } & 1 & 2 & 3 & 4 & 5 & Conteo & Ponderación \\
\hline 1 & Disponibilidad de terrenos & & 0 & 1 & 1 & 1 & 3,00 & $21,43 \%$ \\
2 & Costo de terrenos & 1 & & 1 & 1 & 1 & 4,00 & $28,57 \%$ \\
3 & Existencia de parques Industriales & 1 & 1 & & 1 & 1 & 4,00 & $28,57 \%$ \\
4 & Facilidades Municipales & 0 & 0 & 0 & & 1 & 1,00 & $7,14 \%$ \\
5 & Seguridad Distrital & 1 & 0 & 0 & 1 & & 2,00 & $14,29 \%$ \\
\hline & & & & & & & 14,00 & $100,00 \%$ \\
\cline { 5 - 6 }
\end{tabular}

Elaboración propia

Tabla 3.25

Ranking de Factores (micro)

\begin{tabular}{l|ccccccc}
\hline \multicolumn{1}{c}{ Ciudad } & \multicolumn{3}{c}{ Ate } & \multicolumn{2}{c}{ Lurín } & \multicolumn{2}{c}{ Villa el Salvador } \\
\hline Factor & Peso & Calificación & Puntos & Calificación & Puntos & Calificación & Puntos \\
\hline $\begin{array}{l}\text { Disponibilidad de } \\
\text { terrenos }\end{array}$ & $21,43 \%$ & 4 & 0,86 & 6 & 1,29 & 6 & 1,29 \\
Costo de terrenos & $28,57 \%$ & 6 & 1,71 & 8 & 2,29 & 6 & 1,71 \\
Existencia de parques & $28,57 \%$ & 6 & 1,71 & 8 & 2,29 & 6 & 1,71 \\
Industriales & $7,14 \%$ & 8 & 0,57 & 6 & 0,43 & 6 & 0,43 \\
Facilidades Municipales & $14,29 \%$ & 8 & 1,14 & 6 & 0,86 & 6 & 0,86 \\
Seguridad Distrital & & & 6,00 & & $\mathbf{7 , 1 4}$ & & 6,00 \\
\hline
\end{tabular}

\subsection{Evaluación y selección de localización}

Luego de evaluar los diferentes factores de macro localización y micro localización se concluye que Lurín es el distrito que presenta mayores condiciones para la construcción de la planta garantizando su correcto funcionamiento, además de contar con la cercanía del distrito de Punta Hermosa (Chilca), el cual permitiría una expansión de manera fácil debido a su gran disponibilidad de terrenos en zona industrial. 


\section{CAPÍTULO IV: TAMAÑO DE PLANTA}

Se entiende como tamaño de planta a la capacidad de producción durante un tiempo determinado. En el presente capítulo se deberá determinar un tamaño de planta apropiado, para lo cual se debe tener en cuenta factores determinantes y limitantes como son la tecnología, el pronóstico de la demanda y del mercado, la disponibilidad de los recursos productivos y por último el punto de equilibrio.

\subsection{Relación tamaño - mercado}

Para poder determinar el tamaño de planta en función al requerimiento del mercado se utilizará los datos obtenidos del capítulo 2, en donde se muestra las proyecciones de la demanda, lo cual permite identificar la cantidad máxima de hierbas medicinales que será demandada durante los primeros seis años de operación. En la Tabla 4.1 se observan las ventas proyectadas del proyecto para los próximos seis años, en los que se puede observar que no existe limitación alguna para la elaboración del producto, ya que se cuenta con un mercado dispuesto a probar este nuevo tipo de bebida.

Tabla 4.1

Demanda de bebidas a base de hierbas medicinales embotellada para los próximos seis años

\begin{tabular}{c|cc}
\hline Año & $\begin{array}{c}\text { Demanda } \\
\text { Proyecto (L) }\end{array}$ & $\begin{array}{c}\text { Demanda Proyecto } \\
\text { (Botellas) }\end{array}$ \\
\hline 2019 & 578844 & 1218619 \\
2020 & 610678 & 1285638 \\
2021 & 642583 & 1352807 \\
2022 & 674477 & 1419952 \\
2023 & 706280 & 1486905 \\
2024 & 758049 & 1595893 \\
\hline
\end{tabular}

Elaboración propia

Por ellos se concluye que el tamaño máximo de planta no deberá exceder de 1.595.893 botellas de hierbas medicinales embotellada de $475 \mathrm{ml}$. por año. 


\subsection{Relación tamaño - recursos productivos}

En este punto se analizará la disponibilidad de los recursos necesarios para la producción de la bebida a base de manzanilla, matico, muña y romero, tanto la materia prima e insumos como la mano de obra. En el capítulo III se indicó que Lurín es la localidad más apropiada para la ubicación de la planta pues Lima cuenta con la mayor cantidad de universidades e institutos profesionales en todo el país, es decir, la mano de obra especializada para garantizar la operatividad de la planta no sería un factor que genere problemas, asimismo se dispone de todos los servicios básicos tanto energía eléctrica como el agua o desagüe. Como se indicó anteriormente, la producción de materia prima de Junín (ver anexo 3) en comparación con la cantidad de materia prima necesaria, como se muestra en la tabla 4.2, es mucho mayor y con ello se garantiza la cantidad de materia prima necesaria para los próximos 6 años, por ende, no es una limitante.

Tabla 4.2

Cantidad de hierbas medicinales necesarias para los próximos seis años

\begin{tabular}{cccccc}
\hline Año & $\begin{array}{c}\text { Dem. Proyecto } \\
(\mathbf{L t})\end{array}$ & $\begin{array}{c}\text { Manzanilla } \\
(\mathbf{K g})\end{array}$ & $\begin{array}{c}\text { Matico } \\
(\mathbf{K g})\end{array}$ & $\begin{array}{c}\text { Muña } \\
(\mathbf{K g})\end{array}$ & $\begin{array}{c}\text { Romero } \\
(\mathbf{K g})\end{array}$ \\
\hline 2019 & 578844 & 1736,53 & 868,26 & 868,26 & 868,26 \\
2020 & 610678 & 1832,03 & 916,02 & 916,02 & 916,02 \\
2021 & 642583 & 1927,74 & 963,87 & 963,87 & 963,87 \\
2022 & 674477 & 2023,43 & 1011,71 & 1011,71 & 1011,71 \\
2023 & 706280 & 2118,84 & 1059,42 & 1059,42 & 1059,42 \\
2024 & 758049 & 2274,15 & 1137,07 & 1137,07 & 1137,07 \\
\hline
\end{tabular}

Elaboración propia

\subsection{Relación tamaño - tecnología}

Para la determinación del tamaño - tecnología, es necesario tener en cuenta el proceso. El proceso cuenta con las etapas de selección, pesado, lavado, cortado, cocción, filtrado, mezclado y envasado. Estas etapas se explicarán con mayor detalle en el capítulo 5.

Para este proceso se prevé que el cuello de botella se ubique en la estación de etiquetar, ya que la capacidad menor de la operación se encuentra en la etiquetadora, la cual proporciona 2250169 botellas. 
Tabla 4.3

Producción de bebidas a base de hierbas medicinales en Litros y en Botellas

\begin{tabular}{c|ccccc}
\hline Año & $\begin{array}{c}\text { Demanda. } \\
\text { Proyecto (L) }\end{array}$ & $\begin{array}{c}\text { Demanda } \\
\text { Proyecto } \\
\text { (Botellas) }\end{array}$ & Factor & Litros/hora & Botellas/hora \\
\hline 2019 & 578844 & 1218619 & & 232 & 488 \\
2020 & 610678 & 1285638 & 8 hrs/día & 245 & 515 \\
2021 & 642583 & 1352807 & & 257 & 542 \\
2022 & 674477 & 1419952 & 6 días/semana & 270 & 569 \\
2023 & 706280 & 1486905 & & 283 & 596 \\
2024 & 758049 & 1595893 & 52 semanas/año & 304 & 639 \\
\hline
\end{tabular}

Elaboración propia

Como se observa en la Tabla 4.3, para el año 2024 se necesitará haber procesado

1595893 botellas de bebida. Tomando en cuenta esta información, se buscó máquinas y equipos que cumplan con la demanda. Los cálculos de la capacidad instalada se analizarán en el capítulo 5.4 capacidad instalada. A continuación, en la tabla 4.4, se muestra el tamaño de planta.

Tabla 4.4

Capacidad teórica de planta

\begin{tabular}{cc}
\hline Status & Botellas / Año \\
\hline Tamaño de planta & 2812992 \\
\hline
\end{tabular}

Elaboración propia

\subsection{Relación tamaño - punto de equilibrio}

Para el cálculo del tamaño de planta se tomó en cuenta los costos fijos anuales como se puede observar en la siguiente tabla. En ella se considerará los costos fijos de mano de obra directa, indirecta y servicios requeridos. Asimismo, se obtuvo un costo unitario de S/. 0,8126, el cual se pudo hallar gracias al plan de producción y a los presupuestos de costos de producción que se detallarán en los capítulos posteriores. 
Finalmente, tal como fue mencionado, el precio sugerido será de S/. 2,50, se descuenta el $20 \%$ pues se venderá de forma indirecta, con toda la información se aplicará la siguiente fórmula:

$$
\begin{gathered}
P E=\frac{C F}{(P v-C u)}=\frac{544370}{2,00-0,8126} \\
P E=458446 \text { unidades }
\end{gathered}
$$

Este resultado quiere decir que para ser capaces de cubrir nuestros costos sin tener ganancias es necesario producir y vender 458446 botellas de bebidas a base de hierbas medicinales.

\subsection{Selección de tamaño de planta}

Analizando los diversos factores se concluye que el tamaño de planta quedará definido por el mercado, es decir 1595893 botellas por año; respecto a los recursos productivos, como se analizó en el punto 4.2, estos se encuentran garantizados pues la producción de las materias primas son mucho mayor a la necesaria.

Tabla 4.5

Selección de tamaño de planta

\begin{tabular}{lc}
\hline \multicolumn{1}{c}{ Límite } & $\begin{array}{c}\text { Tamaño } \\
\text { (Botellas/Año) }\end{array}$ \\
\hline Mercado & 1595893 \\
Recursos productivos & No es limitante \\
Tecnología & 2812992 \\
Punto de equilibrio & 458446 \\
\hline
\end{tabular}

Elaboración propia 


\section{CAPÍTULO V: INGENIERÍA DEL PROYECTO}

\subsection{Definición técnica del producto}

\subsubsection{Especificaciones técnicas, composición y diseño del producto}

\section{a. Especificaciones técnicas del producto}

Las especificaciones técnicas del producto son las variables y atributos más resaltantes que este posee. A continuación, se muestra el detalle de las especificaciones técnicas del producto.

\section{Tabla 5.1}

Especificaciones Técnicas del producto

\begin{tabular}{|c|c|c|c|c|c|c|}
\hline $\begin{array}{l}\text { Nombre del } \\
\text { producto: }\end{array}$ & \multicolumn{3}{|c|}{ Agua de Chachakuma } & $\begin{array}{l}\text { Desarrollado } \\
\text { por: }\end{array}$ & \multicolumn{2}{|c|}{ Gerencia General } \\
\hline Función: & \multicolumn{3}{|c|}{$\begin{array}{l}\text { Satisfacer la sed de forma más saludable a base } \\
\text { de una bebida elaborada con hierbas } \\
\text { medicinales }\end{array}$} & $\begin{array}{l}\text { Verificado } \\
\text { por: }\end{array}$ & \multicolumn{2}{|c|}{$\begin{array}{l}\text { Gerencia de } \\
\text { Calidad }\end{array}$} \\
\hline $\begin{array}{l}\text { Insumos } \\
\text { requeridos: }\end{array}$ & \multicolumn{3}{|c|}{$\begin{array}{l}\text { Agua, Manzanilla, Matico, Muña, Romero y } \\
\text { Stevia }\end{array}$} & $\begin{array}{l}\text { Autorizado } \\
\text { por: }\end{array}$ & \multicolumn{2}{|c|}{$\begin{array}{l}\text { Gerencia de } \\
\text { Producción }\end{array}$} \\
\hline $\begin{array}{l}\text { Costos del } \\
\text { producto: }\end{array}$ & \multicolumn{3}{|c|}{ S./ 0,8126} & Fecha: & \multicolumn{2}{|c|}{$\begin{array}{l}17 \text { de Junio del } \\
2019 \\
\end{array}$} \\
\hline \multirow{2}{*}{$\begin{array}{l}\text { Características } \\
\text { del producto }\end{array}$} & \multicolumn{2}{|c|}{ Tipo de característica } & \multirow{2}{*}{$\begin{array}{c}\text { Norma } \\
\text { técnica o } \\
\text { especificación } \\
\text { V.N. } \pm \text { Tol }\end{array}$} & \multirow{2}{*}{$\begin{array}{l}\text { Medio de } \\
\text { control }\end{array}$} & \multirow{2}{*}{$\begin{array}{l}\text { Técnica de } \\
\text { Inspección }\end{array}$} & \multirow{2}{*}{ NCA } \\
\hline & $\begin{array}{l}\text { Variable / } \\
\text { Atributo }\end{array}$ & $\begin{array}{l}\text { Nivel de } \\
\text { Criticidad }\end{array}$ & & & & \\
\hline $\begin{array}{l}\text { Volumen } \\
\text { (Litros) }\end{array}$ & Variable & Menor & $475+/-5 \mathrm{ml}$ & $\begin{array}{l}\text { Sensor de } \\
\text { Nivel }\end{array}$ & Muestra & $0.10 \%$ \\
\hline Color & Atributo & Crítico & Característico & Sensorial & Muestra & $0.10 \%$ \\
\hline Sabor & Atributo & Crítico & Agradable & Sensorial & Muestra & $0.10 \%$ \\
\hline
\end{tabular}

Elaboración propia

\section{b. Composición del producto}

La bebida a base de hierbas medicinales será un producto con envase de vidrio en presentación de $475 \mathrm{ml}$. El producto está compuesto de hierbas medicinales más agua, la proporción de hierbas que se usan está compuesta por un $40 \%$ de manzanilla, $20 \%$ matico, $20 \%$ muña y $20 \%$ Romero. 


\section{c. Diseño del producto}

A continuación, se muestra el diseño del producto final.

Figura 5.1

Diseño del producto
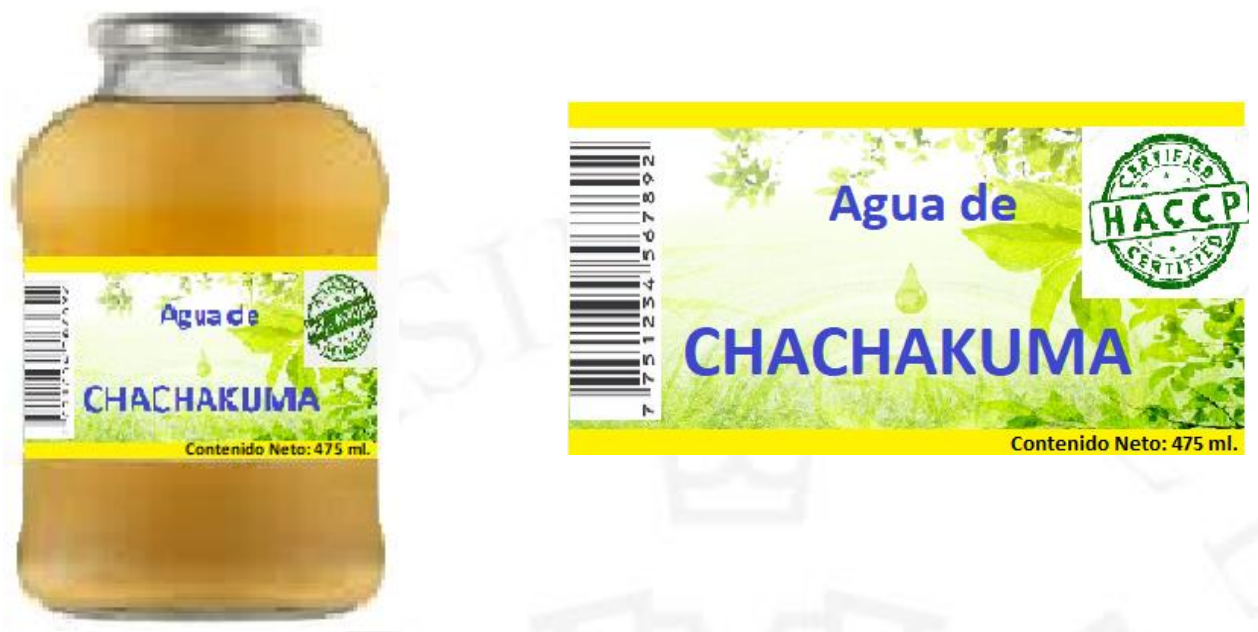

Elaboración propia

\subsubsection{Marco regulatorio para el producto}

Para asegurar la calidad del producto se usará materia prima de calidad para poder cumplir con las especificaciones técnicas del producto, es por ello que su selección deberá estar alineada a las siguientes Normas Técnicas publicadas en INDECOPI:

- NTP 209.650: Etiquetado. Declaraciones de Propiedades.

- $\quad$ NTP 209.038: Alimentos Envasado. Rotulado.

- $\quad$ NTP 209.652: Alimentos Envasados. Etiquetado Nutricional.

- D.S.No.007-98-SA: Vigilancia Sanitaria de Alimentos y Bebidas de Consumo Humano.

- $\quad$ NTP INDECOPI 214.003.: Requisitos que debe cumplir el agua para ser considerada potable.

- Ley N²6842: Ley general de Salud, Artículo 91 (Registro Sanitario).

- Ley N28405: Ley de rotulado de productos industriales manufacturados.

- Ley N²95: Código de protección y defensa del consumidor.

- Codex Alimentarius 


\subsection{Tecnologías existentes y procesos de producción}

\subsubsection{Naturaleza de la tecnología requerida}

\subsubsection{Descripción de las tecnologías existentes}

Las hierbas a utilizar en el proceso de fabricación tienen propiedades medicinales para la ayuda principalmente en el aparato digestivo, afecciones oculares, congestiones nasales, resfríos, etc.

Para la extracción de las propiedades de las hierbas se utilizará al agua, este proceso es simple y no especializado. Por lo que se puede encontrar tecnologías que van desde procesos automatizados, semi automatizados hasta artesanales.

- Artesanal

Es un tipo de tecnología en la que el hombre realiza todo el proceso de producción.

Algo que desfavorece a este tipo de tecnología es su falta de homogeneidad en la calidad de los productos y el tiempo que le dedica es muy alto. Sin embargo, el costo de producción de implementarlo es relativamente bajo y no requiere de mucho conocimiento técnico. Por lo que, las operaciones de recepción y selección de materia prima se pueden efectuar manualmente.

- Semi automática

Se caracteriza por poseer operaciones tanto que requieren mano de obra para el correcto funcionamiento de las máquinas, como es el caso de las actividades del pesado y lavado. Este tipo de tecnología permite tener productos a una mayor escala y el costo de implementación es medianamente bajo.

\section{- Automática}

Todo el proceso es realizado con máquinas especializadas donde la participación del hombre es nula. Solamente se requiere para etapas de reparación o mantenimiento.

Con esta tecnología se incrementa la utilización de la capacidad instalada, disminuye las mermas y el reproceso. Además, mejora la calidad del producto y se ahorra en contratación de personal. Sin embargo, el costo de implementarlo y de mantenerlo operativo es sumamente alto. 
Con estos tres tipos de tecnologías, se detallará en cada etapa el tipo de tecnología a utilizar en el proceso de producción del producto en estudio.

\section{a) Recepción}

En esta etapa se necesitará el uso de un montacarga para la descarga y posterior almacenamiento.

\section{b) Selección y pesado}

La selección y pesado de las hierbas estarán a cargo de los operarios, quienes realizarán una inspección visual y utilizarán balanzas para el pesado de la materia prima.

\section{c) Lavado}

En esta etapa se utilizará una máquina para lavar las hierbas en general, con el fin de eliminar los residuos como tierra o insectos. El lavado húmedo es el más conocido, para el cual se emplea agua y si es necesario se pueden adherir detergentes o sustancias que ayuden a esterilizar el producto, para de esta forma eliminar las impurezas.

\section{d) Cortado}

Para este proceso se utilizarán cuchillas y se realizará de forma manual. De esta forma se cortarán los tallos de las hierbas para poder luego extraer el zumo.

\section{e) Mezclado}

En esta etapa se hará uso de una mezcladora para que el agua caliente que ingresa pueda adquirir la esencia de las hierbas y esta mezcla uniforme de agua de hierbas medicinales pueda pasar al siguiente proceso.

\section{f) Filtrado}

Se hará uso de un colador para poder filtrar las impurezas que dejan las hierbas sobre el agua.

\section{g) Mezclado}

En esta etapa se hará uso de una mezcladora para que el agua de hierbas medicinales pueda adquirir un endulzante. 


\section{h) Pasteurizado}

La mezcla de agua de hierbas medicinales con Stevia se lleva a la máquina de pasteurizado por medio de tuberías de acero inoxidable para eliminar los microorganismos que puedan quedar en la bebida.

\section{i) Envasado y Tapado}

En este proceso se empleará una envasadora de botellas de $475 \mathrm{ml}$. que sellará las botellas herméticamente bajo presión, tener en cuenta que esta máquina previamente al envasado a lavado las botellas.

\section{j) Precintado}

En esta etapa se hará uso de una precintadora para que el producto cuente con un precinto que evite alguna contaminación del producto.

\section{k) Etiquetado y Rotulado}

En esta etapa se utilizará una etiquetadora envolvente para colocar las etiquetas y rótulos a lo largo de todo el perímetro del envase.

\section{1) Empaquetar}

En esta etapa se hará uso de una empaquetadora para que el producto se venda en paquetes de 6 unidades.

\section{Tratamiento de Agua}

\section{a) Osmosis Inversa}

El agua pasa por el proceso de osmosis inversa para eliminar iones, moléculas y partículas más grandes en el agua potable, con ello se busca mejorar la calidad del agua.

\subsubsection{Selección de la tecnología}

Al ser un proyecto nuevo se utilizará la tecnología semiautomática, ya que la automática requiere de una gran inversión económica y volúmenes de producción muy altos para justificar la inversión y lograr un negocio rentable. Asimismo, la tecnología artesanal, no garantiza la uniformidad de los productos y la capacidad de producción es baja. 
De esta manera, los procesos como el pesado, lavado, mezclado, filtrado, pasteurizado, envasado, precintado, etiquetado y empaquetado serán realizados bajo una tecnología semi- automatizada, en otras palabras, las opciones contarán con máquinas que estarán bajo la supervisión de los operarios. Por otra parte, las etapas de la selección de los insumos y el cortado se realizarán de forma manual.

\section{Tabla 5.2}

\section{Tecnología a utilizar en los procesos}

\begin{tabular}{|c|c|c|}
\hline Operación & Tecnología & Descripción \\
\hline $\begin{array}{l}\text { Selección de los } \\
\text { insumos }\end{array}$ & Manual & $\begin{array}{c}\text { Se escogió por los costos más bajos pues los operarios son } \\
\text { los encargados de escoger las hierbas más adecuadas y de } \\
\text { la supervisión. }\end{array}$ \\
\hline Pesado & Semi -automático & $\begin{array}{l}\text { Se utilizará una balanza para saber la cantidad exacta que } \\
\text { se está procesando. }\end{array}$ \\
\hline Lavado & Lavado húmedo & $\begin{array}{l}\text { Tal como se indicó este tipo de lavado, se empleará una } \\
\text { lavadora industrial simple, en la cual se añadirá agua }\end{array}$ \\
\hline Cortado & Manual & $\begin{array}{l}\text { Para este proceso los operarios utilizarán unas cuchillas } \\
\text { para cortar los tallos de las hierbas medicinales. }\end{array}$ \\
\hline Mezclado & Semi - automático & $\begin{array}{l}\text { En este proceso se utilizará una máquina que estará a cargo } \\
\text { de un operario y será la que produzca la bebida. }\end{array}$ \\
\hline Filtrado & Semi - automático & $\begin{array}{c}\text { Para poder eliminar las impurezas que se quedan dentro del } \\
\text { agua de hierbas medicinales. }\end{array}$ \\
\hline Mezclado & Semi - automático & $\begin{array}{c}\text { En este proceso se utilizará una máquina para poder } \\
\text { mezclar la bebida de hierbas medicinales con Stevia y } \\
\text { preservantes. }\end{array}$ \\
\hline Pasteurizado & Semi - automático & $\begin{array}{l}\text { En este proceso se utilizará una máquina para poder } \\
\text { eliminar microorganismos que puedan encontrarse en la } \\
\text { bebida. }\end{array}$ \\
\hline $\begin{array}{l}\text { Envasado y } \\
\text { Tapado }\end{array}$ & Semi-automático & $\begin{array}{l}\text { Se dispondrá de una máquina envasadora que cumpla con } \\
\text { las normas correspondientes y de buena calidad. }\end{array}$ \\
\hline $\begin{array}{l}\text { Etiquetado y } \\
\text { Rotulado }\end{array}$ & Semi-automático & $\begin{array}{l}\text { Este proceso se realizará mediante una máquina que será } \\
\text { alimentada por envases, cuyo funcionamiento será } \\
\text { controlado por un operario. }\end{array}$ \\
\hline Precintado & Semi-automático & $\begin{array}{c}\text { Este proceso se realizará mediante una máquina, la cual } \\
\text { colocará unos precintos de seguridad para evitar alguna } \\
\text { contaminación en la bebida. }\end{array}$ \\
\hline Empaquetado & Semi-automático & $\begin{array}{c}\text { Este proceso se utilizará una máquina para poder } \\
\text { empaquetar el producto terminado en packs de seis } \\
\text { unidades. }\end{array}$ \\
\hline
\end{tabular}

Elaboración propia 


\subsubsection{Proceso de producción}

\subsubsection{Descripción del proceso}

A continuación, se detallará cada una de las etapas necesarias para la producción de la bebida a base de hierbas medicinales.

\section{a) Recepción}

El proceso de producción empieza con la etapa de recepción, cuando tanto los sacos de manzanilla, matico, muña y romero llegan a la planta. Los sacos que llegan serán aproximadamente de 15 kilogramos y serán recibidas por los operarios con la ayuda de un montacarga.

\section{b) Selección y pesado}

Las hierbas medicinales pasarán por un proceso de selección y control visual a cargo de los operarios, con el fin de detectar la materia prima apta para realizar el proceso de producción de la bebida.

Una vez realizado el control, los insumos serán pesados para conocer las cantidades de la materia prima disponible, para luego calcular los rendimientos según el balance de materia calculado.

\section{c) Lavado}

Los insumos serán lavados en una lavadora industrial con agua potable a temperatura ambiente para evitar que contengan tierra u otras impurezas que pudiesen afectar la calidad de las bebidas.

\section{d) Cortado}

Se capacitará a los operarios para que cumplan la función de cortar los tallos de las hierbas medicinales hasta un máximo de $4 \mathrm{~cm}$.

\section{e) Mezclado}

En esta etapa se añade el agua caliente y las hierbas medicinales de acuerdos a las cantidades a calcular en el balance de materia para que el líquido absorba la esencia de las hierbas. 


\section{f) Filtrado}

Con la ayuda de un colador industrial y una vez que el agua con hierbas medicinales haya absorbido la esencia de las hierbas, la bebida se verterá mediante tuberías de acero inoxidable a la siguiente operación quedando sobre el colador algunas hojas o tallos de las hierbas.

\section{g) Mezclado}

Una vez que se tiene la bebida de hierbas medicinales se le añade la Stevia para poder endulzar.

\section{h) Pasteurizado}

Una vez que se tiene la bebida de hierbas medicinales esta ingresa al pasteurizado para poder eliminar microorganismos y así poder garantizar la calidad del producto terminado.

\section{i) Envasado}

La bebida ya preparada se trasladará a una máquina envasadora con la cual también se procederá al tapado roscado de tres vueltas, cerrando las botellas de $475 \mathrm{ml}$ herméticamente para evitar la filtración de humedad.

\section{j) Etiquetado}

En esta etapa las botellas pasarán por una máquina etiquetadora para la colocación de las etiquetas, las cuales deben indicar todas las características del producto.

\section{k) Precintado}

Esta operación consiste en colocar precintos de seguridad al producto para garantizar su no contaminación.

\section{l) Empaquetado}

En esta etapa final las botellas son empaquetadas en cajas, la cual contiene 6 botellas, para luego ser trasladadas al almacén de productos terminados para su próximo despacho. 


\subsubsection{Diagrama de proceso: DOP}

En la figura 5.2 se detalla el diagrama de operaciones del proceso productivo de la bebida natural a base de hierbas medicinales, en el que se detallan los insumos, desperdicios y cada una de las operaciones necesarias para su elaboración.

Figura 5.2

Diagrama de operaciones del proceso de la bebida a base de manzanilla

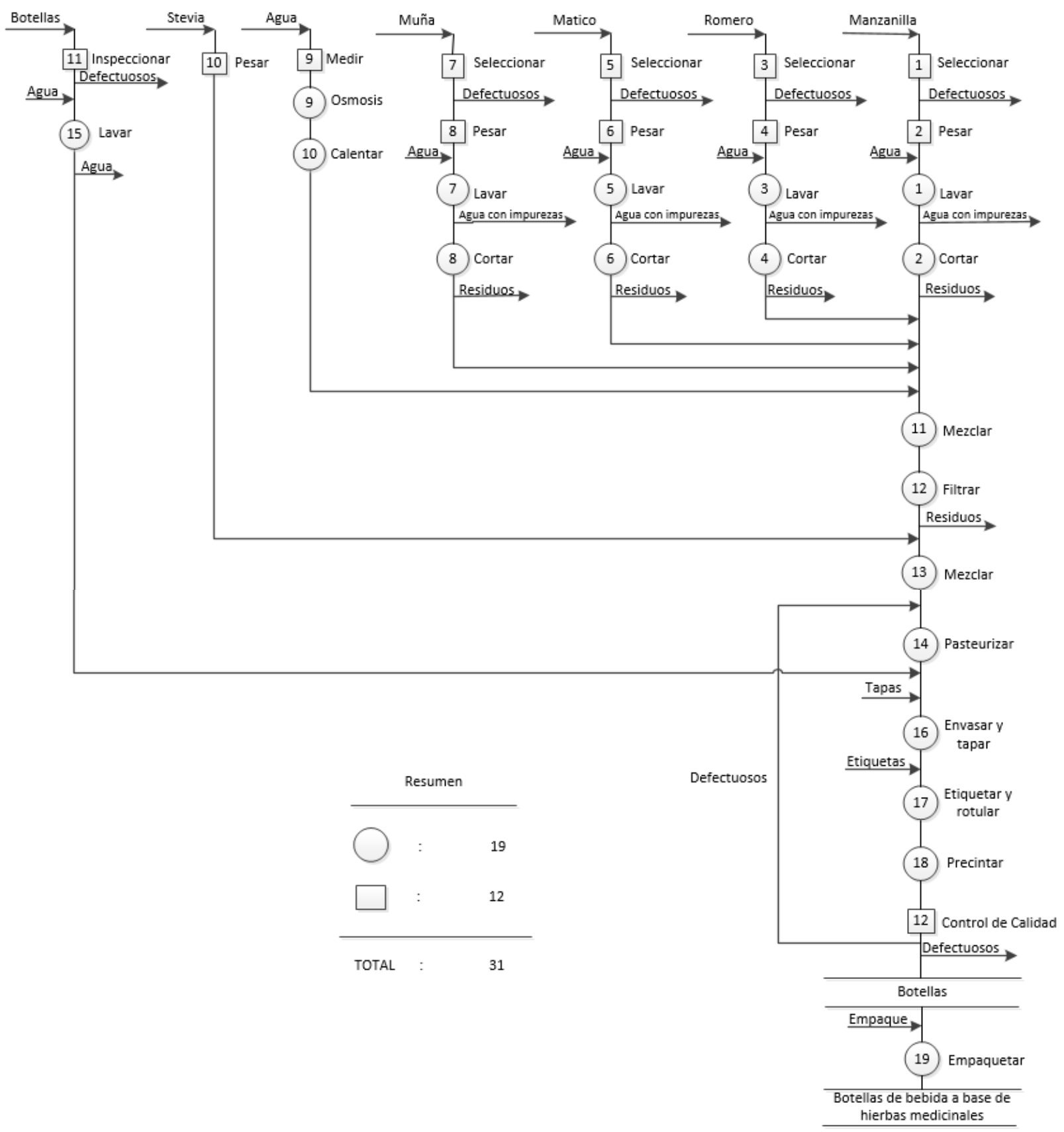

Elaboración propia 


\subsubsection{Balance de materia}

Para realizar el balance de materia se tomó como base la producción anual de botellas que se debe realizar para el año 2024, es decir se calcularon los datos asumiendo que el producto final sería de 1595893 botellas de bebida.

Figura 5.3

Balance de Materia del Proceso

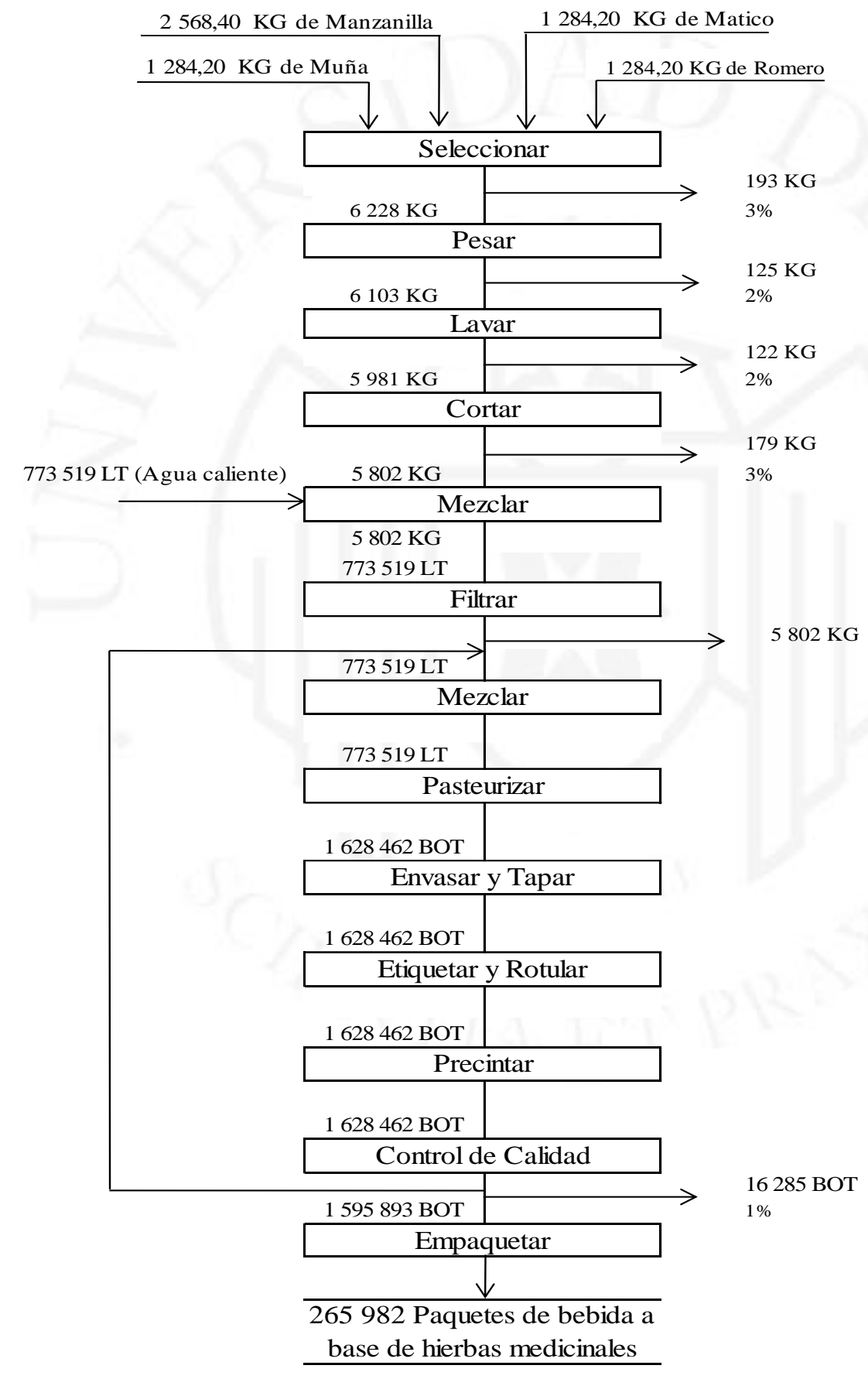

Elaboración propia 


\subsection{Características de las instalaciones y equipos}

\subsubsection{Selección de la maquinaria y equipos}

En este tipo de industrias es muy importante contar con máquinas y equipos confiables que permitan asegurar una buena calidad en los productos finales. De igual forma, se debe emplear maquinaria fabricada con materiales resistentes a la corrosión, lo cual permitirá reducir el riesgo de accidentes y evitar grandes costos.

A continuación, se presenta la lista de las máquinas y equipos necesarios para la operatividad de la planta.

\section{Tabla 5.3}

Máquinas y Equipos a utilizar

\begin{tabular}{ll}
\hline & Máquinas y Equipos \\
\hline Lavadora industrial & Balanza de plataforma industrial \\
Caldero & Mesa de trabajo \\
Máquina de Osmosis & Cuchillas de acero \\
Máquina para mezclar & Tanques de acero inoxidable \\
Máquina para pasteurizar & Coladora industrial \\
Máquina envasadora & Carretilla hidráulica \\
Máquina etiquetadora y rotulado & Montacarga \\
Máquina precintadora & Grupo electrógeno \\
Máquina empaquetadora & \\
\hline
\end{tabular}

Elaboración propia

\subsubsection{Especificaciones de la maquinaria}

A continuación, se detallan las especificaciones de las máquinas y equipos que se encuentran presentes en el proceso de producción. 
Tabla 5.4

Especificaciones de la maquinaria y equipos

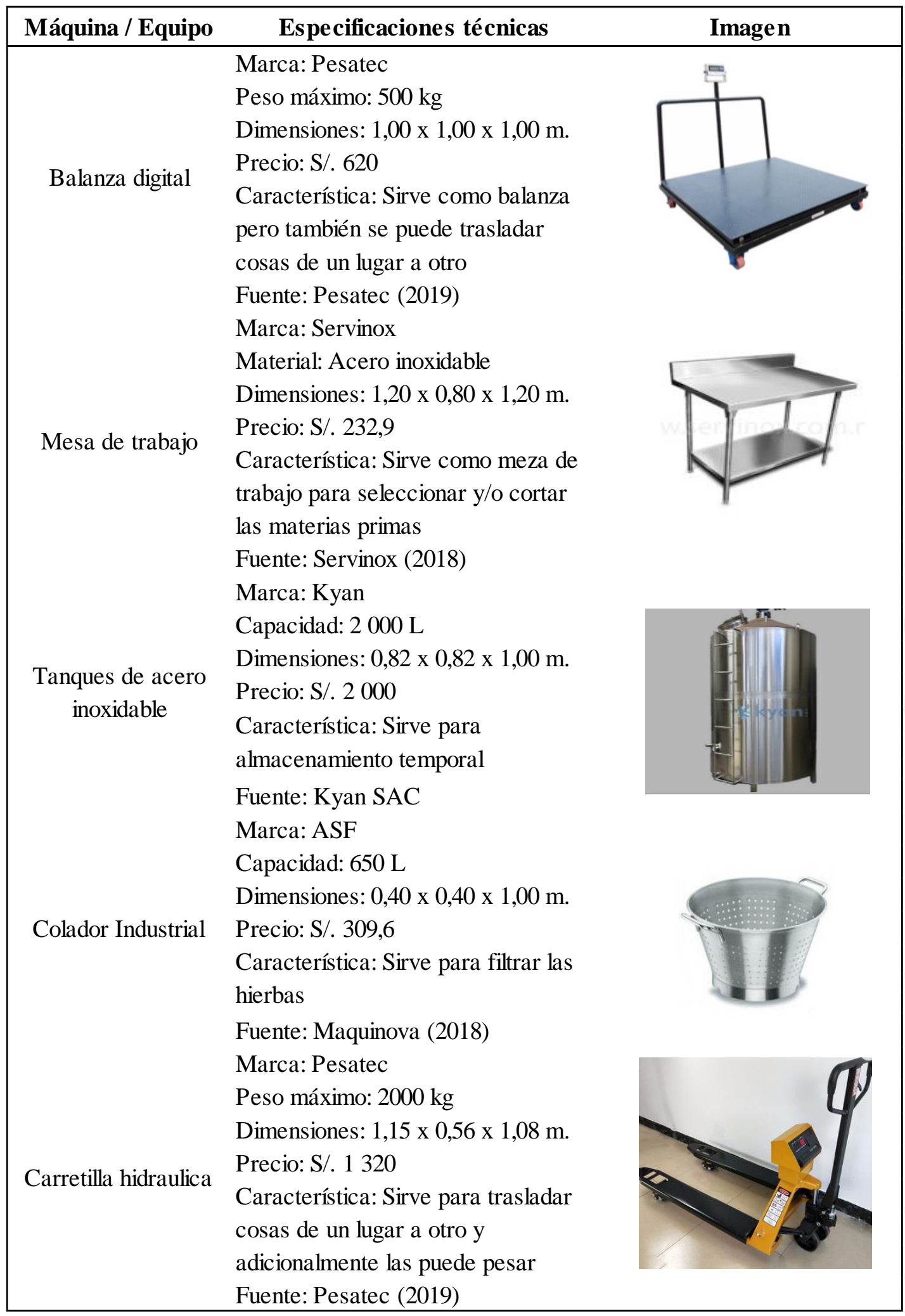

(continúa) 
(continuación)

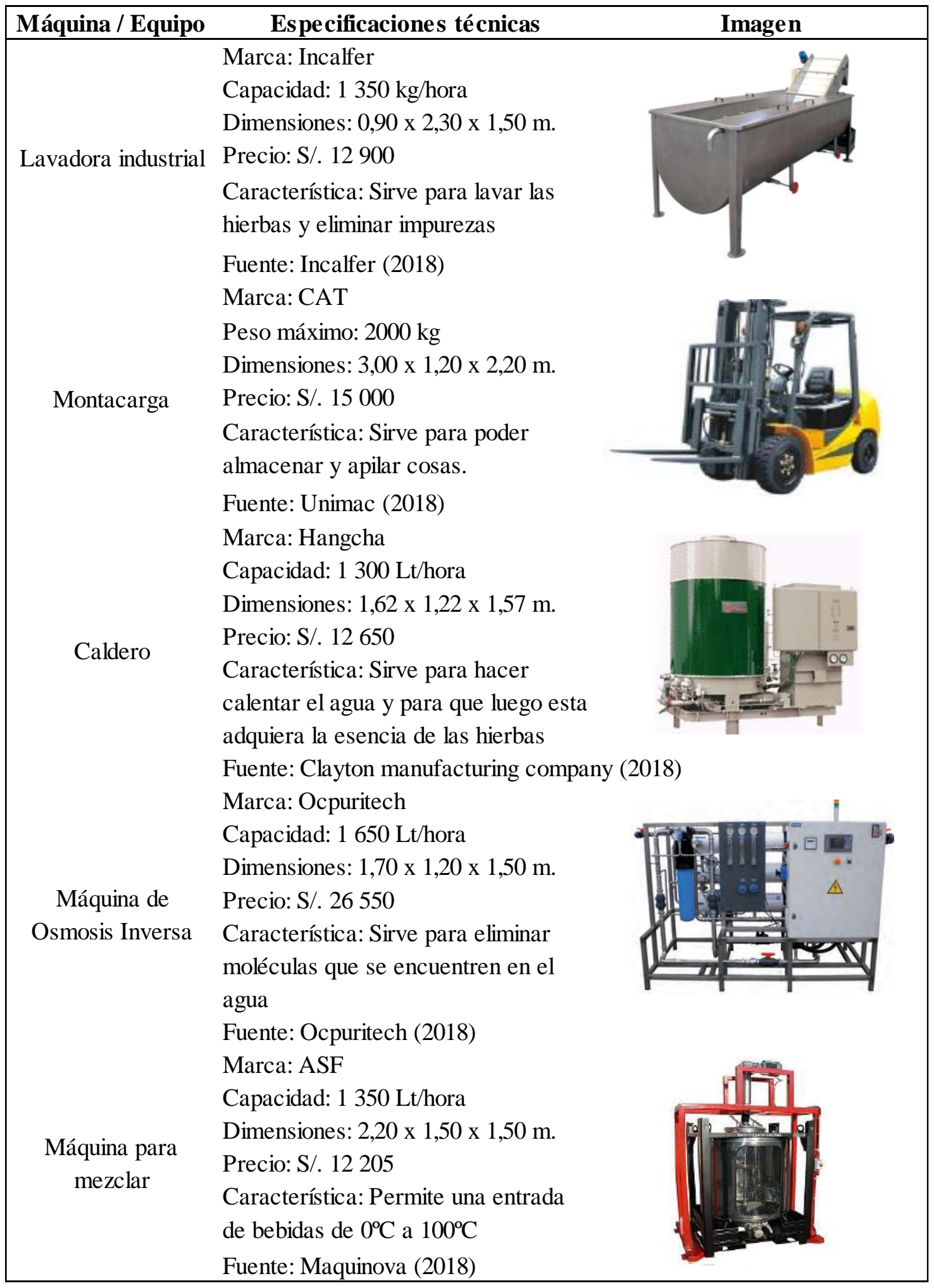

(continúa) 
(continuación)

\begin{tabular}{|c|c|c|}
\hline Máquina / Equipo & Especificaciones técnicas & Imagen \\
\hline $\begin{array}{l}\text { Máquina para } \\
\text { pasteurizar }\end{array}$ & $\begin{array}{l}\text { Marca: Joy light } \\
\text { Capacidad: } 1450 \mathrm{Lt} / \text { hora } \\
\text { Dimensiones: 1,80 x 0,90 x 1,60 m. } \\
\text { Precio: S/. } 21900 \\
\text { Característica: Sirve para eliminar } \\
\text { microorganismos que se pudiesen } \\
\text { encontrar en la bebida } \\
\text { Fuente: Joy light industry (2018) }\end{array}$ & \\
\hline $\begin{array}{c}\text { Máquina para } \\
\text { envasar }\end{array}$ & $\begin{array}{l}\text { Marca: Joy light } \\
\text { Capacidad: } 1350 \text { Bot/hora } \\
\text { Dimensiones: } 2,20 \text { x 1,35 x 2,10 m. } \\
\text { Precio: S/. } 24980 \\
\text { Característica: Sirve para embotellar } \\
\text { la bebida y taparlas, previamente lava } \\
\text { las botellas. } \\
\text { Fuente: Joy light industry (2018) }\end{array}$ & \\
\hline $\begin{array}{l}\text { Máquina para } \\
\text { etiquetar y rotular }\end{array}$ & $\begin{array}{l}\text { Marca: Joy light } \\
\text { Capacidad: } 1150 \text { Bot/hora } \\
\text { Dimensiones: } 1,95 \text { x } 0,90 \text { x } 1,30 \mathrm{~m} \text {. } \\
\text { Precio: S/. } 18640 \\
\text { Característica: Sirve para colocar las } \\
\text { etiquetas y rotulos a las botellas. } \\
\text { Fuente: Joy light industry (2018) }\end{array}$ & \\
\hline $\begin{array}{c}\text { Máquina para } \\
\text { colocar precinto }\end{array}$ & $\begin{array}{l}\text { Marca: Auxiemba } \\
\text { Capacidad: } 1350 \text { Bot/hora } \\
\text { Dimensiones: } 2,15 \text { x } 0,90 \text { x } 1,70 \mathrm{~m} \text {. } \\
\text { Precio: S/. } 16200 \\
\text { Característica: Sirve para empaquetar } \\
\text { el producto final en pack de seis }\end{array}$ & \\
\hline $\begin{array}{c}\text { Máquina para } \\
\text { empaquetar }\end{array}$ & $\begin{array}{l}\text { Marca: Joy light } \\
\text { Capacidad: } 1350 \text { Bot/hora } \\
\text { Dimensiones: } 2,15 \text { x 1,40 x } 1,70 \mathrm{~m} \text {. } \\
\text { Precio: S/. } 19974 \\
\text { Característica: Sirve para empaquetar } \\
\text { el producto final en pack de seis } \\
\text { Fuente: Joy light industry (2018) }\end{array}$ & \\
\hline
\end{tabular}

Elaboración propia 


\subsection{Capacidad instalada}

Se define como la cantidad de producto que se puede obtener en un determinado periodo de tiempo gracias a una unidad productiva, la cual puede ser una máquina o un operario que realice la tarea.

Para el cálculo de la capacidad, se tomará en cuenta dos factores primordiales. El primero es el factor de utilización, en el cual se considera las horas en las que la máquina deja de operar a causa del refrigerio o por algún precalentamiento que se les hace. Por lo tanto, el factor se va a considerar en los cálculos va a ser de 0,889 pues en la operación existe un solo turno de trabajo.

Para el factor de la eficiencia se tomará en cuenta la mano de obra y como son pocas las operaciones que se realizan manualmente, se utilizará un factor de 0,90.

\subsubsection{Cálculo detallado del número de máquinas y operarios requeridos}

Tabla 5.5

Cálculo de número de Operarios

\begin{tabular}{l|ccccc}
\hline \multicolumn{1}{c|}{ Operación } & $\begin{array}{c}\text { Cantidad } \\
\text { Entrante }\end{array}$ & Unid. & $\begin{array}{c}\text { Tiempo de la } \\
\text { Operación } \\
\text { (min/ kg) }\end{array}$ & $\begin{array}{c}\text { Horas por } \\
\text { año }\end{array}$ & $\begin{array}{c}\text { Nro. } \\
\text { Operarios }\end{array}$ \\
\hline Seleccionar & 6421 & $\mathrm{Kg}$ & 0,125 & 2246,4 & 3,00 \\
Cortar & 5981 & $\mathrm{Kg}$ & 0,150 & 2246,4 & 3,00 \\
Control de calidad & 1628462 & $\mathrm{Bot}$ & 0,109 & 2246,4 & 2,00 \\
\hline
\end{tabular}

Elaboración propia 
Tabla 5.6

Cálculo de número de máquinas

\begin{tabular}{l|ccccc}
\hline \multicolumn{1}{c|}{ Operación } & $\begin{array}{c}\text { Cantidad } \\
\text { Entrante }\end{array}$ & Unid. & $\begin{array}{c}\text { Tiempo de la } \\
\text { Operación } \\
\text { (min/kg) }\end{array}$ & $\begin{array}{c}\text { Horas por } \\
\text { año }\end{array}$ & $\begin{array}{c}\text { Nro. } \\
\text { Maquinas }\end{array}$ \\
\hline Pesar & 6228 & $\mathrm{Kg}$ & 0,125 & 1965,60 & 3,00 \\
Lavar & 6103 & $\mathrm{Kg}$ & 0,044 & 1965,60 & 1,00 \\
Mezclar & 779320 & $\mathrm{Kg}$ & 0,048 & 1965,60 & 1,00 \\
Filtrar & 779320 & $\mathrm{Kg}$ & 0,092 & 1965,60 & 2,00 \\
Mezclar & 773519 & $\mathrm{~L}$ & 0,044 & 1965,60 & 1,00 \\
Pasteurizar & 773519 & $\mathrm{~L}$ & 0,041 & 1965,60 & 1,00 \\
Envasar y tapar & 1628462 & Bot & 0,044 & 1965,60 & 1,00 \\
Etiquetar y rotular & 1628462 & Bot & 0,052 & 1965,60 & 1,00 \\
Colocar precinto & 1628462 & Bot & 0,044 & 1965,60 & 1,00 \\
Empaquetar & 1595893 & Bot & 0,044 & 1965,60 & 1,00 \\
\hline
\end{tabular}

Elaboración propia

Tabla 5.7

Cálculo de número de máquinas (Proceso de agua)

\begin{tabular}{l|ccccc}
\hline \multicolumn{1}{c|}{ Operación } & $\begin{array}{c}\text { Cantidad } \\
\text { Entrante }\end{array}$ & Unid. & $\begin{array}{c}\text { Tiempo de la } \\
\text { Operación } \\
\text { (min/kg) }\end{array}$ & $\begin{array}{c}\text { Horas por } \\
\text { año }\end{array}$ & $\begin{array}{c}\text { Nro. } \\
\text { Maquinas }\end{array}$ \\
\hline Osmosis Inversa & 797278 & L & 0,036 & 2156,54 & 1,00 \\
Calentar (Caldera) & 781332 & L & 0,046 & 2156,54 & 1,00 \\
\hline
\end{tabular}

Elaboración propia

\subsubsection{Cálculo de la capacidad instalada}

Para poder determinar que no exista algún limitante en las operaciones secundarias, se verificó como se muestra en la siguiente tabla que las operaciones que se realizan al agua no son limitantes.

Tabla 5.8

Capacidad Instalada (Agua)

\begin{tabular}{|c|c|c|c|c|c|c|c|c|c|c|c|c|}
\hline Operación & $\begin{array}{l}\text { Cantidad } \\
\text { Entrante }\end{array}$ & Unid. & Prod./hora & $\begin{array}{c}\mathbf{N}^{\circ} \\
\text { máquinas / } \\
\text { persona }\end{array}$ & $\begin{array}{l}\text { Dias/ } \\
\text { año }\end{array}$ & $\begin{array}{c}\text { Horas / } \\
\text { Turno }\end{array}$ & $\begin{array}{c}\text { Turno/ } \\
\text { dia }\end{array}$ & $\mathbf{U}$ & $\mathbf{E}$ & $\begin{array}{l}\text { Capacidad de } \\
\text { procesamiento } \\
\text { (unid) }\end{array}$ & $\begin{array}{c}\text { Factor de } \\
\text { conversión } \\
(\mathrm{QF} / \mathrm{QE})\end{array}$ & $\begin{array}{c}\text { Capacidad } \\
\text { de } \\
\text { producción } \\
\text { por PT } \\
\end{array}$ \\
\hline \multirow[t]{2}{*}{ Calentar (Caldera) } & 781332 & $\mathrm{~L}$ & 1300 & 1 & 312 & 8 & 1 & 0,89 & 0,9 & 2595580,416 & 0,99 & 2569625,67 \\
\hline & 773519 & $\mathrm{~L}$ & & & & & & & & & & \\
\hline
\end{tabular}

Elaboración propia 
La capacidad instalada según la siguiente tabla está determinada por la estación cuello de botella del proceso de producción, siendo en este caso la operación de etiquetar con 2250169 botellas / año.

Tabla 5.9

Capacidad Instalada

\begin{tabular}{|c|c|c|c|c|c|c|c|c|c|c|c|c|}
\hline Operación & $\begin{array}{l}\text { Cantidad } \\
\text { Entrante }\end{array}$ & Unid. & $\begin{array}{c}\text { Prod./ } \\
\text { hora }\end{array}$ & $\begin{array}{c}\mathbf{N}^{\circ} \\
\text { máquinas/ } \\
\text { persona }\end{array}$ & $\begin{array}{l}\text { Días / } \\
\text { año }\end{array}$ & $\begin{array}{c}\text { Horas / } \\
\text { Turno }\end{array}$ & $\begin{array}{c}\text { Turno / } \\
\text { día }\end{array}$ & $\mathbf{U}$ & $\mathbf{E}$ & $\begin{array}{c}\text { Capacidad de } \\
\text { procesamiento } \\
\text { (unid) }\end{array}$ & $\begin{array}{c}\text { Factor de } \\
\text { conversión } \\
(\mathrm{QF} / \mathrm{QE})\end{array}$ & $\begin{array}{c}\text { Capacidad } \\
\text { de } \\
\text { producción } \\
\text { por PT } \\
\end{array}$ \\
\hline Seleccionar & 6421 & $\mathrm{Kg}$ & 480 & 3,00 & 312 & 8 & 1 & 1,00 & 0,90 & 3234816,00 & 0,88 & 2842893 \\
\hline Pesar & 6228 & $\mathrm{Kg}$ & 480 & 3,00 & 312 & 8 & 1 & 0,89 & 0,90 & 2875104,46 & 0,91 & 2605065 \\
\hline Lavar & 6103 & $\mathrm{Kg}$ & 1350 & 1,00 & 312 & 8 & 1 & 0,89 & 0,90 & 2695410,43 & 0,92 & 2492270 \\
\hline Cortar & 5981 & $\mathrm{Kg}$ & 400 & 3,00 & 312 & 8 & 1 & 1,00 & 0,90 & 2695680,00 & 0,94 & 2543361 \\
\hline Mezclar & 779320 & $\mathrm{Lt}$ & 1250 & 1,00 & 312 & 8 & 1 & 0,89 & 0,90 & 2495750,40 & 0,97 & 2427631 \\
\hline Filtrar & 779320 & $\mathrm{Lt}$ & 650 & 2,00 & 312 & 8 & 1 & 0,89 & 0,90 & 2595580,42 & 0,97 & 2524735 \\
\hline Mezclar & 773519 & $\mathrm{Lt}$ & 1350 & 1,00 & 312 & 8 & 1 & 0,89 & 0,90 & 2695410,43 & 0,98 & 2641504 \\
\hline Pasteurizar & 773519 & $\mathrm{Lt}$ & 1450 & 1,00 & 312 & 8 & 1 & 0,89 & 0,90 & 2895070,46 & 0,98 & 2837171 \\
\hline Envasar y tapar & 1628462 & Bot & 1350 & 1,00 & 312 & 8 & 1 & 0,89 & 0,90 & 2695410,43 & 0,98 & 2641502 \\
\hline Etiquetar y rotular & 1628462 & Bot & 1150 & 1,00 & 312 & 8 & 1 & 0,89 & 0,90 & 2296090,37 & 0,98 & 2250169 \\
\hline Colocar precinto & 1628462 & Bot & 1350 & 1,00 & 312 & 8 & 1 & 0,89 & 0,90 & 2695410,43 & 0,98 & 2641502 \\
\hline Control de calidad & 1628462 & Bot & 550 & 2,00 & 312 & 8 & 1 & 1,00 & 0,90 & 2471040,00 & 0,98 & 2421619 \\
\hline Empaquetar & 1595893 & Bot & 1350 & 1,00 & 312 & 8 & 1 & 0,89 & 0,90 & 2695410,43 & 1,00 & 2695410 \\
\hline & 758049 & Litros & & & & & & & & & & \\
\hline
\end{tabular}

Elaboración propia 


\subsection{Resguardo de la calidad y/o inocuidad del producto}

\subsubsection{Calidad de la materia prima, de los insumos, del proceso y del producto}

La calidad del producto final se verifica de acuerdo a diversos factores dentro del proceso de producción, empezando por el aseguramiento de la calidad en la materia prima, insumos y del proceso en sí, para ello se debe cumplir en todo el proceso los estándares mínimos de calidad, adicional a ello la bebida pasará por un proceso de pasteurización para garantizar la calidad del producto final.

\section{a) Calidad en la materia prima e insumos}

Por ser un producto de consumo se exige calidad en el tema de higiene y salud, por lo que todas las personas involucradas en el proceso deben tener un adecuado control de salubridad, además se tendrá un ambiente de lavado y desinfección antes de ingresar a la línea de producción.

En primer lugar, se deben establecer las propiedades y características que las materias primas (manzanilla, matico, muña y romero), y los insumos deben de tener para no ser considerados defectuosos.

Luego, durante el proceso de selección de las materias primas se realizará un control de calidad riguroso para separar las hierbas que no cumplan con las especificaciones antes definidas.

Por último, se exigirá a los proveedores un alto nivel de calidad, es decir, tener como máximo un $1 \%$ de defectuosos.

\section{b) Calidad en el proceso}

Para conseguir un adecuado proceso primero se debe tener un adecuado conocimiento del mismo, además de las técnicas, parámetros, tiempos y resultados adecuados en cada una de las operaciones a realizarse en el proceso, así mismo se deberá incluir las posibles acciones a tomar si se presentara algún incidente y de esta forma poder mantener el proceso bajo control. 
Se realizará un análisis completo de los productos lo cual implica que de cada lote de producción se tomarán muestras al azar de los productos en procesos y se registrarán sus características.

Con los resultados obtenidos se podrán identificar los distintos defectos existentes y la magnitud de los mismos para luego establecer medidas correctivas con el objetivo de uniformizar cada vez más los resultados de los procesos.

\section{c) Calidad del producto terminado}

Para garantizar la calidad del producto la bebida pasará por un proceso de pasteurización para poder eliminar algún microorganismo no deseado. Por último, se realizará un control de calidad del producto final mediante la selección de algunas muestras para verificar que cumplan con los estándares establecidos en cuestiones de apariencia, peso y color.

\subsection{Estudio de Impacto Ambiental}

- El estudio de impacto ambiental es un informe técnico que documenta el proceso de evaluación de impacto ambiental.

- Contiene el análisis, pronósticos y medidas que se toman para que las acciones del proyecto sean compatibles con la protección del ambiente.

- Pronostica los cambios en los factores ambientales y sociales que resulten de un proyecto propuesto.

- Asegura que los problemas potenciales se hayan señalado y previsto en la fase de planificación y diseño del proyecto.

- Analiza de manera interdisciplinaria.

- Trata de equilibrar los factores económicos, técnicos y ambientales con los costos correspondientes.

- Describe las consecuencias ambientales de las principales actuaciones que afecten significativamente a la calidad del ambiente. 


\section{a) Etapa de Construcción}

La planta para la producción de bebidas a base de hierbas medicinales se construirá en el distrito de Lurín siguiendo los cuidados adecuados para esta etapa pues se podrían presentar altos impactos negativos producidos por el levantamiento de polvo y tierra ocasionados principalmente por el trabajo de las excavadoras, aplanadoras y los camiones que se encargan del traslado de los materiales de construcción, lo cual perjudicaría a las personas más cercanas con enfermedades respiratorias es por ello que la empresa tomará medidas preventivas como cercar el lugar, usar EPP y la utilización de equipos modernos que no generen ruidos mayores a los límites permisibles.

\section{b) Etapa de Operación}

Para poder entender de una mejor manera los impactos ambientales tanto negativos como positivos en la etapa de Operación usaremos la matriz de Leopold la cual concluye que la operación que mayor impacto negativo trae en el ambiente es la etapa de ruido y emisiones pues se presenta contaminación del aire por el ruido y contaminación por generación de emisiones.

Las contaminaciones que se producen son mínimas debido a que nuestro producto es a base de insumos naturales y por ende la materia prima no causará impactos ambientales negativos.

Por otro lado, es importante indicar que para todos estos posibles impactos se tomarán medidas preventivas, como el mantenimiento de las máquinas para poder reducir el nivel de ruido generado y la cantidad de desechos producidos. 
Tabla 5.10

Impacto ambiental en los procesos

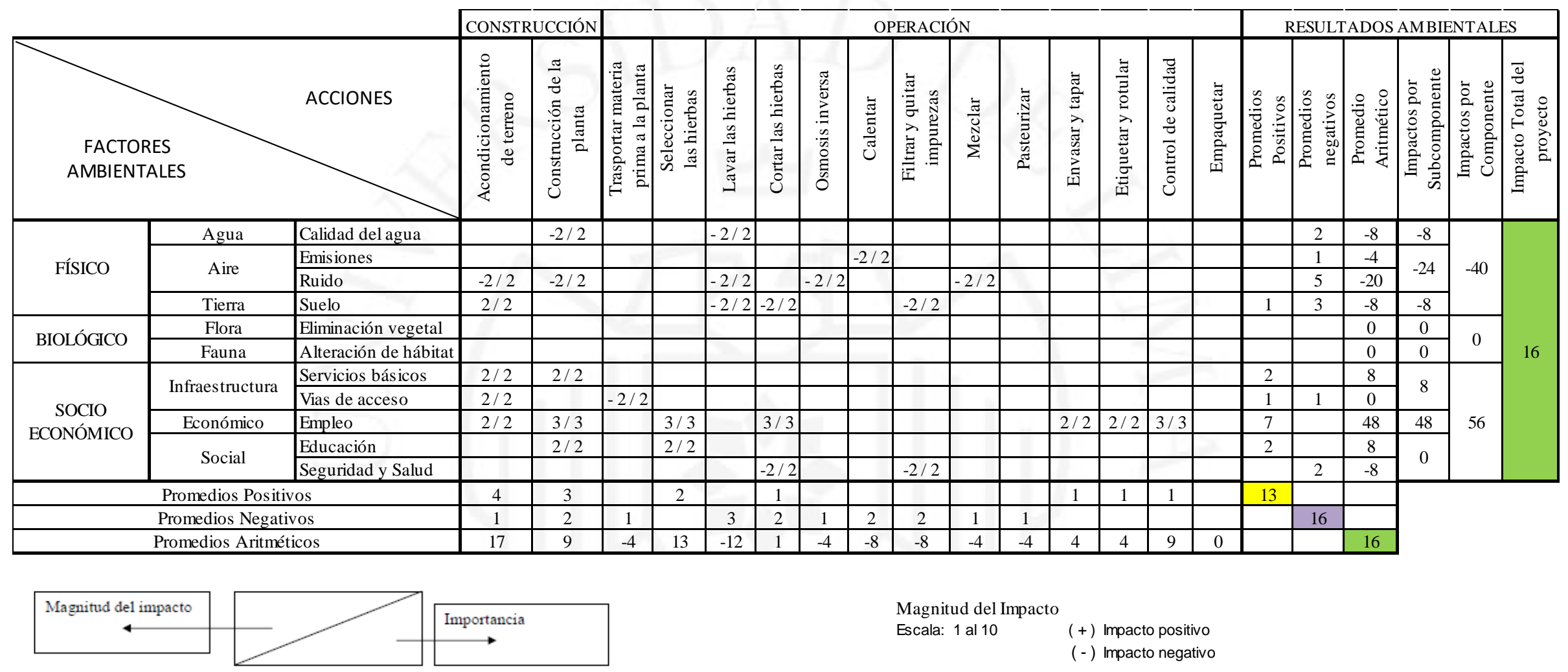

Elaboración propia 


\subsection{Seguridad y Salud Ocupacional}

Se deberá presentar una atención especial a la seguridad y salud ocupacional pues los posibles perjudicados serían los trabajadores por ello se proveerá seguridad, protección y atención a los empleados en el desempeño de su labor lo cual implicará tener un manual de datos básicos para prevenir accidentes, evaluaciones medicas de los empleados y un programa de entrenamiento contra accidentes.

Además, se brindará equipos de protección personal adecuados para las distintas labores (botas, casco, guantes, orejeras), así mismo se contará con un tópico en caso sea necesario una atención.

Según la ley 29783 los diversos factores que afectan directamente las condiciones de trabajo son temperatura, humedad, ruido e iluminación.

\section{a) Ruido}

La norma indica que un trabajador debería estar expuesto como máximo a un sonido de 85 decibeles durante 8 horas.

\section{b) Iluminación}

La iluminación es un factor importante pues influirá directamente en el desempeño del trabajador, pues su adecuada implementación ayudará a evitar fatigas visuales, disminuir el número de accidentes y realizar mejores controles de calidad.

El nivel de iluminación varía por áreas, es decir, para almacén sería 200 lux, producción 300 lux y para calidad 500 lux.

\section{c) Extintores}

Para la planta de bebidas a base de hierbas medicinales se usará distintos tipos de extintores según el tipo de fuego que podría generarse. En primer lugar, el fuego de clase "A" que se debe a un incendio ocasionado por sólidos como papel, plásticos y madera el cual se puede presentar con mayor frecuencia en el área administrativa. Así mismo, para la zona de producción se podría iniciar un incendio de clase $\mathrm{C}$ generado por riesgos eléctricos.

Se sugiere instalar en la empresa un tipo de extintor eficiente para los distintos tipos de incendio por lo cual se decidió que el extintor Polvo $\mathrm{ABC}$ es el más eficiente. 


\section{d) Señalización}

La señalización tanto de las zonas seguras como las rutas de escape, salida entre otras es un buen sistema de prevención ante la ocurrencia de un accidente, aunque deben ser complementadas con simulacros.

La norma técnica peruana 399.010-1 2015 hace referencia a las distintas formas geométricas, colores, tamaños y significado de las señales de seguridad.

Figura 5.4

Señalización de seguridad y salud en el trabajo

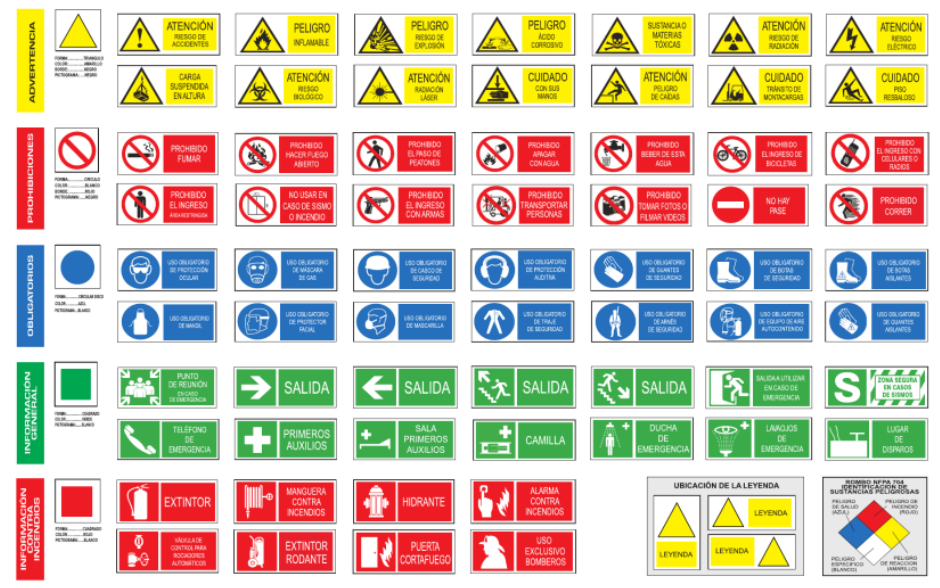

Elaboración propia

Luego de ver los diferentes aspectos donde podría ocurrir algún daño ocupacional, se mostrará la tabla de riesgos o peligros con el análisis de cada proceso. Luego se escogerá un proceso para poder hallar sus puntos críticos de control. 
Tabla 5.11

Análisis de riesgos y peligros

\begin{tabular}{|c|c|c|c|c|c|}
\hline $\begin{array}{l}\text { ETAPA DE } \\
\text { PROCESO }\end{array}$ & PELIGROS & $\begin{array}{c}\text { iEL } \\
\text { PELIGRO } \\
\text { ES } \\
\text { SIGNIFICAT } \\
\text { IVO? }\end{array}$ & JUSTIFICACIÓN & $\begin{array}{l}\text { ¿QUÉ MEDIDAS } \\
\text { PREVENTIVAS } \\
\text { PUEDER SER } \\
\text { APLICADAS? }\end{array}$ & $\begin{array}{l}\text { ¿ES ESTA } \\
\text { ETAPA } \\
\text { UN PCC? } \\
\text { (SÍ/NO) }\end{array}$ \\
\hline $\begin{array}{l}\text { SELECCIÓN DE } \\
\text { MATERIA PRIMA }\end{array}$ & $\begin{array}{l}\text { CRECIMIENTO } \\
\text { BACTERIANO } \\
\text { DESCOMPOSICIÓN } \\
\underline{\text { QUÍMICO }} \\
\text { CONTAMINACIÓN } \\
\text { QUÍMICA }\end{array}$ & NO & $\begin{array}{l}\text { HIERBAS QUE } \\
\text { PUEDEN } \\
\text { CONTAMINARSE } \\
\text { A TRAVEZ DE } \\
\text { GÉRMENES DEL } \\
\text { SUELO } \\
\text { PRODUCTOS } \\
\text { QUIMICOS }\end{array}$ & $\begin{array}{l}\text { LAVAR Y } \\
\text { DESINFECTAR } \\
\text { ANTES DE SER } \\
\text { USADAS } \\
\text { USAR HIERBAS DE } \\
\text { CULTIVO SEGURO } \\
\text { ANÁLISIS MICRO } \\
\text { BIOLÓGICOS }\end{array}$ & NO \\
\hline PESADO & $\begin{array}{l}\underline{\text { FISICO }} \\
\text { CONTAMINACIÓN } \\
\text { POR RESIDUOS EN } \\
\text { BALANZA } \\
\text { BOOŚGICO. }\end{array}$ & NO & $\begin{array}{l}\text { CONTAMINACIÓN } \\
\text { CRUZADA CON } \\
\text { OTROS INSUMOS } \\
\text { EN LA BALANZA }\end{array}$ & $\begin{array}{l}\text { LIMPIEZA } \\
\text { CONTINUA DE } \\
\text { BALANZA (POES) }\end{array}$ & NO \\
\hline LAVADO & $\begin{array}{l}\text { CONTAMINACIÓN } \\
\text { MICROBIOLÓGICA }\end{array}$ & NO & $\begin{array}{l}\text { AGUA DE } \\
\text { CALIDAD } \\
\text { SANITARIA } \\
\text { ADECUADA }\end{array}$ & $\begin{array}{l}\text { CUENTA CON SSOP } \\
\text { (POES) PROGRAMA } \\
\text { ESTANDAR } \\
\text { OPERACIONAL DE } \\
\text { SANITIZACIÓN Y } \\
\text { (BPM) BUENAS } \\
\text { PRÁCTICAS DE } \\
\text { MANUFACTURA }\end{array}$ & NO \\
\hline CORTAR & $\frac{\text { BIOLÓGICO }}{\text { DESCOMPOSICIÓN }}$ & NO & $\begin{array}{l}\text { EL PROCESO ES } \\
\text { RÁPIDO }\end{array}$ & BPM-POES & NO \\
\hline CALENTAR & $\underline{\text { BIOLÓGICO }}$ & SI & $\begin{array}{l}\text { EL PROCESO DE } \\
\text { CALENTAR NO } \\
\text { GARANTIZA QUE } \\
\text { NO EXISTA MICRO } \\
\text { ORGANISMOS. }\end{array}$ & $\begin{array}{l}\text { LA BEBIDA PASARÁ } \\
\text { POR UN PROCESO } \\
\text { DE PASTEURIZADO } \\
\text { PARA GARANTIZAR } \\
\text { QUE NO EXISTA } \\
\text { MICRO } \\
\text { ORGANISMOS }\end{array}$ & SI \\
\hline ENVASADO & $\begin{array}{l}\text { SUPERVIVENCIA DE } \\
\text { MICROORGANISMOS } \\
\text { PATÓGENOS } \\
\text { BIOLÓGICO } \\
\text { RECONTAMINACIÓN } \\
\text { DE ORGANISMOS } \\
\text { PATÓGENOS }\end{array}$ & SI & $\begin{array}{l}\text { NO EXISTE UNA } \\
\text { APLICACIÓN } \\
\text { ADECUADA DE } \\
\text { SSOP }\end{array}$ & $\begin{array}{l}\text { LAVADO Y } \\
\text { DESINFECCIÓN DE } \\
\text { ENVASES; } \\
\text { CERRADO } \\
\text { HERMÉTICO EN } \\
\text { CALIENTE }\end{array}$ & NO \\
\hline AMACENAMIENTO & $\begin{array}{l}\text { BIOLÓGICO } \\
\text { AUMENTO DE } \\
\text { MICROORGANISMOS } \\
\text { PATÓGENOS }\end{array}$ & NO & $\begin{array}{l}\text { PODRÍA HABER } \\
\text { UN DESCUIDO EN } \\
\text { LIMPIEZA E } \\
\text { HIGIENE }\end{array}$ & $\begin{array}{l}\text { EXISTEN BPA Y } \\
\text { POES; USO DE } \\
\text { TEMPERATURA } \\
\text { ADECUADA }\end{array}$ & NO \\
\hline
\end{tabular}

Elaboración propia 
Tabla 5.12

Puntos críticos en el calentamiento

\begin{tabular}{|c|c|c|c|c|c|c|c|c|c|}
\hline \multirow{2}{*}{$\begin{array}{c}\text { PUNTOS } \\
\text { CRÍTICOS } \\
\text { DE } \\
\text { CONTROL }\end{array}$} & \multirow{2}{*}{$\begin{array}{c}\text { PELIGROS } \\
\text { SIGNIFICATIVOS }\end{array}$} & \multirow{2}{*}{$\begin{array}{c}\text { LÍMITES } \\
\text { CRÍTICOS PARA } \\
\text { CADA MEDIDA } \\
\text { PREVENTIVA }\end{array}$} & \multicolumn{3}{|c|}{ MONITOREO } & \multirow[b]{2}{*}{ Quién } & \multirow{2}{*}{$\begin{array}{c}\text { ACCIONES } \\
\text { CORRECTIVAS }\end{array}$} & \multirow{2}{*}{ REGISTROS } & \multirow{2}{*}{ VERIFICACIÓN } \\
\hline & & & Qué & Cómo & Frecuencia & & & & \\
\hline \multirow{3}{*}{ Calentamiento } & \multirow{3}{*}{$\begin{array}{l}\text {-Supervivencia de } \\
\text { microorganismos } \\
\text { patógenos. }\end{array}$} & $\begin{array}{c}\text {-Temperaturas entre } \\
60 \text { a } 99^{\circ} \mathrm{C}\end{array}$ & $\begin{array}{c}\text { Parámetros } \\
\text { físicos y } \\
\text { químicos }\end{array}$ & Termómetro & \multirow{3}{*}{$\begin{array}{l}\text { Al inicio y al } \\
\text { final de } \\
\text { calentar }\end{array}$} & \multirow{3}{*}{$\begin{array}{l}\text { Asegura- } \\
\text { miento de la } \\
\text { calidad }\end{array}$} & \multirow{3}{*}{$\begin{array}{c}\text { Añadir más agua para } \\
\text { compensar lo que se } \\
\text { evaporó } \\
\text { Añadir más agua o } \\
\text { esencia para bajar o } \\
\text { subir la concentración }\end{array}$} & \multirow[t]{3}{*}{$\begin{array}{l}\text { Cocción y } \\
\text { adición }\end{array}$} & \multirow{3}{*}{$\begin{array}{c}\text {-Verificar } \\
\text { diariamente que los } \\
\text { instrumentos se } \\
\text { encuentren } \\
\text { calibrados. } \\
\text {-Mantenimiento de } \\
\text { equipos cada } 30 \\
\text { días }\end{array}$} \\
\hline & & - pH de 6,5 a 8,5 & & $\begin{array}{c}\text { Medidor de } \\
\text { Ph }\end{array}$ & & & & & \\
\hline & & Norma técnica & & $\begin{array}{l}\text { Método de } \\
\text { laboratorio }\end{array}$ & & & & & \\
\hline
\end{tabular}

Elaboración propia 


\subsection{Sistema de mantenimiento}

El mantenimiento es muy importante para la producción de un bien debido a que asegura la disponibilidad, la cual es muy buena pues permite la operatividad, un buen mantenimiento y confiabilidad de todas las máquinas requeridas para la cadena productiva.

En primer lugar, se deberá contar con un manual de mantenimiento de cada máquina en el cual se especificará las distintas características y necesidades de las mismas; cabe indicar que todo mantenimiento realizado deberá ser documentado para poder analizar el desempeño de la máquina.

Para la planta de bebidas a base de hierbas medicinales se prevé implementar dos tipos de mantenimiento:

\section{a) Mantenimiento reactivo:}

Es un tipo de mantenimiento no planificado el cual se realiza cuando alguna parte de la maquinaria presenta una falla, la cual quita operatividad a la máquina, es por ello que este tipo de mantenimiento se realiza en equipos que sean rápidos de reparar, los repuestos sean fáciles de conseguir y de bajo costo en este tipo de mantenimiento tenemos a la mesa de trabajo, carretilla hidráulica, colador industrial y la balanza.

\section{b) Mantenimiento preventivo:}

Es un tipo de mantenimiento planificado, es decir, la parada de la máquina se realiza en un tiempo previsto y en un periodo constante, este tipo de mantenimiento se caracteriza porque cambia las piezas antes de que la máquina presente una falla y por ende minimiza el número de las mismas, la parada de estas máquinas podrían representar altos costos para la empresa es por ello que a la máquina de osmosis, máquina para mezclar, máquina para pasteurizar, máquina envasadora, máquina etiquetadora, máquina precintadora u máquina empaquetadora se les ejecutará este tipo de mantenimiento.

El mantenimiento servirá para alargar la vida útil, disponibilidad y confiabilidad de la maquinaria evitando así incurrir en paralizaciones y gastos que se podría generar.

Se considera que es importante contar con algunos indicadores que ayuden a medir la labor del mantenimiento en la planta, para ello se empleará: 
- MTBF: Indica cada cuánto tiempo va a fallar mi activo.

- MTTR: Tiempo promedio que dura una reparación.

- Disponibilidad (A): Indica el tiempo que una máquina funciona sin causar problemas.

\subsection{Diseño de la Cadena de Suministro}

La cadena de suministro de la empresa dedicada a la elaboración de bebidas a base de hierbas medicinales inicia con la recepción de las materias primas, es decir, manzanilla, matico, muña y romero; luego de su recepción y descarga se ubican las distintas hierbas en sus lugares correspondientes dentro del almacén para que al momento de ser requeridas estas se dirijan a la planta de producción en donde se producirá el producto embotellado y empacado, el cual se dirigirá al almacén de producto terminado para que por último sea distribuido mediante un canal de distribución Indirecto. 
Figura 5.5

Cadena de suministro

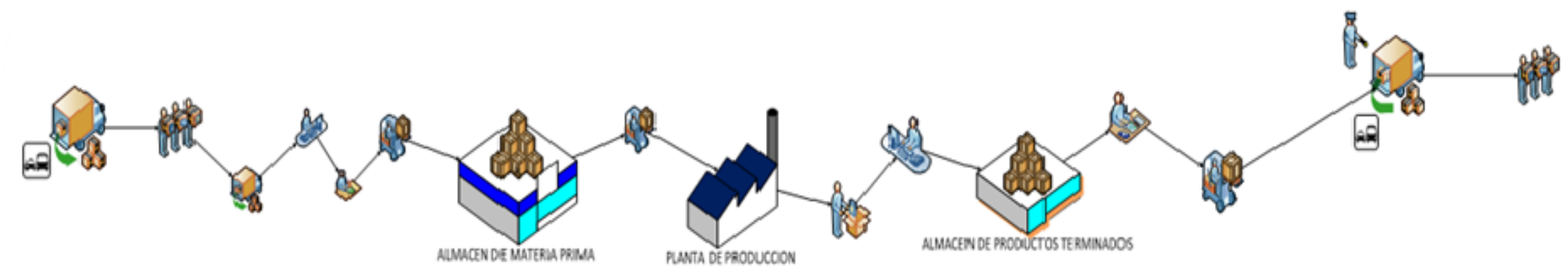

Elaboración propia 


\subsection{Programa de producción}

Para poder calcular el programa producción, primero se tiene que calcular la cantidad de botellas que se venderán durante toda la vida útil del proyecto.

Como se sabe que el tamaño de planta está dado en función a la demanda, por lo cual no existirán problemas de generación de horas extras.

En la siguiente tabla se calculará el stock de seguridad que habrá por cada año con la finalidad de cubrir cualquier tipo de improviso que ocurra. Por ello es que se tomó en cuenta para el cálculo del stock el 5\% de la demanda de cada año como desviación estándar y además se considerará un nivel de seguridad del 95\%.

Tabla 5.13

Programa de Producción

\begin{tabular}{c|cccccc}
\hline Año & $\begin{array}{c}\text { Dem. Proyecto } \\
\text { (Botellas) }\end{array}$ & $\mathbf{Z ~ ( 9 5 \% )}$ & $\boldsymbol{\sigma}=\mathbf{5 \%}$ & $\begin{array}{c}\text { Stock de } \\
\text { seguridad } \\
\text { (botellas) }\end{array}$ & $\begin{array}{c}\text { Programa de } \\
\text { producción } \\
\text { (botellas/año) }\end{array}$ & $\begin{array}{c}\text { Programa } \\
\text { de } \\
\text { producción } \\
\text { (Litros/año) }\end{array}$ \\
\hline 2019 & 1218619 & & 60930,93 & 100536,03 & 1319155 & 626598 \\
2020 & 1285638 & & 64281,91 & 106065,15 & 1391703 & 661059 \\
2021 & 1352807 & \multirow{2}{*}{1,65} & 67640,35 & 111606,57 & 1464414 & 695596 \\
2022 & 1419952 & & 70997,61 & 117146,06 & 1537098 & 730122 \\
2023 & 1486905 & & 74345,26 & 122669,67 & 1609575 & 764548 \\
2024 & 1595893 & & 79794,64 & 131661,16 & 1727554 & 820588 \\
\hline
\end{tabular}

Elaboración propia

\subsection{Requerimientos de insumos, servicios y personal indirecto}

\subsubsection{Materia prima, insumos y otros materiales}

Para el cálculo de la materia prima y los demás materiales que se utilizarán se tomará como base el plan de producción hallado en el punto anterior. Cabe mencionarlo, la utilización de cada tipo de hierbas por litro de bebida es de 3 gramos de manzanilla y 1,5 gramos de matico, muña y romero.

Según la prueba de laboratorio realizada, se considerará 1 gramos de Stevia por litro de bebida y en caso de los preservantes, 1 gramo por cada litro de bebida. 
Tabla 5.14

Cantidad de Insumos

\begin{tabular}{lcccccccc}
\hline Año & $\begin{array}{c}\text { Programa de } \\
\text { producción } \\
\text { (und/año) }\end{array}$ & $\begin{array}{c}\text { Muña } \\
(\mathbf{k g})\end{array}$ & $\begin{array}{c}\text { Matico } \\
(\mathbf{k g})\end{array}$ & $\begin{array}{c}\text { Romero } \\
(\mathbf{k g})\end{array}$ & $\begin{array}{c}\text { Manzanilla } \\
(\mathbf{k g})\end{array}$ & Stevia (kg) & $\begin{array}{c}\text { Botellas } \\
\text { (und) }\end{array}$ & $\begin{array}{c}\text { Etiquetas } \\
\text { (und) }\end{array}$ \\
\hline 2019 & 1319155 & 1054 & 1054 & 1054 & 2107 & 702 & 1319155 & 1319155 \\
2020 & 1391703 & 1112 & 1112 & 1112 & 2223 & 741 & 1391703 & 1391703 \\
2021 & 1464414 & 1169 & 1169 & 1169 & 2339 & 780 & 1464414 & 1464414 \\
2022 & 1537098 & 1227 & 1227 & 1227 & 2455 & 818 & 1537098 & 1537098 \\
2023 & 1609575 & 1285 & 1285 & 1285 & 2571 & 857 & 1609575 & 1609575 \\
2024 & 1727554 & 1380 & 1380 & 1380 & 2759 & 920 & 1727554 & 1727554 \\
\hline
\end{tabular}

Elaboración propia

\subsubsection{Servicios: energía eléctrica, agua, vapor, combustible, etc.}

A continuación, se detallarán los servicios de suma importancia para el trabajo diario en la empresa y para la producción.

\section{- Energía eléctrica}

La energía eléctrica es importante para el funcionamiento de las diversas máquinas que se utilizarán en el proceso de producción. En la siguiente Tabla 5.15 se detalla la cantidad de energía que consumiría cada máquina por año, dato que además servirá en el siguiente capítulo para hallar el costo de la energía.

Tabla 5.15

Cantidad de energía por máquina

\begin{tabular}{l|cc}
\hline \multicolumn{1}{c|}{ Operación } & Kw / Hora & Kw / año \\
\hline Pesar & 2,00 & 4992,00 \\
Lavar & 2,20 & 5491,20 \\
Mezclar 1 & 2,40 & 5990,40 \\
Mezclar 2 & 2,30 & 5740,80 \\
Pasteurizar & 4,20 & 10483,20 \\
Envasar y tapar & 3,20 & 7987,20 \\
Etiquetar y rotulado & 2,40 & 5990,40 \\
Colocar precinta & 2,00 & 4992,00 \\
Empaquetar & 2,45 & 6115,20 \\
Osmosis inversa & 3,32 & 8286,72 \\
Caldera & 3,15 & 7862,40 \\
\hline \multicolumn{2}{l}{} \\
\cline { 2 - 3 } & 29,62 & 73931,52 \\
\hline
\end{tabular}

Elaboración propia 
- Agua

La cantidad de agua que se necesita para cubrir la demanda de la producción se muestra en la siguiente tabla.

Tabla 5.16

Cantidad de agua por año

\begin{tabular}{ccccccc}
\hline Ítem & $\mathbf{2 0 1 9}$ & $\mathbf{2 0 2 0}$ & $\mathbf{2 0 2 1}$ & $\mathbf{2 0 2 2}$ & $\mathbf{2 0 2 3}$ & $\mathbf{2 0 2 4}$ \\
\hline Agua (Litros) & 702300 & 740924 & 779634 & 818330 & 856916 & 919726 \\
\hline Elaboración propia
\end{tabular}

La cantidad de agua requerida para el uso administrativo se muestra en la siguiente tabla, se tomó en cuenta que para un trabajador que labora en oficina 15 litros diarios y por operario de planta 80 litros diarios, ya que estos necesitan utilizar las duchas para asearse luego de la jornada laboral (PUCP,2014)

Tabla 5.17

Cantidad de agua de uso administrativo por año

\begin{tabular}{c|cccc}
\hline & Cantidad & Litros / día & Litros / año & Soles /año \\
\hline Oficina & 12 & 15 & 56160 & 318 \\
Operarios & 14 & 80 & 349440 & 1978 \\
Total & 26 & 95 & 405600 & 2296,10 \\
\hline
\end{tabular}

Elaboración propia

\section{- Internet, telefonía y cable}

Respecto al servicio de telefonía, cable e internet se necesitará de un buen servicio para la correcta comunicación de los trabajadores, lo cual tendrá un costo anual según la siguiente tabla.

Tabla 5.18

Telefonía e Internet

\begin{tabular}{ccccccc}
\hline & $\mathbf{2 0 1 9}$ & $\mathbf{2 0 2 0}$ & $\mathbf{2 0 2 1}$ & $\mathbf{2 0 2 2}$ & $\mathbf{2 0 2 3}$ & $\mathbf{2 0 2 4}$ \\
\hline $\begin{array}{c}\text { Telefonía e } \\
\text { internet }\end{array}$ & S/.3600 & S/.3600 & S/.3600 & S/.3600 & S/. 3600 & S/.3600 \\
\hline
\end{tabular}

Elaboración propia

\subsubsection{Determinación del número de trabajadores indirectos}

El requerimiento de mano de obra directa para el proyecto se encontrará en función al número de máquinas que se utilizará en cada proceso. 
Tal como se mostró en el punto 5.4, en el proceso de producción cuenta con operaciones manuales y semiautomática.

Sin embargo, para las operaciones manuales no necesariamente será igual al cálculo de la capacidad, ya que tanto las operaciones como selección y cortado son operaciones simples y no requieren de mucho personal. También se busca reducir los costos y evitar la mano de obra ociosa.

Tabla 5.19

Número de operarios en las operaciones manuales

\begin{tabular}{lc}
\hline \multicolumn{1}{c}{ Operación } & $\begin{array}{c}\text { Número de } \\
\text { Operarios }\end{array}$ \\
\hline Seleccionar & 3 \\
Cortar & 3 \\
Control de calidad & 2 \\
\hline
\end{tabular}

Elaboración Propia

Para el caso de las operaciones semiautomáticas, habrá un operario controlando cada máquina que se utilizará. Por lo que la cantidad de operarios que se tendrán en estas operaciones será la siguiente:

Tabla 5.20

Número de operarios en las operaciones semiautomáticas

\begin{tabular}{l|cc}
\hline \multicolumn{1}{c|}{ Operación } & $\begin{array}{c}\text { Número de } \\
\text { Máquinas }\end{array}$ & $\begin{array}{c}\text { Número de } \\
\text { Operarios }\end{array}$ \\
\hline Pesar & 3 & 2 \\
Lavar & 1 & 1 \\
Mezclar & 1 & 1 \\
Filtrar & 2 & 1 \\
Mezclar & 1 & 1 \\
Pasteurizar & 1 & \\
Envasar y tapar & 1 & \\
Etiquetar y rotular & 1 & 1 \\
Colocar precinto & 1 & \\
Empaquetar & 1 & \\
Osmosis Inversa & 1 & \\
Calentar (Caldera) & 1 & \\
\hline
\end{tabular}

Elaboración propia 
Por otro lado, la empresa requiere de profesionales que sepan administrar y poner en marcha la producción de las bebidas, generando estrategias para ser una empresa rentable. El detalle de las funciones que cumplirá cada personal administrativo se verá en el capítulo 6. El resumen del personal administrativo se puede observar en la tabla 5.21 .

Tabla 5.21

Personal Administrativo

\begin{tabular}{lc}
\hline \multicolumn{1}{c}{ Puesto } & $\begin{array}{c}\text { \# de } \\
\text { Trabajadores }\end{array}$ \\
\hline Gerente General & 1 \\
Jefe de Finanzas & 1 \\
Jefe de Operaciones & 1 \\
Jefe de Ventas & 1 \\
Supervisor de Logística & 1 \\
Asistente de Finanzas & 1 \\
Técnico de Calidad & 2 \\
Vendedores & 3 \\
Asistente de gerencia & 1 \\
\hline
\end{tabular}

Elaboración propia

\subsubsection{Servicios de terceros}

Se contratarán servicios a terceros en actividades donde se requiere una ayuda específica para el beneficio tanto de la compañía como de los propios trabajadores. Los servicios tomados son:

- Servicio de transporte, el cual es necesario para la distribución del producto final a los clientes, que en este proyecto serían los supermercados o las bodegas. Entre las empresas que mejor destacan se encuentra TerraTrans, la cual brinda un servicio de distribución para empresas del sector alimenticio. Esto es muy importante, ya que conocen el medio y además saben la manera correcta de distribuir el producto a producir.

- Servicio de telefonía e internet, será importante para poder tener una mejor comunicación con los clientes, proveedores y entre los mismos trabajadores. Para ello se contará con un servicio de la empresa Movistar, la cual ofrece diversos paquetes de acuerdo a la necesidad de cada empresa. 
- Servicio de vigilancia, esto debido a la creciente inseguridad que ocurre en el país. La empresa que se encargará de velar por la seguridad de la planta y de los trabajadores será Prosegur. Dicha empresa es reconocida en el medio por sus avanzados aparatos tecnológicos de seguridad y también por el personal altamente capacitado.

- Servicio de mantenimiento, el cual será terciarizado y permitirá el correcto mantenimiento preventivo y correctivo de las máquinas y equipos.

\subsection{Disposición de planta}

\subsubsection{Características físicas del proyecto}

\section{a. Factor edificio}

La edificación que se planea tener para la empresa se diseñará de manera que cuente con unas instalaciones y ambientes adecuados para un óptimo desempeño del empleador. Para ello se tendrá en cuenta lo siguiente:

- El terreno debe tener un tamaño adecuado para que se pueda construir todas las áreas definidas en el estudio.

- Las diversas áreas que se construirán deberán estar ubicadas de tal manera que mejore la comunicación y además no exista interferencias en lo que respecta a la luz y ventilación.

- El piso de la planta deberá estar hecho de un material homogéneo, llano y liso por lo que lo ideal sería que sea de cemento aislado. Además, es preferible que sea también de un material fácil de limpiar.

- El sistema de suministro de agua debe garantizar la disponibilidad de este recurso para los empleados en cualquier momento que lo requieran.

- Para las instalaciones eléctricas se tendrá mucho cuidado al momento de las instalaciones, ya que estas no deben estar expuestas a ningún contacto con cualquier trabajador o expuesto al aire porque podría originar algún accidente.

- Para el caso de la iluminación, se distribuirá de manera correcta los diferentes focos en diversos puntos de la planta. Además, estos focos deben ser ahorradores con el fin de que genere un menor gasto y cuide el planeta. 
- El número de baños a construir será acorde a la cantidad de personal que trabajará en la empresa.

- La planta cumplirá estrictamente las diferentes normas de seguridad, lo que incluirá una correcta señalización indicando las salidas de emergencia y las zonas de seguridad para casos de sismo.

\section{b. Factor servicio}

\section{- Servicios relativos al personal}

- Vías de acceso: Será necesario diseñar las puertas de ingreso y salida del personal de manera que sean independientes de los lugares asignados a la recepción de materia prima y despacho de productos con la finalidad de evitar algún inconveniente.

- Servicio de alimentación: Se asignará un área que pueda albergar a un total de 30 personas para que los empleados puedan almorzar de manera cómoda. Este lugar estará equipado con 4 mesas con 6 sillas cada una y se dispondrá de dos hornos microondas para el uso de los trabajadores.

- Servicios higiénicos: El número de retretes ideal para la planta sería 3, muy aparte de las oficinas administrativas, en la cual se contará con un baño para hombres, uno para mujeres y uno unisex. En los baños que estarán cerca de donde se realiza la producción se contará con casilleros, duchas y lava manos con la finalidad que los operarios puedan hacer uso de ellas al iniciar y al culminar sus labores diarias.

- Servicios médicos: Se deberá incluir dentro de la distribución de la planta un pequeño tópico que pueda atender accidentes leves.

\section{- Servicios relativos al material}

- Controles de calidad: La planta contará con un adecuado control de la materia prima que ingresa al área de recepción. Las hierbas u otros insumos que se encuentren defectuosos serán retirados del proceso. También se tendrá un control durante todo el proceso para verificar el adecuado manejo de materiales y su correcta elaboración. Al final se evaluará los productos finales y serán retirados los que presenten alguna falla en la presentación como podría ser rajaduras en la botella, errores en las etiquetas, tapas mal puestas, entre otros. 
- Servicios relativos a la maquinaria

- Instalación eléctrica: Las instalaciones eléctricas que se realicen en la empresa siempre deben respetar lo que indica el Código Nacional de Electricidad, cuya finalidad es la protección de los empleados y también de las personas que manipulen equipos eléctricos, ya que estos principalmente deben contar con un equipamiento de protección especial. La planta contará con un grupo electrógeno que se ubicará al exterior.

- Protección contra incendios: El principal objetivo de prevenir un incendio es lograr que tanto el personal como las máquinas y los materiales no sufran algún tipo de daño, por lo que la protección consistirá en minimizar los riesgos y siempre teniendo las vías de acceso libres.

\subsubsection{Determinación de las zonas físicas requeridas}

Para tener completa la línea de producción de bebidas a base hierbas medicinales, se considerará las siguientes áreas:

\section{a. Laboratorio de control de calidad}

Es el lugar donde se realizará las pruebas de calidad a los insumos y a las bebidas que se produzcan, con el fin de verificar si cumple con las especificaciones establecidas. Además, se almacenarán los equipos que sean necesarios para el técnico de calidad para realizar las pruebas.

\section{b. Oficinas administrativas}

En dicha área, estarán ubicados el gerente general, la asistenta de gerencia, los jefes y demás personal encargado de la gestión administrativa de la empresa. Está área debe ser cómoda y adecuada para el trabajo que desempeñarán, siempre contando con sus respectivos instrumentos de trabajos como lo son las computadoras, escritorios, sillas ergonómicas y también contar con una sala de reuniones la cual es importante para poder conversar sobre temas referidos a la empresa. 


\section{c. Patio de carga y descarga}

Esta área estará destinada para la recepción de las diferentes hierbas e insumos y además para poder despachar los diversos pedidos a los clientes.

\section{d. Almacenes}

Se dispondrá de dos tipos de almacenes. El primer servirá para la conservación de la materia prima e insumos y el segundo para almacenar el producto terminado. Ambos almacenes estarán ubicados cerca de la zona de producción para una mejor distribución de los productos.

Para el cálculo del área de los almacenes se consideró las medidas de las parihuelas que se van a utilizar, la cantidad de productos que usan por parihuela y la cantidad de niveles para apilar.

\section{e. Patio de maniobras}

Se asignará un espacio que servirá para que los montacargas puedan transitar y se puedan transportar los productos terminados y los insumos.

\subsubsection{Cálculo de áreas para cada zona}

En este punto de mostrará los diferentes espacios que tendrá la planta con su respectivo metraje.

En primer lugar, se analizará el espacio requerido para el proceso de producción, en el cual se utilizará el método de Guerchet.

Para este cálculo se consideró a los operarios una superficie estática de $0.5 \mathrm{~m}^{2}$ con una altura de 1,65 metros y se usó las siguientes ecuaciones.

Superficie estática $(\mathrm{Ss})=$ Largo $\mathrm{x}$ Ancho

Superficie gravitacional $(\mathrm{Sg})=\mathrm{Ss} \times \mathrm{N}$

Superficie de evolución $(\mathrm{Se})=(\mathrm{Ss}+\mathrm{Sg}) \times \mathrm{k}$

Altura promedio de equipos que se desplazan (hEM)

Altura promedio de equipos que no se desplazan (hEE)

$h E M=\Sigma(S s \times n \times h) / \Sigma(S s \times n)$

$h E E=\Sigma(S S \times n \times h) / \Sigma(S s \times n)$

$k=h E M / 2 x h E E$ 
Los diversos cálculos se observan en la siguiente tabla:

Tabla 5.22

Cálculo de área producción

\begin{tabular}{|c|c|c|c|c|c|c|c|c|c|c|c|}
\hline Elementos estáticos & $\mathbf{L}$ & $\mathbf{A}$ & $\mathbf{h}$ & $\mathbf{N}$ & $\mathbf{n}$ & Ss & Sg & Se & St & Ss $\times \mathrm{n}$ & Ss $\times n \times h$ \\
\hline Balanza & 1,00 & 1,00 & 1,00 & 1,00 & 3,00 & 1,00 & 1,00 & 1,30 & 9,91 & 3,00 & 3,00 \\
\hline Almacén temporal & 1,20 & 1,00 & & 2,00 & 1,00 & 1,20 & & 0,78 & 1,98 & 1,20 & \\
\hline Mesa de trabajo & 1,20 & 0,80 & 1,20 & 2,00 & 8,00 & 0,96 & 1,92 & 1,87 & 38,04 & 7,68 & 9,22 \\
\hline Almacén temporal & 1,20 & 1,00 & & 2,00 & 1,00 & 1,20 & & 0,78 & 1,98 & 1,20 & \\
\hline Lavadora industrial & 2,30 & 0,90 & 1,50 & 2,00 & 1,00 & 2,07 & 4,14 & 4,04 & 10,25 & 2,07 & 3,11 \\
\hline Maquinaria de Osmosis & 1,70 & 1,20 & 1,50 & 1,00 & 1,00 & 2,04 & 2,04 & 2,66 & 6,74 & 2,04 & 3,06 \\
\hline Caldero & 1,62 & 1,22 & 1,57 & 2,00 & 1,00 & 1,98 & 3,95 & 3,86 & 9,79 & 1,98 & 3,10 \\
\hline Máquina para mezclar & 2,20 & 1,50 & 1,50 & 2,00 & 2,00 & 3,30 & 6,60 & 6,44 & 32,69 & 6,60 & 9,90 \\
\hline Máquina Pasteurizadora & 1,80 & 0,90 & 1,60 & 1,00 & 1,00 & 1,62 & 1,62 & 2,11 & 5,35 & 1,62 & 2,59 \\
\hline Tanques de acero & 0,82 & 0,82 & 1,00 & 1,00 & 2,00 & 0,67 & 0,67 & 0,88 & 4,44 & 1,34 & 1,34 \\
\hline Máquina envasadora & 2,20 & 1,35 & 2,10 & 1,00 & 1,00 & 2,97 & 2,97 & 3,87 & 9,81 & 2,97 & 6,24 \\
\hline Almacén temporal & 1,20 & 1,00 & & 2,00 & 1,00 & 1,20 & & 0,78 & 1,98 & 1,20 & \\
\hline Máquina etiquetadora & 1,95 & 0,90 & 1,30 & 2,00 & 1,00 & 1,76 & 3,51 & 3,43 & 8,69 & 1,76 & 2,28 \\
\hline Almacén temporal & 1,20 & 1,00 & & 2,00 & 1,00 & 1,20 & & 0,78 & 1,98 & 1,20 & \\
\hline Precintadora de frascos & 2,15 & 0,90 & 1,70 & 2,00 & 1,00 & 1,94 & 3,87 & 3,78 & 9,58 & 1,94 & 3,29 \\
\hline Máquina de empaquetar & 2,15 & 1,40 & 1,70 & 2,00 & 1,00 & 3,01 & 6,02 & 5,88 & 14,91 & 3,01 & 5,12 \\
\hline Almacén temporal & 1,20 & 1,00 & & 2,00 & 1,00 & 1,20 & & 0,78 & 1,98 & 1,20 & \\
\hline Total & & & & & & & & & 170,10 & 42,00 & 52,25 \\
\hline Elementos móviles & $\mathbf{L}$ & $\mathbf{A}$ & $\mathbf{h}$ & $\mathbf{N}$ & $\mathbf{n}$ & Ss & Sg & Se & St & Ss $\times$ n & Ss $\times n \times h$ \\
\hline Operarios & & & 1,65 & $\mathrm{X}$ & 14,00 & 0,50 & $X$ & $\mathrm{X}$ & $\mathrm{X}$ & 7,00 & 11,55 \\
\hline Carretilla hidráulica & 1,20 & 0,50 & 1,20 & $\mathrm{X}$ & 5,00 & 0,60 & $X$ & $\mathrm{X}$ & $\mathrm{X}$ & 3,00 & 3,60 \\
\hline Montacarga & 3,00 & 0,60 & 2,20 & $\mathrm{X}$ & 1,00 & 1,80 & $\mathrm{X}$ & $\mathrm{X}$ & $\mathrm{X}$ & 1,80 & 3,96 \\
\hline & \multicolumn{2}{|c|}{ Ss $\times$ n } & \multicolumn{2}{|c|}{ Ss $\times n \times h$} & \multicolumn{2}{|c|}{ hee } & hem & \multicolumn{2}{|l|}{$\mathbf{k}$} & & \\
\hline Elementos estáticos & \multicolumn{2}{|c|}{42,00} & \multicolumn{2}{|c|}{52,25} & \multirow{2}{*}{\multicolumn{2}{|c|}{1,24}} & & \multirow{2}{*}{\multicolumn{2}{|c|}{0,651}} & & \\
\hline Elementos móviles & 11 & & 19 & & & & 1,62 & & & & \\
\hline
\end{tabular}

Elaboración propia

Según el cálculo de Guerchet, la parte de producción requerirá un espacio mínimo de $170,10 \mathrm{~m}^{2}$.

Luego se detallará en la siguiente tabla 5.23 las diferentes áreas que se mencionaron anteriormente. Esto permitirá conocer el tamaño ideal para que la empresa opere de manera adecuada. 


\section{Tabla 5.23}

Detalle de áreas de la empresa

\begin{tabular}{lc}
\hline & Área $\left(\mathbf{m}^{2}\right)$ \\
\hline Gerencia general & 24 \\
Área de finanzas & 17,5 \\
Área de logística & 21 \\
Área de ventas & 17,5 \\
Área de calidad & 15 \\
Sala de reuniones & 15 \\
Recepción & 10 \\
Garita & 5 \\
SSHH & 18 \\
SSHH Administrativo & 12,5 \\
Lava manos & 6 \\
Vestidores & 10,5 \\
Tópico & 10 \\
Almacén de MP & 38,5 \\
Almacén de PT & 38,5 \\
Zona de Residuos & 6 \\
Comedor & 32 \\
Área del grupo electrógeno & 1,2 \\
Patio de maniobras & 175 \\
Área de mantenimiento & 10 \\
Área de producción & 170,10 \\
\hline & 653,32 \\
\cline { 2 - 2 } &
\end{tabular}

Elaboración propia

Estos espacios mencionados en la tabla serán principalmente los que se ubicarán en las partes laterales de la planta. Además, para visualizar mejor el plano, se redondeará el metraje de la planta a $700 \mathrm{~m}^{2}$.

\subsubsection{Dispositivos de seguridad industrial y señalización}

La señalización es una acción que se refiere a un objeto, una actividad o situación determinada que proporciona una indicación, una obligación, una advertencia o una prohibición.

Para la empresa será necesario adquirir los siguientes elementos de seguridad con el fin de velar por los trabajadores:

- Equipos contra incendios.

- Detectores y alarmas.

- Avisos de seguridad, que son conocidos mayormente mediante símbolos

- Señalización acústica como altavoces o sirenas. 
Cabe resaltar que además de los dispositivos, todos los trabajadores de la empresa estarán en constante capacitación en temas relacionados a seguridad, tales como charlas instructivas, simulacros, pruebas, etc.

\subsubsection{Disposición de detalle de la zona productiva}

Para la disposición al detalle de la zona productiva primero se realizará un diagrama relacional de actividades que permitirá evaluar y mejorar la distribución de planta.

\section{Tabla 5.24}

Identificación de actividades

\section{Almacén de materias primas}

2. Zona de selección y pesado de MP

3. Zona de lavar

4. Zona de cortar

5. Filtrar, Osmosis y calentar

6. Mezclar y filtrar

7. Mezclar y Pasteurizar

8. Envasar y tapar

9. Etiquetar y rotular

10. Precintar y empaquetar

11. Control de calidad

12. Almacén de producto terminado

13. Patio de maniobras

14. Zona adminis trativa

15. Gerencia general

16. Comedor

17. Servicios higiénicos

18. Área de residuos

Elaboración propia 
Luego de identificar las actividades se utilizará el análisis relacional entre actividades, el cual permitirá obtener una propuesta de distribución basada en la cercanía que deberían tener las distintas áreas.

\section{Tabla 5.25}

Código de proximidades

\begin{tabular}{clcc}
\hline Código & \multicolumn{1}{c}{ Proximidad } & Color de las líneas & $\mathbf{N}^{\circ}$ de líneas \\
\hline A & Absolutamente necesario & Rojo & 4 rectas \\
E & Especialmente necesario & Amarillo & 3 rectas \\
I & Importante & Verde & 2 rectas \\
O & Normal & Azul & 1 recta \\
U & sin importancia & - & - \\
X & No deseable & Plomo & 1 zig-zag \\
XX & Altamente no deseable & Negro & 2 zig-zag \\
\hline
\end{tabular}

Elaboración propia

Adicionalmente, se debe presentar cada una de las actividades con símbolos que indiquen que significan cada una de ellas.

Tabla 5.26

Símbolo de actividades

\begin{tabular}{lll}
\hline Símbolo & Color & \multicolumn{1}{c}{ Actividad } \\
\hline & Verde & Operación, proceso o fabricación \\
& Naranja & Almacenaje \\
& Amarillo & Transporte \\
& Azul & Control \\
& Azul & Servicios \\
& Pardo & Administración \\
\hline
\end{tabular}

Elaboración propia

Por último, se detalla la lista de razones para establecer las relaciones y el valor de la proximidad entre las diferentes actividades. 
Tabla 5.27

Lista de motivos

\begin{tabular}{cl}
\hline Código & \multicolumn{1}{c}{ Lista de motivos } \\
\hline 1 & Secuencia de operaciones \\
2 & Mínima distancia por recorrer \\
3 & Posible contaminación cruzada \\
4 & Servicios para el personal \\
5 & Importancia de los contactos \\
6 & administrativos \\
\hline
\end{tabular}

Elaboración propia

Tabla 5.28

Tabla relacional de actividades

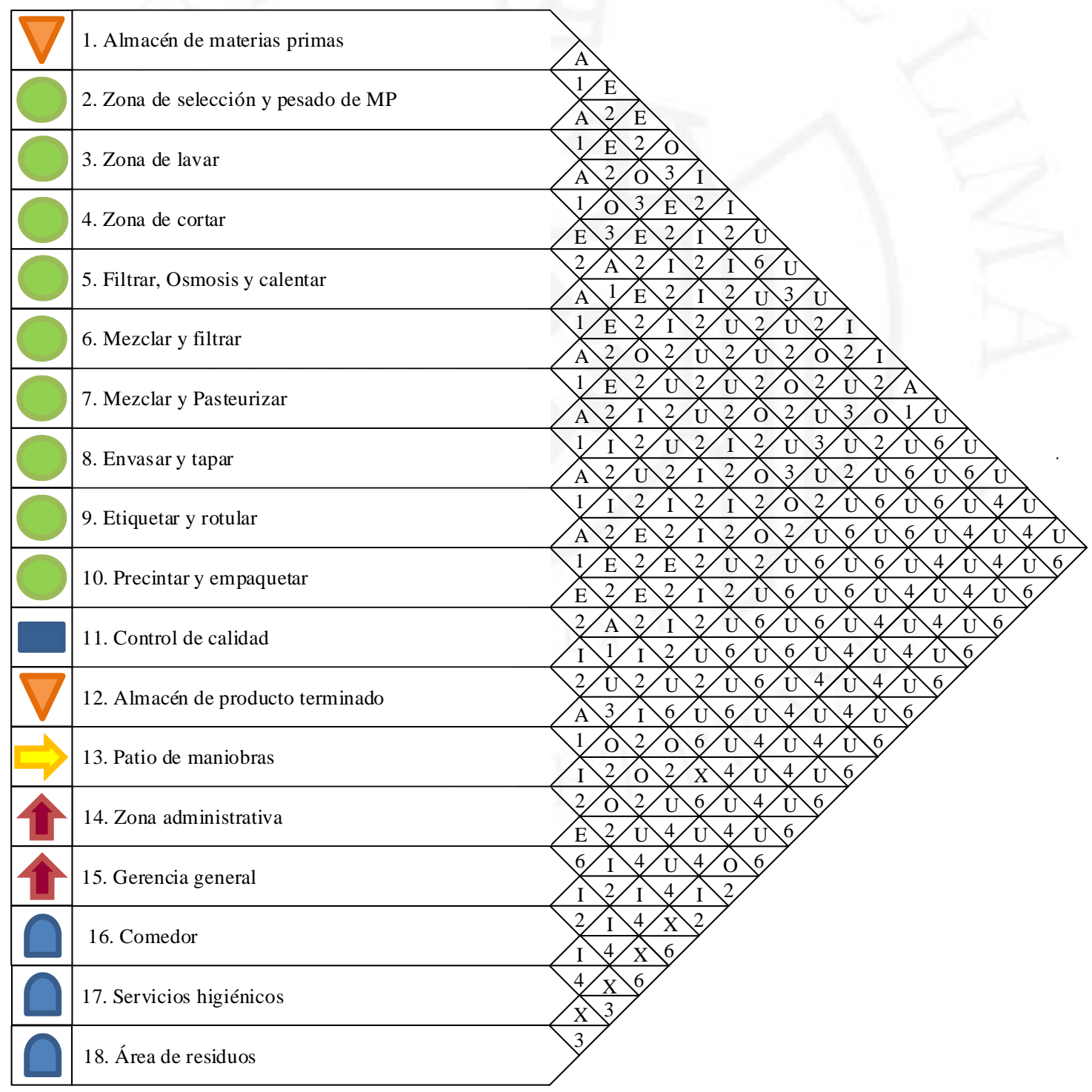

Elaboración propia 
Figura 5.6

Diagrama relacional de actividades

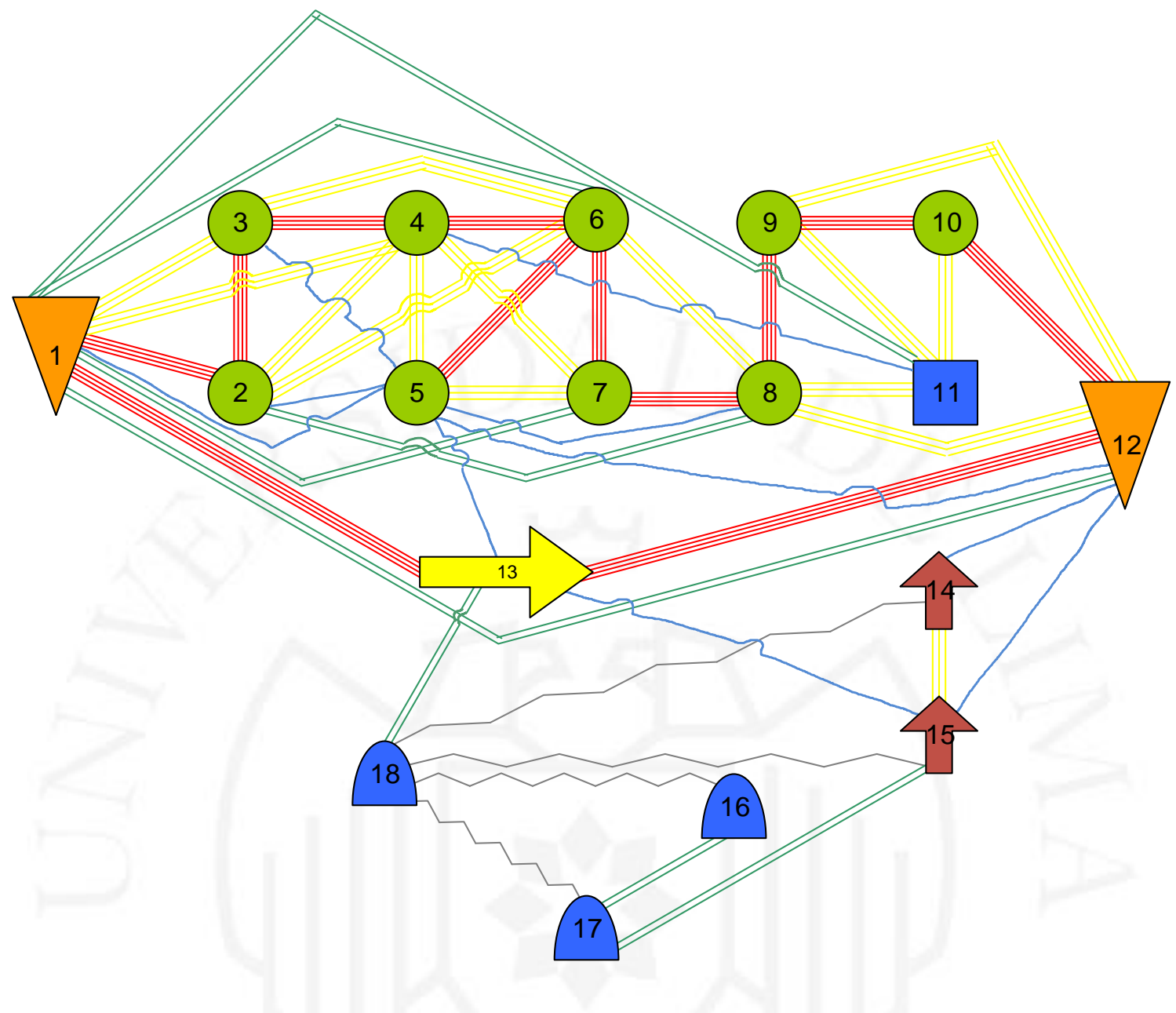

Elaboración propia

\subsubsection{Disposición general}

A continuación, se presenta el plano de la planta industrial para la elaboración de la bebida a base de hierbas medicinales. 
Figura 5.7

Plano de la planta de producción

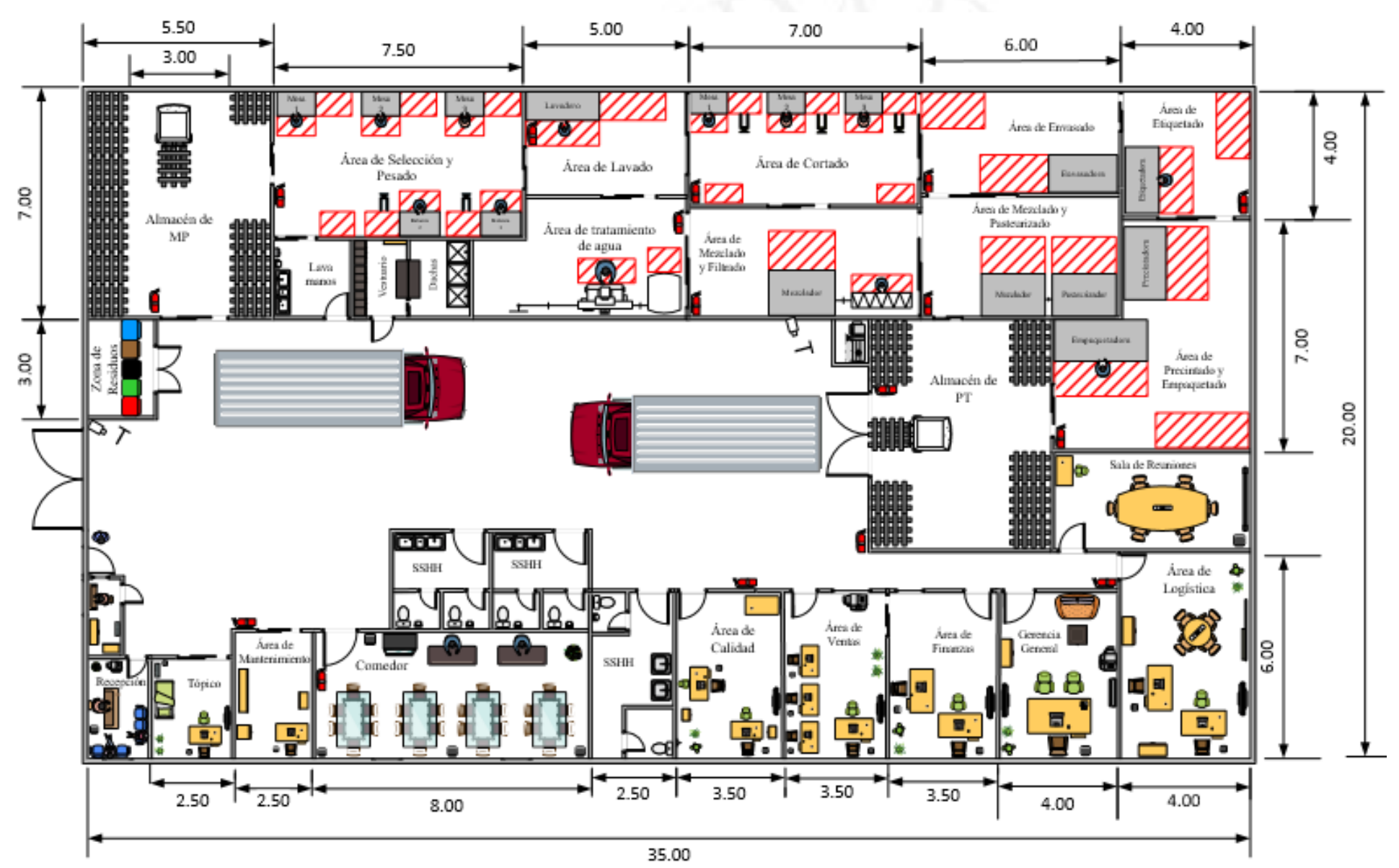

\begin{tabular}{|c|c|c|}
\hline \multicolumn{2}{|c|}{ Planta industrial para la elaboración de una bebida a base de manzanilla, muña, matico y romero } \\
\hline Universidad de Lima & \multirow{2}{*}{ Integrante: Cahuana Apolinario Jhairo Alex } & Escala: $1: 200$ \\
\cline { 3 - 3 } & & Área total: $700 \mathrm{~m}^{2}$. \\
\hline
\end{tabular}




\subsection{Cronograma de implementación del proyecto}

Para la implementación del proyecto se pronosticó que este tendría una duración aproximada de 40 semanas, tal como se muestra en el siguiente Diagrama de Gantt:

\section{Figura 5.8}

Cronograma de implementación del proyecto

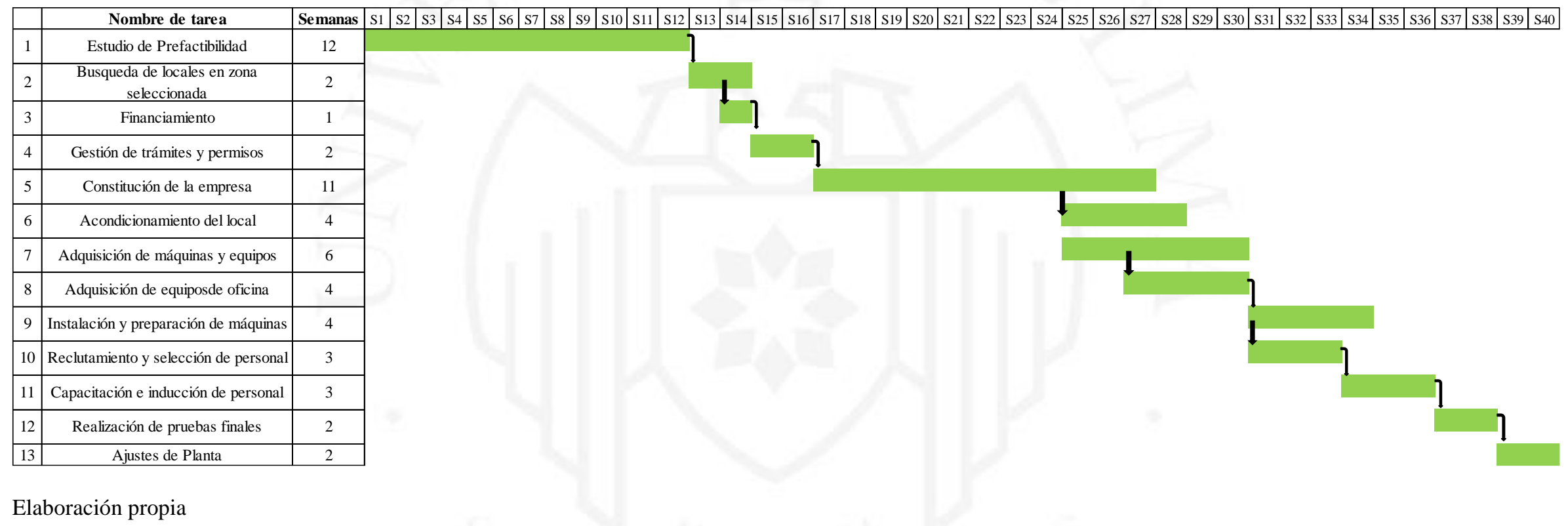




\section{CAPÍTULO VI: ORGANIZACIÓN Y ADMINISTRACIÓN}

\subsection{Formación de la organización empresarial}

La organización es el diseño y mantenimiento de un sistema de funcionamiento, el cual se basa en determinar los diversos roles que debe cumplir cada integrante de una empresa. Cuyo objetivo es maximizar los resultados que se obtienen de la colaboración, el trabajo y la relación que existe entre los propios trabajadores de una empresa.

El primer paso fundamental para la empresa será como va a ser registrada en los Registros Públicos. Según la naturaleza de la empresa, lo más adecuado sería que sea una Sociedad Anónima Cerrada (SAC), ya que es la más común para empresas comerciales o mercantiles y además porque el número de accionistas no va a exceder de 20 personas.

Un aspecto fundamental de la organización es el establecimiento de departamentos o un área en particular, en el cual la persona encargada posee autoridad respecto al desempeño de actividades específicas.

\subsection{Requerimientos del personal directivo, administrativo y de servicios; y}

\section{funciones generales de los principales puestos}

Al ser una empresa nueva, la organización estará conformada por un número limitado de puestos. Para comenzar las operaciones, los puestos y las funciones que realizarán son las siguientes:

\section{a) Gerente General}

- Liderar la gestión estratégica y los planes a corto y largo plazo.

- Dirigir y controlar el desempeño de las áreas.

- Ser el representante legal de la empresa.

\section{b) Jefe de finanzas}

- Supervisar la elaboración de la información contable y financiera de la empresa.

- Formular las políticas de elaboración del presupuesto de la empresa.

- Evaluar los indicadores claves de ejecución del área. 


\section{c) Jefe de Operaciones}

- Definir los objetivos y planes anuales de la planta en concordancia a las políticas y objetivos de la empresa.

- Evaluar constantemente el cumplimiento de los estándares y objetivos de producción.

- Analizar y planificar los procesos, sugiriendo mejoras e innovación.

- Evaluar constantemente la seguridad en la planta

\section{d) Jefe de ventas}

- Desarrollar los planes de negocio.

- Desarrollar campañas de ventas y comunicación.

- Generar informes de gestión y cumplimiento, alienado al presupuesto.

\section{e) Supervisor de logística}

- Evaluar constantemente el cumplimiento de los estándares y objetivos de producción.

- Planificar los procesos, sugiriendo mejoras e innovación.

\section{f) Asistente de finanzas}

- Reportar a los jefes del área la ejecución, seguimiento y control de actividades relacionadas.

- Mantener un control adecuado de las facturas o boletas de venta.

- Participar en establecer y brindar seguimiento a las oportunidades de mejora de las áreas.

\section{g) Técnico de calidad}

- Controlar la calidad de la materia prima e insumos, productos en proceso y producto terminado

- Realizar muestreo de los productos en producción, en stock y materia prima.

- Verificar que el producto cumpla con todos los parámetros establecidos por los clientes. 


\section{h) Vendedores}

- Salir a los diferentes puntos de distribución a ofrecer la bebida.

- Velar porque los mayoristas o distribuidoras paguen a tiempo sus productos.

i) Asistente de gerencia

- Recopilar y realizar el archivamiento de documentos.

- Redactar cartas de acuerdo a lo solicitado.

- Recepción de llamadas y facilitar soluciones eficaces a los clientes.

\section{j) Operarios}

- Realizar los trabajos de producción de la bebida

- Verificar periódicamente alguna falla que pudiera ocurrir al supervisor.

- Participar en las actividades que pudiera haber en la empresa como capacitaciones, simulacros, auditorías e inspecciones relacionadas a la calidad, seguridad y medio ambiente.

\subsection{Esquema de la estructura organizacional}

El organigrama de la empresa según los puestos con los que iniciará la operación de la empresa se refleja en la siguiente figura: 
Figura 6.1

Organigrama de la empresa

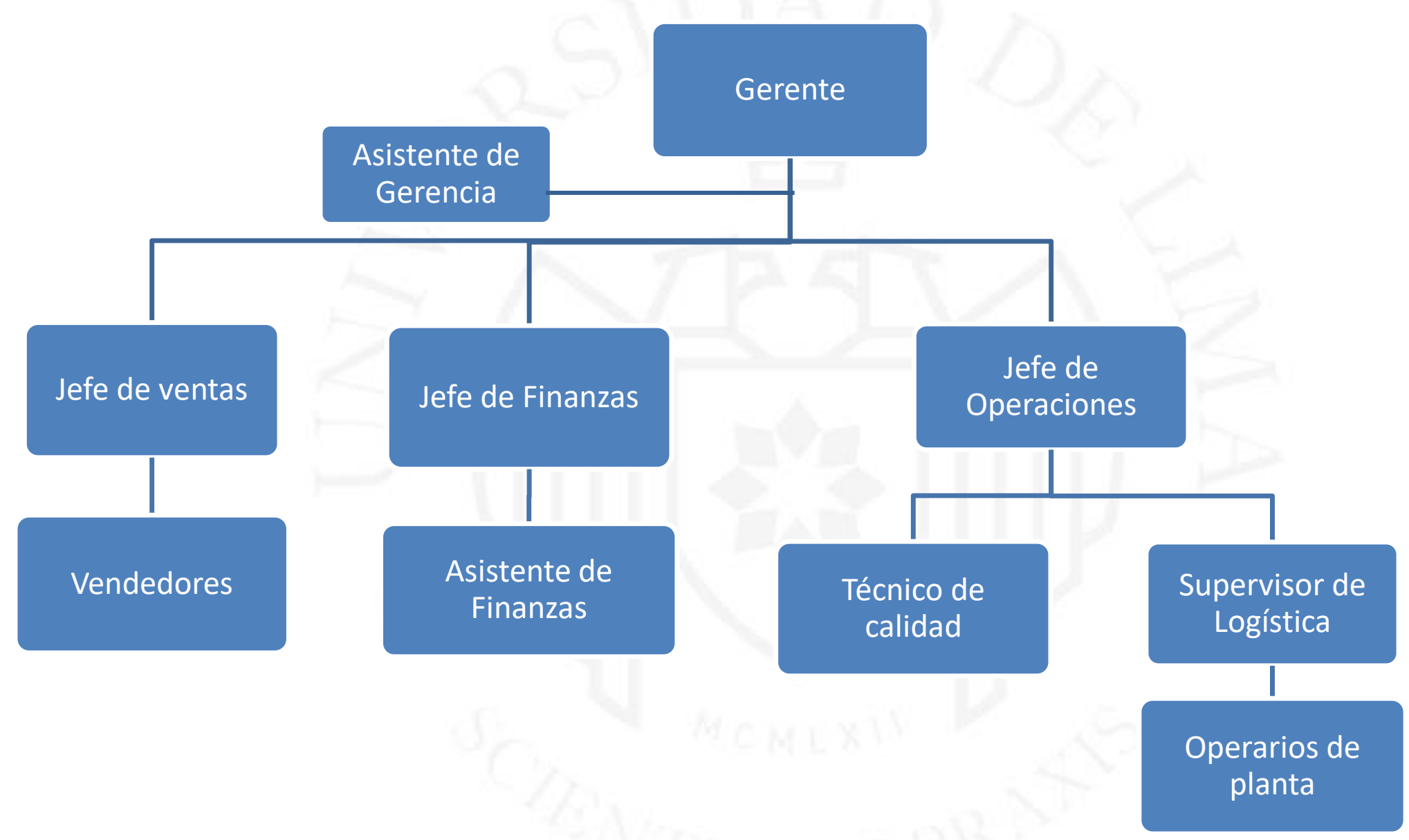

Elaboración propia 


\section{CAPÍTULO VII: PRESUPUESTOS Y EVALUACIÓN DEL PROYECTO}

\subsection{Inversiones}

El objetivo de este capítulo es cuantificar los recursos necesarios para la realización del proyecto en estudio y luego poder analizar la rentabilidad de este.

\subsubsection{Estimación de las inversiones de largo plazo}

Para estimar las inversiones a largo plazo se procederá a cotizar adecuadamente las siguientes inversiones para poder operar satisfactoriamente.

\section{a. Inversión fija intangible}

Este punto incluye todos los gastos que no se pueden percibir con ninguno de los sentidos pero que son de mucha importancia y se presentarán durante la puesta en marcha del proyecto, es decir durante la etapa pre-operativa.

- Estudios de pre factibilidad y factibilidad: Para el estudio de pre factibilidad se necesitará aproximadamente S/. 7.000 y para el estudio de factibilidad S/. 9.000

- Gasto de puesta en marcha: Se estima alrededor de S/. 11.000 el cual está constituido por todos los desembolsos que se realizarán para el diseño de los sistemas de información, licencia de funcionamiento, registro de marca y certificados sanitarios.

- Contingencias: Sirve como prevención en caso suceda algún acontecimiento inesperado durante la etapa de construcción de la planta por lo cual se contará con una bolsa de S/. 3.000. 
Tabla 7.1

Inversión Intangible

\begin{tabular}{|c|c|c|c|c|c|c|c|c|c|}
\hline $\begin{array}{c}\text { Inversión } \\
\text { Intangible } \\
\end{array}$ & $\begin{array}{l}\text { Costo } \\
\text { Total } \\
\end{array}$ & Amortización & 2019 & 2020 & 2021 & 2022 & 2023 & 2024 & VNL \\
\hline $\begin{array}{l}\text { Estudio de pre } \\
\text { factibilidad }\end{array}$ & S/. $\quad 7000$ & 6,00 & S/. 1167 & S/. 1167 & S/. 1167 & S/. 1167 & S/. 1167 & S/. 1167 & S/. - \\
\hline $\begin{array}{l}\text { Estudio de } \\
\text { factibilidad }\end{array}$ & S/. 9000 & 6,00 & S/. 1500 & S/. 1500 & S/. 1500 & S/. 1500 & S/. 1500 & S/. 1500 & S/. - \\
\hline $\begin{array}{l}\text { Puesta en } \\
\text { marcha }\end{array}$ & S/. 11000 & 6,00 & S/. 1833 & S/. 1833 & S/. 1833 & S/. 1833 & S/. 1833 & S/. 1833 & $\mathrm{~S} /$. \\
\hline Contingencias & S/. 3000 & 6,00 & S/. 500 & S/. 500 & S/. $5 \quad 00$ & S/. 500 & S/. 500 & S/. $5 \quad 00$ & $\mathrm{~S} /$. \\
\hline Total & S/. 30000 & & S/. 5000 & S/. 5000 & S/. 5000 & S/. 5000 & S/. 5000 & S/. 5000 & $\mathrm{~S} /$. \\
\hline
\end{tabular}

Elaboración propia

\section{b. Inversión fija tangible}

Son todos los gastos que se realizarán para la obtención de un bien físico, el cual se debe contar antes de la planta empiece a operar, a continuación, se presentan los bienes tangibles.

Tabla 7.2

Costo del terreno

\begin{tabular}{cccc}
\hline Terreno & $\begin{array}{c}\text { Cantidad } \\
\left(\mathbf{m}^{2}\right)\end{array}$ & \multicolumn{2}{c}{ Costo Total } \\
\hline Cantidad de Terreno & 700 & S/. & 582750 \\
\hline
\end{tabular}

Elaboración propia

\section{Tabla 7.3}

Gastos de mobiliario administrativo

\begin{tabular}{|c|c|c|c|c|c|c|c|c|c|}
\hline $\begin{array}{c}\text { Mobiliario } \\
\text { Administrativo }\end{array}$ & $\begin{array}{l}\text { Costo } \\
\text { Total } \\
\end{array}$ & $\begin{array}{c}\text { Depreciación } \\
\text { No Fabril } \\
\end{array}$ & 2019 & 2020 & 2021 & 2022 & 2023 & 2024 & VNL \\
\hline Escritorio & S/. 3840 & 10,00 & S/. 384 & S/. 384 & S/. 384 & S/. 384 & S/. 384 & S/. 384 & S/. 1536 \\
\hline $\begin{array}{l}\text { Computadoras } \\
\text { portátiles }\end{array}$ & S/.16 200 & 10,00 & S/.1 620 & S/.1 620 & S/.1 620 & S/.1 620 & S/.1 620 & S/.1 620 & S/. 6480 \\
\hline $\begin{array}{l}\text { Sillas para } \\
\text { escritorio }\end{array}$ & S/. $\quad 840$ & 10,00 & $\mathrm{~S} /$. & $\mathrm{S} /$. & $\mathrm{S} /$. & $\mathrm{S} /$. & $\mathrm{S} /$. & $\mathrm{S} /$. & 336 \\
\hline Impresora & S/. $\quad 680$ & 10,00 & S/. $\quad 68$ & $\mathrm{~S} /$. & $\mathrm{S} /$. & $\mathrm{S} /$. & S/. & $\mathrm{S} /$. & 272 \\
\hline Total & S/.21 560 & & S/.2 156 & S/.2 156 & S/.2 156 & S/.2 156 & S/.2 156 & S/.2 156 & S/. 8624 \\
\hline
\end{tabular}

Elaboración propia 
Tabla 7.4

Costos de las maquinarias y equipos

\begin{tabular}{|c|c|c|c|c|c|c|c|c|c|c|c|c|c|c|c|c|c|c|c|c|}
\hline \multirow{2}{*}{$\begin{array}{l}\text { Maquinaria y Equipo } \\
\text { Balanza }\end{array}$} & \multirow{2}{*}{$\frac{\text { Cantidad }}{3}$} & \multicolumn{2}{|c|}{ Costo unitario } & \multicolumn{2}{|c|}{ Costo Total } & \multicolumn{2}{|c|}{$\begin{array}{c}\text { Depreciacion } \\
\text { Fabril }\end{array}$} & \multicolumn{2}{|c|}{2019} & \multicolumn{2}{|c|}{2020} & \multicolumn{2}{|c|}{2021} & \multicolumn{2}{|c|}{2022} & \multicolumn{2}{|c|}{2023} & \multicolumn{2}{|r|}{2024} & VNL \\
\hline & & $\mathrm{S} /$. & 620 & $\mathrm{~S} /$. & 1860 & S/. & 10 & S/. & 186 & $\mathrm{~S} /$. & 186 & $\mathrm{~S} /$. & 186 & $\mathrm{~S} /$. & 186 & $\mathrm{~S} /$. & 186 & S/. & 186 & $\mathrm{~S} /$. \\
\hline Mesa de trabajo & 8 & $\mathrm{~S} /$. & 233 & $\mathrm{~S} /$. & 1863 & S/. & 10 & S/. & 186 & $\mathrm{~S} /$. & & $\mathrm{S} /$. & 186 & S/. & 86 & $\mathrm{~S} /$. & 186 & $\mathrm{~S} /$. & 186 & $\mathrm{~S} /$. \\
\hline & 1 & S/. & 12900 & $\mathrm{~S} /$. & 12900 & S/. & 10 & $\mathrm{~S} /$. & 1290 & $\mathrm{~S} /$. & 1290 & $\mathrm{~S} /$. & 1290 & $\mathrm{~S} /$. & 90 & $\mathrm{~S} /$. & 1290 & $\mathrm{~S} /$. & 1290 & 5160 \\
\hline $\mathrm{ro}$ & 1 & & & $\mathrm{~S} /$. & 12650 & S/. & 10 & S/. & 1265 & $\mathrm{~S} /$. & & $\mathrm{S} /$. & & $\mathrm{S} /$. & 65 & $\mathrm{~S} /$. & & $\mathrm{S} /$. & 65 & S/. 5060 \\
\hline smos: & 1 & S/. & 550 & $\mathrm{~S} /$. & 26550 & S/. & 10 & $\mathrm{~S} /$. & 2655 & $\mathrm{~S} /$. & 2655 & $\mathrm{~S} /$. & 2655 & $\mathrm{~S} /$. & 2655 & $\mathrm{~S} /$. & 2655 & $\mathrm{~S} /$. & 2655 & S/. 10620 \\
\hline & 2 & $\mathrm{~S} /$. & & $\mathrm{S} /$. & 619 & S/. & 10 & $\mathrm{~S} /$. & 62 & $\mathrm{~S} /$. & 62 & $\mathrm{~S} /$. & 62 & $\mathrm{~S} /$. & 62 & $\mathrm{~S} /$. & 62 & $\mathrm{~S} /$. & 62 & 248 \\
\hline & 2 & $\mathrm{~S} /$. & & $\mathrm{S} /$. & 24410 & S/. & 10 & S/. & 2441 & $\mathrm{~S} /$. & & S/. & 2441 & $\mathrm{~S} /$. & & $\mathrm{S} /$. & & $\mathrm{S} /$. & 2441 & 2764 \\
\hline & 1 & $\mathrm{~S} /$. & & $\mathrm{S} /$. & 21900 & S/. & 10 & $\mathrm{~S} /$. & 2190 & $\mathrm{~S} /$. & 2190 & $\mathrm{~S} /$. & 2190 & $\mathrm{~S} /$. & 2190 & $\mathrm{~S} /$. & 2190 & $\mathrm{~S} /$. & 2190 & 8760 \\
\hline & 2 & S/. & & $\mathrm{S} /$. & & $\mathrm{S} /$. & 10 & S/. & 400 & $\mathrm{~S} /$. & 400 & $\mathrm{~S} /$. & 400 & $\mathrm{~S} /$. & 400 & $\mathrm{~S} /$. & 400 & S/. & 400 & 1600 \\
\hline & 1 & S/. & 2498 & S/. & 249 & $\mathrm{~S} /$. & 10 & S/. & 2498 & $\mathrm{~S} /$. & 2498 & $\mathrm{~S} /$. & 2498 & S/. & 2498 & $\mathrm{~S} /$. & 2498 & S/. & 2498 & 9992 \\
\hline & 1 & S/. & & $\mathrm{S} /$. & 18640 & S/. & & S/. & 1864 & $\mathrm{~S} /$ & 1864 & $\mathrm{~S} /$. & 1864 & $\mathrm{~S} /$. & 1864 & $\mathrm{~S} /$. & 1864 & S/. & 1864 & 7456 \\
\hline & 1 & S/. & 19 & $\mathrm{~S} /$. & 19974 & S/. & & S/. & 1997 & $\mathrm{~S} /$ & 1997 & S/. & 1997 & $\mathrm{~S} /$. & 1997 & $\mathrm{~S} /$. & 1997 & $\mathrm{~S} /$. & 1997 & 7990 \\
\hline & 1 & S/. & & $\mathrm{S} /$. & 1620 & S/. & & S/. & 1620 & $\mathrm{~S} /$. & 1620 & S/. & 1620 & $\mathrm{~S} /$. & 1620 & $\mathrm{~S} /$. & 1620 & S/. & 1620 & 6480 \\
\hline & 1 & S/. & & S/. & 150 & S/. & & S/. & 1500 & $\mathrm{~S} /$. & 1500 & $\mathrm{~S} /$. & 1500 & $\mathrm{~S} /$. & 1500 & $\mathrm{~S} /$. & 1500 & S/. & 1500 & 6000 \\
\hline & 5 & S/. & & $\mathrm{S} /$. & & S/. & & S/. & 660 & $\mathrm{~S} /$. & 660 & $\mathrm{~S} /$. & 660 & $\mathrm{~S} /$. & 660 & $\mathrm{~S} /$. & 660 & S/. & 660 & 2640 \\
\hline & 1 & $\mathrm{~S} /$. & 15290 & $\mathrm{~S} /$. & 15290 & S/. & 10 & $\mathrm{~S} /$. & 1829 & $\mathrm{~S} /$. & 1829 & $\mathrm{~S} /$. & 1829 & $\mathrm{~S} /$. & 1829 & $\mathrm{~S} /$. & 1829 & $\mathrm{~S} /$. & 1829 & 7316 \\
\hline Total & 32 & $\mathrm{~S} /$. & 203772 & $\mathrm{~S} /$. & 226437 & $\mathrm{~S} /$. & 190 & $\mathrm{~S} / .2$ & 22644 & $\mathrm{~S} /$. & 22644 & $\mathrm{~S} / .2$ & 22644 & $\mathrm{~S} / .2$ & 22644 & $\mathrm{~S} / .2$ & 22644 & $\mathrm{~S} /$. & 22644 & S/. 90575 \\
\hline
\end{tabular}

Elaboración propia

\section{Tabla 7.5}

Utensilios Administrativos

\begin{tabular}{|c|c|c|c|c|c|c|c|c|c|}
\hline $\begin{array}{c}\text { Utensilios } \\
\text { Administrativos }\end{array}$ & $\begin{array}{l}\text { Costo } \\
\text { Total }\end{array}$ & Amortización & 2019 & 2020 & 2021 & 2022 & 2023 & 2024 & VNL \\
\hline Microondas & S/. 480 & & S/. 80 & S/. 80 & & S/. 80 & S/. 80 & $\mathrm{~S} / .80$ & S/. \\
\hline Refri & S/. 700 & & & S/. 117 & S/. 117 & S/. 117 & S/. 117 & S/. 117 & S/. \\
\hline medor & S/. 280 & & S/. 47 & S/. 47 & S/. 47 & S/. 47 & S/. 47 & S/. 47 & S/. \\
\hline de comedor & S/. 720 & & S/. 120 & S/. 120 & S/. 120 & S/. 120 & S/. 120 & S/. 120 & $\mathrm{~S} /$. \\
\hline Extintores & S/. 1260 & & S/. 210 & S/. 210 & S/. 210 & S/. 210 & S/. 210 & S/. 210 & $\mathrm{~S} /$. \\
\hline Total & S/. 3440 & & S/. 573 & S/. 573 & S/. 573 & S/. 573 & S/. 573 & S/. 573 & $\mathrm{~S} /$. \\
\hline
\end{tabular}

Elaboración propia 


\subsubsection{Estimación de las inversiones de corto plazo}

En lo que se refiere a la estimación de la inversión a corto plazo, se estimará la cantidad necesaria de capital de trabajo que se necesita para los primeros tres meses de operatividad. Este monto será útil para cubrir sueldos, salarios, inventarios de materia prima, servicios entre otros gastos que se necesiten antes que la empresa perciba los ingresos de dinero por ventas.

Para poder calcular el tiempo que se necesitará cubrir con los costos y gastos mencionados, se utilizará la fórmula de ciclo de caja, la cual es:

Ciclo de caja $=$ Periodo promedio de inventario + Periodo promedio de cobro - Periodo promedio de pago

Para saber el periodo promedio que se tendrá de inventario, será aproximadamente de un mes y para casos excepcionales se tendrá que pagar un costo adicional si faltara algún insumo.

El periodo promedio de cobro será aproximadamente de dos meses, ya que nuestros principales clientes son los supermercados y estaciones servicio. Estos acostumbran a pagar a sus proveedores a los dos meses.

Por lo que el ciclo de caja será aproximado de cuarenta y cinco días y el capital de trabajo estará conformado de la siguiente manera:

Tabla 7.6

Capital de trabajo

\begin{tabular}{lrr}
\hline \multicolumn{1}{c}{ Rubro } & \multicolumn{2}{c}{ Cantidad } \\
\hline Gasto operativo diario & S/. & 5544 \\
Días al año & & 312 \\
Gasto operativo anual & S/. & 729703 \\
Capital de Trabajo & S/. & 249476 \\
Pago a proveedores (días) & & 30 \\
Pago de clientes (días) & & 60 \\
Días de Inventario (días) & & 15 \\
Ciclo de caja (días) & & 45 \\
\hline
\end{tabular}

Elaboración propia 


\subsection{Costos de producción}

Los costos de producción se refieren a todos los costos que se realizan hacia los materiales, insumos, mano de obra y servicios que incurren en el proceso de producción de la bebida a base de hierbas medicinales.

\subsubsection{Costos de las materias primas}

Para la producción de la bebida a base de hierbas medicinales se empleará como materia prima cuatro diferentes hierbas: manzanilla, matico, muña y romero; por otro lado, también se requerirá de botellas de vidrio, tapas y etiquetas para la presentación final del producto.

\section{Tabla 7.7}

Costo de materia prima e insumos

\begin{tabular}{lcc}
\hline \multicolumn{1}{c}{ Materia prima } & \multicolumn{2}{c}{$\begin{array}{c}\text { Costo } \\
\text { (Sin IGV) }\end{array}$} \\
\hline Manzanilla (Kg) & S/. & 1,69 \\
Muña $(\mathrm{Kg})$ & $\mathrm{S} /$ & 1,40 \\
Matico(Kg) & $\mathrm{S} /$. & 1,02 \\
Romero (Kg) & $\mathrm{S} /$. & 1,27 \\
Stevia (Kg) & S/. & 33,90 \\
Agua (Litros) & $\mathrm{S} /$. & 0,0056 \\
Envases (Unidad) & S/. & 0,22 \\
Etiquetas (Unidad) & S/. & 0,08 \\
Tapas (Unidad) & S/. & 0,10 \\
Embalaje (Unidad) & S/. & 0,10 \\
\hline
\end{tabular}

Fuente: Ministerio de Agricultura y Riego, MINAGRI (2018)

\subsubsection{Costo de la mano de obra}

Se ha determinado que la jornada laboral será de 8 horas durante los 6 días a la semana. El horario será de 8 am hasta las $5 \mathrm{Pm}$.

Para el caso de los trabajadores de planta, en el cálculo de sus remuneraciones estará incluido los salarios mensuales, gratificaciones, seguro social, CTS.

En la tabla 7.8 se muestra el salario mensual de los trabajadores que laborarán en la empresa. 
Tabla 7.8

Planilla

\begin{tabular}{|c|c|c|c|c|c|c|c|c|}
\hline Puesto & $\begin{array}{c}\text { Sueldo } \\
\text { Mensual }\end{array}$ & $\begin{array}{l}\text { Sueldo } \\
\text { Anual }\end{array}$ & $\begin{array}{c}\text { Gratificación } \\
\text { Anual }\end{array}$ & CTS Anual & $\begin{array}{c}\text { Essalud } \\
\text { Anual }\end{array}$ & Planilla c/u & $\begin{array}{c}\text { \# de } \\
\text { Trabajadores }\end{array}$ & Planilla Total \\
\hline Gerente General & S/. 12000 & S/. 144000 & S/. 24000 & S/. 14000 & S/. 12960 & S/. 194960 & 1 & S/. 194960 \\
\hline Jefe de Finanzas & S/. 6000 & S/. 72000 & S/. 12000 & S/. 7000 & S/. 6480 & S/. 97480 & 1 & S/. 97480 \\
\hline Jefe de Operaciones & S/. 6000 & S/. 72000 & S/. 12000 & S/. 7000 & S/. 6480 & S/. 97480 & 1 & S/. 97480 \\
\hline Jefe de Ventas & S/. 4000 & S/. 48000 & S/. 8000 & S/. 4667 & S/. 4320 & S/. 64987 & 1 & S/. 64987 \\
\hline Supervisor de Logística & S/. 2500 & S/. 30000 & S/. 5000 & S/. 2917 & S/. 2700 & S/. 40617 & 1 & S/. 40617 \\
\hline Asistente de Finanzas & S/. 2000 & S/. 24000 & S/. 4000 & S/. 2333 & S/. 2160 & S/. 32493 & 1 & S/. 32493 \\
\hline Técnico de Calidad & S/. 2000 & S/. 24000 & S/. 4000 & S/. 2333 & S/. 2160 & S/. 32493 & 2 & S/. 64987 \\
\hline Vendedores & S/. 1700 & S/. 20400 & S/. 3400 & S/. 1983 & S/. 1836 & S/. 27619 & 3 & S/. 82858 \\
\hline Asistente de gerencia & S/. 1200 & S/. 14400 & S/. 2400 & S/. 1400 & S/. 1296 & S/. 19496 & 1 & S/. 19496 \\
\hline Operarios (Almacén) & S/. 1100 & S/. 13200 & S/. 2200 & S/. 1283 & S/. 1188 & S/. 17871 & 14 & S/. 250199 \\
\hline \multicolumn{2}{|l|}{ TOTAL } & $x_{1}$ & & & & & 26 & S/. 945556 \\
\hline
\end{tabular}

Elaboración propia

\section{Costo de mano de obra directa:}

Para determinar el costo anual de la mano de obra directa también se considerará los mismos beneficios indicados anteriormente.

Tabla 7.9

Detalle del costo anual de Mano de obra

\begin{tabular}{ccccccccc}
\hline \multicolumn{1}{c}{ Puesto } & $\begin{array}{c}\text { Sueldo } \\
\text { Mensual }\end{array}$ & $\begin{array}{c}\text { Sueldo } \\
\text { Anual }\end{array}$ & $\begin{array}{c}\text { Gratificación } \\
\text { Anual }\end{array}$ & CTS Anual & $\begin{array}{c}\text { Essalud } \\
\text { Anual }\end{array}$ & Planilla c/u & $\begin{array}{c}\text { \# de } \\
\text { Trabajadores }\end{array}$ & Planilla \\
\hline Operarios (Almacén) & S/. 1100 & S/.13200 & S/.2200 & S/.1283 & S/. 1 188 & S/. 17 871 & 14 & S/.250 199 \\
\hline
\end{tabular}

Elaboración propia 


\subsubsection{Costo indirecto de fabricación}

Los costos indirectos de fabricación están conformados por la mano de obra indirecta, es decir, el personal que no tiene relación directa en el proceso de producción de la bebida, se considerará los materiales indirectos y costos generales de la planta

Tabla 7.10

Costo Mano de obra indirecta

\begin{tabular}{|c|c|c|c|c|c|c|c|c|}
\hline Puesto & Cant. & $\begin{array}{c}\text { Sueldo } \\
\mathrm{C} / \mathrm{u}\end{array}$ & 2019 & 2020 & 2021 & 2022 & 2023 & 2024 \\
\hline $\begin{array}{l}\text { Jefe de } \\
\text { Operaciones }\end{array}$ & 1 & S/. 6000 & S/. 64987 & S/. 64987 & S/. 64987 & S/. 64987 & S/. 64987 & S/. 64987 \\
\hline $\begin{array}{l}\text { Supervisor } \\
\text { de Logistica }\end{array}$ & 1 & S/. 2500 & S/. 19496 & S/. 19496 & S/. 19496 & S/. 19496 & S/. 19496 & S/. 19496 \\
\hline $\begin{array}{l}\text { Técnico de } \\
\text { Calidad }\end{array}$ & 2 & S/. 2000 & S/. 35743 & S/. 35743 & S/. 35743 & S/. 35743 & S/. 35743 & S/. 35743 \\
\hline \multicolumn{3}{|c|}{ Total } & S/.120 225 & S/.120 225 & S/.120 225 & S/. 120225 & S/.120 225 & S/.120 225 \\
\hline
\end{tabular}

Elaboración propia

Tabla 7.11

Otros costos indirectos de fabricación

\begin{tabular}{|c|c|c|c|c|c|c|}
\hline CIF & 2019 & 2020 & 2021 & 2022 & 2023 & 2024 \\
\hline Energía & S/. 24336 & S/. 24336 & S/. 24336 & S/. 24336 & S/. 24336 & S/. 24336 \\
\hline Depr. Fabril & S/. 22644 & S/. 22644 & S/. 22644 & S/. 22644 & S/. 22644 & S/. 22644 \\
\hline Mantenimiento & S/. 21600 & S/. 21600 & S/. 21600 & S/. 21600 & S/. 21600 & S/. 21600 \\
\hline $\begin{array}{l}\text { Lubricante y/o } \\
\text { aceites }\end{array}$ & S/. 1920 & S/. 1920 & S/. 1920 & S/. 1920 & S/. 1920 & S/. 1920 \\
\hline Transporte & S/. 39600 & S/. 39600 & S/. 39600 & S/. 39600 & S/. 39600 & S/. 39600 \\
\hline Total & S/. 110100 & S/. 110100 & S/. 110100 & S/. 110100 & S/. 110100 & S/. 110100 \\
\hline
\end{tabular}

Elaboración propia

\subsection{Presupuestos Operativos}

\subsubsection{Presupuesto de ingreso por ventas}

Es la cantidad de dinero que ingresa a la empresa por venta directa de los productos en todos los canales que posee la empresa. Para este cálculo se utilizará el precio de venta que fue establecido anteriormente para el canal distribuidor, este precio para el minorista es de 2,00 soles (incluido IGV), por lo cual el valor que se tiene para las ventas será 1,69 soles. 
Tabla 7.12

Presupuesto de ingresos de ventas

\begin{tabular}{c|cccccc}
\hline Ítem & $\mathbf{2 0 1 9}$ & $\mathbf{2 0 2 0}$ & $\mathbf{2 0 2 1}$ & $\mathbf{2 0 2 2}$ & $\mathbf{2 0 2 3}$ & $\mathbf{2 0 2 4}$ \\
\hline $\begin{array}{c}\text { Cantidad } \\
\text { (Botellas) }\end{array}$ & 1319155 & 1391703 & 1464414 & 1537098 & 1609575 & 1727554 \\
Costo & S/. 1,69 & S/. 1,69 & S/. 1,69 & S/. 1,69 & S/. 1,69 & S/. 1,69 \\
Ventas & S/. 22 235 855 & S/. 2358 319 & S/. 2482057 & S/. 2605251 & S/. 2728093 & S/. 2928058 \\
\hline
\end{tabular}

Elaboración propia

\subsubsection{Presupuesto operativo de costos}

Los costos calculados significan los desembolsos realizados para poder realizar la elaboración de la bebida. Estos se diferencian por si tienen una relación directa o indirecta en el proceso de producción.

Tabla 7.13

Presupuesto operativo de costos

\begin{tabular}{|c|c|c|c|c|c|c|}
\hline Ítem & 2019 & 2020 & 2021 & 2022 & 2023 & 2024 \\
\hline Materia Prima & S/. 591387 & S/. 623911 & S/. 656508 & S/. 689093 & S/. 721585 & S/. 774476 \\
\hline Mano de Obra & S/. 250199 & S/. 250199 & S/. 250199 & S/. 250199 & S/. 250199 & S/. 250199 \\
\hline CIF (Total) & S/. 230326 & S/. 230326 & S/. 230326 & S/. 230326 & S/. 230326 & S/. 230326 \\
\hline Total & S/. 1071911 & S/. 1104435 & S/. 1137032 & S/. 1169617 & S/. 1202109 & S/. 1255000 \\
\hline
\end{tabular}

Elaboración propia

\subsubsection{Presupuesto operativo de gastos}

Los gastos operativos serán los necesarios para que las operaciones funcionen de manera adecuada.

Tabla 7.14

Costo de personal administrativo

\begin{tabular}{|c|c|c|c|c|c|c|c|}
\hline Puesto & Sueldo C/u & 2019 & 2020 & 2021 & 2022 & 2023 & 2024 \\
\hline Gerente General & S/. 12000 & S/. 194960 & S/. 194960 & S/. 194960 & S/. 194960 & S/. 194960 & S/. 194960 \\
\hline Jefe de Finanzas & S/. 6000 & S/. 97480 & S/. 97480 & S/. 97480 & S/. 97480 & S/. 97480 & S/. 97480 \\
\hline Jefe de Ventas & S/. 4000 & S/. 64987 & S/. 64987 & S/. 64987 & 64987 & S/. 64987 & 64987 \\
\hline Asistente de Finanzas & S/. 2000 & S/. 32493 & S/. 32493 & S/. 32493 & 32493 & 32493 & 32493 \\
\hline Vendedores & S/. 1700 & S/. 82858 & S/. 82858 & S/. 82858 & 82858 & 82858 & 82858 \\
\hline Asistente de Gerencia & S/. 1200 & S/. 19496 & S/. 19496 & S/. 19496 & S/. 19496 & S/. 19496 & S/. 19496 \\
\hline Total & & S/. 492274 & S/. 492274 & S/. 492274 & S/. 492274 & S/. 492274 & S/. 492274 \\
\hline
\end{tabular}

Elaboración propia 
Tabla 7.15

Gastos Indirectos de fabricación

\begin{tabular}{|c|c|c|c|c|c|c|}
\hline GIF & 2019 & 2020 & 2021 & 2022 & 2023 & 2024 \\
\hline Teléfono e internet & S/. 3600 & S/. 3600 & S/. 3600 & S/. 3600 & S/. 3600 & S/. 3600 \\
\hline Depreciación No fabril & S/. 10156 & S/. 10156 & S/. 10156 & S/. 10156 & S/. 10156 & S/. 10156 \\
\hline Seguros & S/. 7500 & S/. 7500 & S/. 7500 & S/. 7500 & S/. 7500 & S/. 7500 \\
\hline Seguridad (Vigilancia) & S/. 24000 & S/. 24000 & S/. 24000 & S/. 24000 & S/. 24000 & S/. 24000 \\
\hline Amortización & S/. 5573 & S/. 5573 & S/. 5573 & S/. 5573 & S/. 5573 & S/. 5573 \\
\hline Publicidad & S/. 111793 & S/. 117941 & S/. 124103 & S/. 130263 & S/. 136405 & S/. 146403 \\
\hline Agua (Adm) & S/. 2296 & S/. 2296 & S/. 2296 & S/. 2296 & S/. 2296 & S/. 2296 \\
\hline Herramientas (Adm) & S/. 600 & S/. 600 & S/. 600 & S/. 600 & S/. 600 & S/. 600 \\
\hline Total & S/. 165518 & S/. 171666 & S/. 177828 & S/. 183988 & S/. 190130 & S/. 200128 \\
\hline
\end{tabular}

Elaboración propia

\subsection{Presupuestos Financieros}

\subsubsection{Presupuesto de Servicio de Deuda}

Para poder determinar el servicio a la deuda se analizó los intereses otorgados por las entidades bancarias. Se tomará un préstamo por un periodo mayor a 360 días en el banco "Banbif" el cual brinda una TEA de $12.33 \%$ (Superintendencia de banca y seguros, 2019).

Para el financiamiento de máquinas, equipos, mobiliario se optará por el crédito del TEA de $12.33 \%$, cuotas decrecientes y amortización constante.

Tabla 7.16

Inversión Total

\begin{tabular}{llr}
\hline \multicolumn{1}{c}{ Rubro } & \multicolumn{2}{c}{ Gasto total } \\
\hline Terreno & S/. & 582750 \\
Construcción & S/. & 80000 \\
Maquinaria y equipos & S/. & 226437 \\
Mobiliario administrativo & S/. & 21560 \\
Utensilios administrativos & S/. & 3440 \\
Capital de Trabajo & S/. & 249476 \\
Intangibles & S/. & 30000 \\
\hline Total & S/. & 1193663 \\
\hline
\end{tabular}

Elaboración propia 
Tabla 7.17

Estructura de Financiamiento

\begin{tabular}{lccc}
\hline \multicolumn{1}{c}{ Fuente } & Porcentaje & \multicolumn{2}{c}{ Monto } \\
\hline Capital Propio & $60 \%$ & S/. & 716198 \\
Crédito Bancario & $40 \%$ & S/. & 477465 \\
\hline Total & $100 \%$ & S/. 1193663 \\
\hline
\end{tabular}

Elaboración propia

Tabla 7.18

Servicio a la deuda

\begin{tabular}{rrrlrlrlrl}
\hline Año & \multicolumn{2}{c}{ Deuda } & \multicolumn{2}{c}{ Amortización } & \multicolumn{2}{c}{ Intereses } & \multicolumn{2}{c}{ Cuota } \\
\hline 2019 & S/. & 477465 & S/. & 79578 & S/. & 58871 & S/. & 138449 \\
2020 & S/. & 397888 & S/. & 79578 & S/. & 49060 & S/. & 128637 \\
2021 & S/. & 318310 & S/. & 79578 & S/. & 39248 & S/. & 118825 \\
2022 & S/. & 238733 & S/. & 79578 & S/. & 29436 & S/. & 109013 \\
2023 & S/. & 159155 & S/. & 79578 & S/. & 19624 & S/. & 99201 \\
2024 & S/. & 79578 & S/. & 79578 & S/. & 9812 & S/. & 89389 \\
\hline
\end{tabular}

Elaboración propia

Se puede visualizar que la amortización es constante, intereses decrecientes y que el préstamo se termina de pagar en el sexto año.

\subsubsection{Presupuesto de Estado de Resultados}

Con los datos hallados en los puntos anteriores se puede mostrar el siguiente estado de resultados que vienes a ser el esquema el cual muestra las ganancias y pérdidas de la empresa en un periodo determinado. En la tabla 7.19 se puede observar que la utilidad es positiva en todos los años, por lo cual siempre hay ingresos útiles a la empresa. 
Tabla 7.19

Estados de Resultados por año

\begin{tabular}{|c|c|c|c|c|c|c|}
\hline & 2019 & 2020 & 2021 & 2022 & 2023 & 2024 \\
\hline Ventas & S/. 2235855 & S/. 2358819 & S/. 2482057 & S/. 2605251 & S/. 2728093 & S/. 2928058 \\
\hline Costo de Ventas & S/. 1071911 & S/. 1104435 & S/. 1137032 & S/. 1169617 & S/. 1202109 & S/. 1255000 \\
\hline Ut. Bruta & S/. 1163944 & S/. 1254384 & S/. 1345025 & S/. 1435634 & S/. 1525984 & S/. 1673058 \\
\hline Gastos Administrativos & S/. 492274 & S/. 492274 & S/. 492274 & S/. 492274 & S/. 492274 & S/. 492274 \\
\hline Gastos Operativos & S/. 165518 & S/. 171666 & S/. 177828 & S/. 183988 & S/. 190130 & S/. 200128 \\
\hline Gasto Financiero & 58871 & 49060 & 39248 & 29436 & S/. 19624 & 9812 \\
\hline Valor Libros & & & & & & S/. 131199 \\
\hline Valor Mercado & & & & & & S/. 849414 \\
\hline $\begin{array}{l}\text { Ut. Antes de participación e } \\
\text { Impuestos }\end{array}$ & S/. 447280 & S/. 541384 & S/. 635675 & S/. 729937 & S/. 823956 & S/. 1689059 \\
\hline Participación a los trabajadores & 44728 & 54138 & 63568 & 72994 & S/. 82396 & S/. 168906 \\
\hline $\begin{array}{l}\text { Ut. Antes Impuestos y reserva } \\
\text { legal }\end{array}$ & S/. 402552 & S/. 487246 & S/. 572108 & S/. 656943 & S/. 741561 & S/. 1520153 \\
\hline Imp. Renta & S/. 120766 & S/. 146174 & 171632 & 197083 & S/. 222468 & S/. 456046 \\
\hline Ut. Antes de la reserva legal & 281787 & 341072 & 400475 & 459860 & S/. 519092 & S/. 1064107 \\
\hline Reserva legal & 28179 & 34107 & 40048 & 45986 & S/. 51909 & S/. 106411 \\
\hline Ut. Neta & S/. $\quad 253608$ & S/. $\quad 306965$ & S/. $\quad 360428$ & S/. 413874 & S/. 467183 & S/. 957697 \\
\hline
\end{tabular}

Elaboración propia

\subsubsection{Presupuesto de Estado de Situación Financiera (apertura)}

El estado de situación financiera es una visión de cómo está la empresa financieramente en un momento determinado. Para realizar el estado de situación financiera se tomaron solamente los puntos que se necesita cuando la empresa comience a operar. 
Tabla 7.20

Estado de situación financiera (apertura)

\section{Activo}

\section{Activo Corriente}

Cap. Trabajo (Efectivo y equivalentes)

S/. 249476

S/. $\quad 249476$

Total Activo Corriente

\section{Activo No Corriente}

Terreno

S/. $\quad 582750$

Maquinaria y equipo

Mobiliario

Administrativo

Estudio de Pre-

factibilidad

Estudio de Factibilidad

Puesta en Marcha

Contingencia

Construcción

Total Activo No

Corriente

S/. $\quad 226437$

S/. $\quad 25000$

S/. $\quad 7000$

S/. $\quad 9000$

S/. $\quad 11000$

S/. $\quad 3000$

S/. $\quad 80000$

S/. $\quad 944187$
Capital Social

Total Patrimonio

S/. 1193663
S/. $\quad 397888$

Total Pasivo No

Corriente

S/. $\quad 397888$

Total Pasivo

S/. $\quad 477465$

Cuenta por Pagar
Patrimonio

Pasivo

Pasivo Corriente

\section{Pasivo No corriente}

Patrimonio

Total Activo

Elaboración propia 


\subsubsection{Flujo de fondos netos}

\subsubsection{Flujo de fondos económicos}

A continuación, se muestra el flujo de fondos económico con los montos hallados en los puntos anteriores.

Tabla 7.21

Flujo de fondos económico

\begin{tabular}{|c|c|c|c|c|c|c|c|c|c|c|c|c|c|c|}
\hline FFE & & 2018 & & 2019 & & 2020 & & 2021 & & 022 & & 023 & & 2024 \\
\hline Ut. Neta & & & $\mathrm{S} /$. & 253608 & $\mathrm{~S} /$. & 306965 & $\mathrm{~S} /$. & 360428 & S/. & 413874 & $\mathrm{~S} /$. & 467183 & S/. & 957697 \\
\hline Inversión & $\mathrm{S} /$. & -1193663 & & & & & & & & & & & & \\
\hline Dep.y Amort. & & & $\mathrm{S} /$. & 38373 & $\mathrm{~S} /$. & 38373 & $\mathrm{~S} /$. & 38373 & $\mathrm{~S} /$. & 38373 & $\mathrm{~S} /$. & 38373 & $\mathrm{~S} /$. & 38373 \\
\hline Valor Libro & & & & & & & & & & & & & $\mathrm{S} /$. & 131199 \\
\hline Cap. Trabajo & & & & & & & & & & & & & $\mathrm{S} /$. & 249476 \\
\hline Gast. Financiero & & & $\mathrm{S} /$. & 41210 & $\mathrm{~S} /$. & 34342 & $\mathrm{~S} /$. & 27473 & $\mathrm{~S} /$. & 20605 & $\mathrm{~S} /$. & 13737 & $\mathrm{~S} /$. & 6868 \\
\hline FFE & S/. & -1193663 & S/. & 333191 & S/. & 379679 & $\mathrm{~S} /$. & 426274 & S/. & 472852 & S/. & 519293 & S/. & 1383613 \\
\hline Flujo Actualizado & $\mathrm{S} /$. & -1193663 & S/. & 286247 & S/. & 326185 & $\mathrm{~S} /$. & 366215 & $\mathrm{~S} /$. & 406230 & $\mathrm{~S} /$. & 446128 & $\mathrm{~S} /$. & 1.188671 \\
\hline Flujo Acumulado & $\mathrm{S} /$. & -1193663 & $\mathrm{~S} /$. & -907417 & S/. & -581232 & S/. & -215017 & $\mathrm{~S} /$. & 191214 & S/. & 637342 & S/. & 1826013 \\
\hline
\end{tabular}

Elaboración propia

Como se puede observar el capital es negativo hasta el año 2021, es decir, la recuperación de la inversión se puede realizar en tres años. El valor presente del dinero ingresado al año 2024 es de 1826013 soles con un COK de 18,56\%. 


\subsubsection{Flujo de fondos financieros}

Para los flujos de fondos financieros se tomará en cuenta la deuda adquirida en el banco, principalmente la amortización del préstamo de cada uno durante los seis años.

\section{Tabla 7.22}

Flujo de fondos financieros

\begin{tabular}{|c|c|c|c|c|c|c|c|c|c|c|c|c|c|c|}
\hline FFF & & 2018 & & 2019 & & 2020 & & 2021 & & 2022 & & 2023 & & 2024 \\
\hline Ut. Neta & & & $\mathrm{S} /$. & 253608 & $\mathrm{~S} /$. & 306965 & $\mathrm{~S} /$. & 360428 & $\mathrm{~S} /$. & 413874 & $\mathrm{~S} /$. & 467183 & $\mathrm{~S} /$. & 957697 \\
\hline Inversión & $\mathrm{S} /$. & -1193663 & & & & & & & & & & & & \\
\hline Deuda & $\mathrm{S} /$. & 477465 & & & & & & & & & & & & \\
\hline Dep.y Amort. & & & $\mathrm{S} /$. & 38373 & $\mathrm{~S} /$. & 38373 & $\mathrm{~S} /$. & 38373 & $\mathrm{~S} /$. & 38373 & $\mathrm{~S} /$. & 38373 & $\mathrm{~S} /$. & 38373 \\
\hline Valor Libro & & & & & & & & & & & & & $\mathrm{S} /$. & 131199 \\
\hline Cap. Trabajo & & & & & & & & & & & & & $\mathrm{S} /$. & 249476 \\
\hline Amort. Deuda & & & $\mathrm{S} /$. & -79578 & $\mathrm{~S} /$. & -79578 & $\mathrm{~S} /$. & -79578 & $\mathrm{~S} /$. & -79578 & $\mathrm{~S} /$. & -79578 & $\mathrm{~S} /$. & -79578 \\
\hline FFF & S/. & -716198 & S/. & 212403 & S/. & 265760 & $\mathrm{~S} /$. & 319223 & $\mathbf{S} /$. & 372670 & $\mathrm{~S} /$. & 425979 & S/. & 1297167 \\
\hline Flujo Actualizado & $\mathrm{S} /$. & -716198 & $\mathrm{~S} /$. & 182477 & $\mathrm{~S} /$. & 228316 & $\mathrm{~S} /$. & 274247 & $\mathrm{~S} /$. & 320163 & $\mathrm{~S} /$. & 365961 & $\mathrm{~S} /$. & 1114405 \\
\hline Flujo Acumulado & $\mathrm{S} /$. & -716198 & $\mathrm{~S} /$. & -533721 & $\mathrm{~S} /$. & -305404 & $\mathrm{~S} /$. & -31158 & $\mathrm{~S} /$. & 289005 & $\mathrm{~S} /$. & 654966 & $\mathrm{~S} /$. & 1769371 \\
\hline
\end{tabular}

Elaboración propia

Como se puede observar, el capital solo es negativo hasta el año 2020. Eso quiere decir que la inversión hecha se puede recuperar en dos años. El valor presente del dinero ingresado a la empresa para el año 2024 es de S/ 1769371 con un COK de 18,56\%. 


\subsection{Evaluación Económica y Financiera}

Para este punto se evaluará los aspectos económicos y financieros de la empresa mediante indicadores. Para ello, se tomará en consideración el COK el cual viene a ser el retorno esperado por los inversionistas.

$\mathrm{COK}=\mathrm{RF}+\mathrm{B} *(\mathrm{RM}-\mathrm{RF})+\mathrm{RPAIS}$

Dónde:

B: el factor de riesgo, que viene a ser la cantidad de riesgo con respecto al portafolio de empresas en el mercado. Este valor viene a ser 0,89 (Emerging Market, 2019)

RF: tasa libre de riesgo, es el valor que muestra el riesgo libre. Este valor vendrá a ser 2,25\% (Bloomberg, 2019)

RM: es la tasa promedio de mercado, la rentabilidad promedio de las empresas más representativas del mercado es $19,13 \%$

RPAIS: La tasa RPAIS para junio 2019 es 1,28\% (BCRP, 2019)

Se dará como resultado que un COK de 18,56\%.

Para la evaluación económica se analizará los indicadores valor actual neto económico (VANE), tasa interna de retorno económica (TIR), relación beneficio costo (B/C) y el periodo de recupero (PR).

\subsubsection{Evaluación económica: VAN, TIR, B/C, PR}

Con el costo de oportunidad indicado, se realizó la evaluación económica de los flujos económicos, determinando para ello los siguientes indicadores:

Tabla 7.23

Indicadores de la evaluación económica

\begin{tabular}{lr}
\hline VANE & S/. 572817 \\
TIRE & $32,29 \%$ \\
B/C & 1,94 \\
P.R. (Años) & 3,53 \\
\hline
\end{tabular}

Elaboración propia 
- VANE:

El valor actual económico neto es el valor actual del dinero que tiene la empresa, originados por la inversión inicial. Este se calcula trayendo los valores del dinero de cada año al valor que el dinero tuviera en la actualidad y restándole la inversión del año 0. El VANE para este caso es S/ 572817 lo cual es positivo.

- TIRE:

La tasa interna de retorno económica es el rendimiento futuro que se espera que dé la inversión. Este se calcula con los flujos finales de cada año. El TIR presenta un valor de $32,29 \%$, lo cual quiere decir que la inversión que se realice dará un rendimiento de $32,29 \%$.

- $\mathrm{B} / \mathrm{C}$ :

La relación de beneficio costo económica es un indicador que refleja cuanto es el beneficio que da un sol invertido en el proyecto. El indicador dio un valor de 1,94, lo cual quiere decir que por cada sol invertido en el proyecto el beneficio será de 1,94.

- P.R.:

El periodo de recupero económico es el lapso de tiempo a transcurrir para poder recuperar la inversión que se hizo en el año 0 . El periodo de recupero muestra un valor de 3,53, lo cual quiere decir que en ese tiempo en años se empezará a tener ganancias.

\subsubsection{Evaluación financiera: VAN, TIR, B/C, PR}

Para la evaluación financiera se utilizará el mismo costo de oportunidad que la evaluación económica y los flujos de fondos financieros.

Tabla 7.24

Indicadores de la evaluación financiera

\begin{tabular}{lr}
\hline VANF & S/. 681401 \\
TIRF & $42,02 \%$ \\
B/C & 3,04 \\
P.R. (Años) & 3,10 \\
\hline
\end{tabular}

Elaboración propia 
- VANF:

El valor actual financiero neto es el valor actual del dinero que tiene la empresa, originados por la inversión inicial. Este se calcula trayendo los valores del dinero de cada año al valor que el dinero tuviera en la actualidad y restándole la inversión del año 0. El VANE para este caso es S/ 681401 lo cual es positivo.

- TIRF:

La tasa interna de retorno financiero es el rendimiento futuro esperado que dará la inversión. Este se calcula con los flujos finales de cada año. El TIR presenta un valor de $42,02 \%$, lo cual quiere decir que la inversión que se realice dará un rendimiento de $42,02 \%$.

- $\mathrm{B} / \mathrm{C}$ :

La relación de beneficio costo financiero es un indicador que representa cuanto es el beneficio que da un sol invertido en el proyecto. El indicador dio un valor de 3,04, lo cual quiere decir que por cada sol invertido en el proyecto el beneficio será de 3,04.

- P.R.:

El periodo de recupero financiero es el lapso de tiempo a transcurrir para poder recuperar la inversión que se hizo en el año 0. El periodo de recupero muestra un valor de 3,10, lo cual quiere decir que en ese tiempo en años se empezará a tener ganancias. 
7.5.3. Análisis de ratios (liquidez, solvencia, rentabilidad) e indicadores económicos $y$ financieros del proyecto

El análisis de ratios permite a evaluar cómo se encuentra la empresa en términos financieros. A continuación, se muestran los ratios de liquidez, solvencia y rentabilidad.

a. Liquidez

ANÁLISIS DE LIQUIDEZ

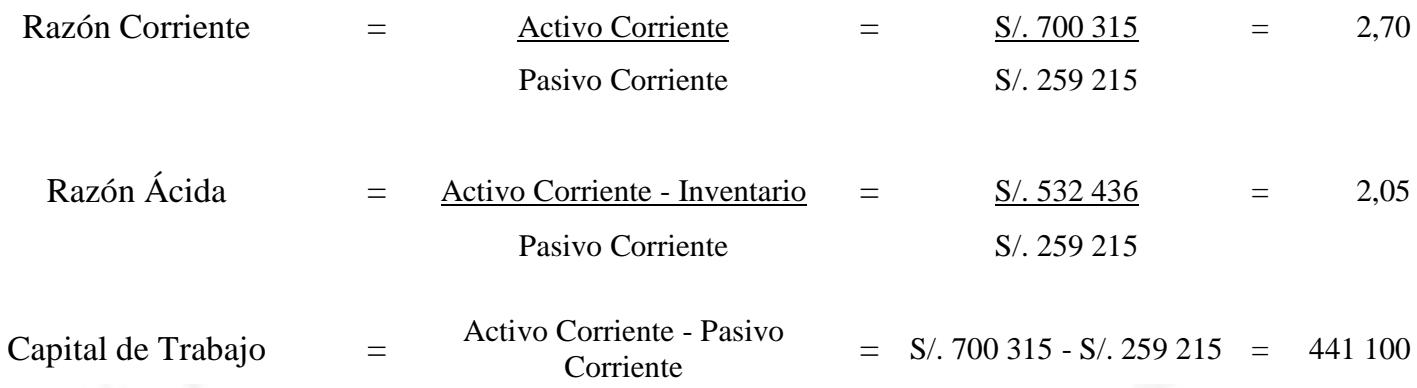

- Razón corriente: Ratio que mide la capacidad de la empresa para poder rendir cuenta de sus obligaciones a corto plazo. La razón corriente es de 2,70 lo cual quiere decir que por cada $\mathrm{S} / 1,00$ de deuda a pagar se tiene S/ 2,70 para afrontar las deudas a corto plazo.

- Razón ácida: Ratio que mide la liquidez neta de la empresa, puesto que deja de lado los inventarios en el activo. El valor del ratio es de 2,05, lo cual quiere decir que por cada $\mathrm{S} / 1,00$ de deuda se tiene $\mathrm{S} / 2,05$ para afrontar sus deudas a corto plazo.

- Capital de trabajo: Índice que mide los recursos que posee la empresa para poder funcionar y posteriormente, cubrir sus obligaciones a corto plazo. Se muestra un valor de 441100 soles lo cual dice que la empresa posee dicha cantidad de dinero para necesidades u operaciones, luego de cubrir sus deudas a corto plazo. 


\section{b. Solvencia}

ANÁLISIS DE SOLVENCIA

\begin{tabular}{|c|c|c|c|c|c|c|}
\hline Solvencia Total & $=$ & Activo Total & $=$ & S/. 1626909 & $=$ & 2,48 \\
\hline & & Pasivo Total & & S/. 657103 & & \\
\hline Razón de Endeudamiento & $=$ & $\frac{\text { Pasivo Total }}{\text { Activo Total }}$ & $=$ & $\frac{S / .657103}{S / .1626909}$ & $=$ & $40 \%$ \\
\hline Razón Deuda Patrimonio & $=$ & $\frac{\text { Pasivo Total }}{\text { Patrimonio Neto }}$ & $=$ & $\frac{\mathrm{S} / .657103}{\mathrm{~S} / .969806}$ & $=$ & 0,68 \\
\hline Calidad de Deuda & $=$ & $\frac{\text { Pasivo Corriente }}{\text { Pasivo Total }}$ & $=$ & $\frac{S / .259215}{S / .657103}$ & $=$ & 39 \\
\hline
\end{tabular}

- Solvencia total: Ratio que mide la capacidad de la empresa para poder hacer frente y cubrir sus obligaciones totales de pago. El ratio muestra un valor de 2,48, el cual quiere decir que por cada $S / 1,00$ de deuda que hay, se tiene S/ 2,48 para afrontar dichas deudas.

- Razón de endeudamiento: Indicador que muestra la cantidad de activos que son financiados por terceros. El valor del indicador es $40 \%$, lo cual quiere decir que del $100 \%$ de los activos que posee la empresa, el $40 \%$ son financiados por terceros.

- Razón deuda patrimonio: Ratio que deja ver la relación de la deuda total respecto al aporte de los propietarios. El valor obtenido es 0,68 lo cual indica que por cada S/ 1,00 de aporte de los accionistas se tiene una deuda de $S / 0,68$.

- Calidad de deuda: Ratio que permite medir el tipo de financiamiento que maneja la empresa. Este valor muestra un $39 \%$, que quiere decir que mayormente la empresa usa financiamiento a largo plazo. 


\section{c. Rentabilidad}

ANÁLISIS DE RENTABILIDAD

\begin{tabular}{|c|c|c|c|c|c|c|}
\hline \multirow[t]{2}{*}{$\begin{array}{l}\text { Rentabilidad Bruta } \\
\text { sobre Ventas }\end{array}$} & \multirow[t]{2}{*}{$=$} & Ventas - Costo de Ventas & \multirow[t]{2}{*}{$=$} & S/. 2235855 - S/. 1071911 & \multirow[t]{2}{*}{$=$} & \multirow[t]{2}{*}{$52,06 \%$} \\
\hline & & Ventas & & S/. 2235855 & & \\
\hline \multirow[t]{2}{*}{$\begin{array}{c}\text { Rentabilidad Neta } \\
\text { sobre Ventas }\end{array}$} & $=$ & $\underline{\text { Utilidad Neta }}$ & $=$ & $\underline{\mathrm{S} / .253608}$ & $=$ & $11,34 \%$ \\
\hline & & Ventas Netas & & S/. 2235855 & & \\
\hline \multirow[t]{2}{*}{$\begin{array}{l}\text { Rentabilidad Neta } \\
\text { del Patrimonio }\end{array}$} & $=$ & $\underline{\text { Utilidad Neta }}$ & $=$ & $\underline{\text { S/. } 253608}$ & $=$ & $26,15 \%$ \\
\hline & & Patrimonio & & S/. 969806 & & \\
\hline \multirow[t]{2}{*}{$\begin{array}{l}\text { Rentabilidad Neta } \\
\text { sobre Activos }\end{array}$} & $=$ & $\underline{\text { Utilidad Neta }}$ & $=$ & $\underline{\mathrm{S} / .253608}$ & $=$ & $15,59 \%$ \\
\hline & & Activo Total & & S/. 1626909 & & \\
\hline
\end{tabular}

- Rentabilidad bruta sobre ventas: Representa la utilidad bruta respecto a las ventas efectuadas, es decir, el margen bruto. El valor obtenido es $52,06 \%$ lo cual quiere decir que del 100\% de ingresos de ventas, el 52,06\% representa utilidad bruta y el resto representa otros gastos de la empresa.

- Rentabilidad neta sobre ventas: Indica en que porcentaje las ventas se convierten en utilidad neta. El valor es de $11,34 \%$, lo cual quiere decir que del $100 \%$ de las ventas en un periodo, el $11,34 \%$ de este se convierte en utilidad neta para la empresa.

- Rentabilidad neta del patrimonio: Indicador que refleja la capacidad de la empresa para poder generar utilidades con la inversión aportada por los inversionistas, es decir, el retorno del capital del accionista. El valor obtenido de $26,15 \%$ quiere decir que del $100 \%$ de aporte de los accionistas, se genera una utilidad de $26,15 \%$ para el inversionista. Este valor es positivo puesto que el aporte del inversionista genera utilidades grandes para la empresa.

- Rentabilidad neta sobre activos: Indicador que permite medir la capacidad de los activos para generar utilidades. El valor hallado es 15,59\% lo cual quiere decir que del $100 \%$ de activos que tiene en la empresa, el $15,59 \%$ se convierte en utilidad neta para la empresa. 


\subsubsection{Análisis de sensibilidad del proyecto}

Como bien se conoce, el mercado puede cambiar por diferentes aspectos como puede ser la inflación, reducción de consumos, inestabilidad económica, entre otros. Todo ello implicaría un determinado riesgo en la rentabilidad pronosticada.

El análisis de sensibilidad es un aspecto a tomar en cuenta puesto que este análisis ayuda a poder observar diferentes escenarios a los cuales la empresa se puede enfrentar.

\section{Tabla 7.25}

Tipos de escenario

\begin{tabular}{lcc}
\hline Escenario & Probabilidad & Var. Ventas \\
\hline Pesimista & $20,0 \%$ & $0.85 *$ Ventas \\
Medio & $50,0 \%$ & Ventas \\
Optimista & $30,0 \%$ & $1.15 *$ Ventas \\
\hline
\end{tabular}

Elaboración propia

Con estas variaciones en las ventas se presentan a continuación los ratios económicos y financiero.

Tabla 7.26

Indicadores Ponderados

\begin{tabular}{|c|c|c|c|c|c|}
\hline Escenario & Probabilidad & VANE & TIRE & VANF & TIRF \\
\hline Pesimista & $20 \%$ & S/. $\quad-505919$ & $10,1 \%$ & S/. $\quad-393687$ & $10,8 \%$ \\
\hline Medio & $50 \%$ & S/. $\quad 572817$ & $32 \%$ & S/. $\quad 681401$ & $42 \%$ \\
\hline Optimista & $30 \%$ & S/. 1303588 & $49 \%$ & S/. 1670571 & $67 \%$ \\
\hline TOTAL & $100 \%$ & S/. 576301 & $32 \%$ & S/. $\quad 763134$ & $42 \%$ \\
\hline
\end{tabular}

Elaboración propia

Con esto se puede observar que en casi todos los distintos escenarios se obtiene resultados positivos que la empresa refleja por su buen manejo de actividades. 


\section{CAPÍTULO VIII: EVALUACIÓN SOCIAL DEL PROYECTO}

\subsection{Indicadores Sociales}

Se definió que la producción de la bebida a base de hierbas medicinales se efectuará en Lurín y la comercialización se concentrará en Lima. Esto traerá beneficios en estas dos locaciones puesto o que generaran más puestos de trabajo (Lurín) y aumentaran los ingresos de las instituciones donde se vendan (Lima).

\subsection{Interpretación de indicadores Sociales}

Se calculará el valor agregado, el valor económico que adquiere el bien que se produce en la transformación de la materia prima en producto terminado. A continuación, se mostrará las dos formas en cómo se puede calcular este indicador:

Tabla 8.1

Valor Agregado Opción 1

\begin{tabular}{|c|c|c|c|c|c|c|}
\hline Año & 2019 & 2020 & 2021 & 2022 & 2023 & 2024 \\
\hline MO & S/. 250199 & S/. 250199 & S/. 250199 & S/. 250199 & S/. 250199 & S/. 250199 \\
\hline CIF & S/. 230326 & S/. 230326 & S/. 230326 & S/. 230326 & S/. 230326 & S/. 230326 \\
\hline $\begin{array}{l}\text { Gastos } \\
\text { Administrativos }\end{array}$ & S/ 492274 & S/. 492274 & S/. 492274 & S/. 492274 & S/. 492274 & S/. 492274 \\
\hline $\begin{array}{l}\text { Gastos } \\
\text { Operativos }\end{array}$ & S/. 165518 & S/. 171666 & S/. 177828 & S/. 183988 & S/. 190130 & S/. 200128 \\
\hline $\begin{array}{l}\text { Gastos } \\
\text { Financieros }\end{array}$ & S/. $\quad 58871$ & S/. 49060 & 39248 & 29436 & S/. 19624 & 9812 \\
\hline $\begin{array}{l}\text { Valor Neto en } \\
\text { Libros }\end{array}$ & & & & & & S/. 131199 \\
\hline $\begin{array}{l}\text { Valor de } \\
\text { Mercado }\end{array}$ & & & & & & S/. 849414 \\
\hline Participación & S/. $\quad 44728$ & 54138 & 63568 & 72994 & 82396 & S/. 168906 \\
\hline Impuesto & S/. 120766 & S/. 146174 & 171632 & 197083 & S/. 222468 & S/. 456046 \\
\hline Reserva legal & 28179 & 34107 & 40048 & 45986 & 51909 & S/. 106411 \\
\hline Utilidad Neta & S/. 253608 & S/. 306965 & S/. 360428 & 413874 & S/. 467183 & S/. 957697 \\
\hline Valor Agregado & S/.1 644468 & S/.1 734908 & S/. 1825549 & S/. 1916159 & S/.2 006508 & S/. 2153582 \\
\hline Valor Agregado & S/.7 709 & & & & & \\
\hline
\end{tabular}

Elaboración propia 
Tabla 8.2

Valor Agregado Opción 2

\begin{tabular}{|c|c|c|c|c|c|c|}
\hline Año & 2019 & 2020 & 2021 & 2022 & 2023 & 2024 \\
\hline Ventas & S/. 2235855 & S/. 2358819 & S/. 2482057 & S/. 2605251 & S/. 2728093 & S/. 2928058 \\
\hline MP & S/. 591387 & S/. $\quad 623911$ & S/. $\quad 656508$ & S/. $\quad 689093$ & S/. 721584 & S/. $\quad 774475$ \\
\hline $\begin{array}{l}\text { Valor } \\
\text { Agregado }\end{array}$ & S/. 1644468 & S/. 1734908 & S/. 1825549 & S/. 1916159 & S/. 2006508 & S/. 2153582 \\
\hline $\begin{array}{l}\text { Valor } \\
\text { Agregado }\end{array}$ & S/. 7709454 & & & & & \\
\hline
\end{tabular}

Elaboración propia

El primer indicador que se calculará será la densidad de capital, el cual señala la relación que hay entre la inversión del capital con el número de empleados.

Densidad de Capital $=\frac{\text { Inversión Total }}{\text { Empleados }}=\frac{\mathrm{S} / .1193663}{26}=45910$

El valor dio como resultado 45910 soles, lo cual quiere decir que para generar un puesto de trabajo se necesita una inversión aproximada de S/ 45 910. Se puede indicar que este indicador se debe a que la empresa es semi automatizada.

Otro indicador a evaluar es el de la intensidad de capital. Este indicador refleja la relación que tiene la inversión que se genera del proyecto respecto al valor agregado que da el proceso al producto. Con esto se podrá medir el grado de aporte que tiene el proyecto:

$\begin{aligned} & \text { Intensidad de } \\ & \text { Capital }\end{aligned} \quad \begin{aligned} & \text { Inversión Total } \\ & \text { Valor Agregado }\end{aligned}=\quad \frac{\mathrm{S} / .1193663}{\mathrm{~S} / .7709454}=0,15$

Este indicador muestra un resultado de 0,15 , lo cual quiere decir que para poder dar S/ 1,00 de valor al producto en toda su transformación se requiere invertir S/ 0,15. Se ve que este valor es óptimo, puesto que la inversión es poca para que el producto obtenga mayor valor. 
Otro indicador importante a evaluar es el producto capital o también llamado coeficiente de capital, que mide la relación que existe entre el valor agregado del producto y la inversión total que se efectúa en el proyecto.

Producto Capital $=\frac{\text { Valor Agregado }}{\text { Inversión Total }}=\frac{\underline{S} / .7709454}{S / .1193663}=6,46$

Se puede visualizar que el valor del indicador es 6,46, lo cual quiere decir que por cada $S / 1,00$ que se invierte, se genera un valor adicional al producto de $S / 6,46$. Este indicador es óptimo puesto que el valor agregado por cada sol de inversión es alto. Se estima y espera que este valor incremento a lo largo del proyecto.

Por último, la productividad de M.O. es un ratio que indica cuantos productos son generados por un puesto de trabajo, sea aporte directo o indirecto.

Productividad M.O. $=\frac{\text { Producción Anual }}{\text { Puesto Generados }}=\frac{1508250}{26}=58010$

Se puede observar que el indicador es 58010 unidades, lo cual quiere decir que por un puesto se contribuye a generar 58010 unidades de producto terminado. Se ve que este indicador es positivo puesto que la producción por persona es alta. Se estima que este indicador tienda a crecer para poder aumentar así la productividad de la empresa.

Con todos los indicadores sociales se puede observar que la empresa da grandes beneficios para la sociedad. 


\section{CONCLUSIONES}

A continuación, se detallarán las conclusiones:

- Se concluye que la ejecución del proyecto de instalación de una planta productora de bebidas a base de hierbas medicinales presenta una viabilidad de mercado, tecnológica, financiera y social. Además, se prevé un crecimiento en la demanda para los próximos años.

- La mejor localización de planta de producción y envasado de bebidas a base de hierbas medicinales es Lurín, debido a las facilidades de vías de acceso, la cercanía al mercado final, calidad de los servicios y menores costos.

- En cuanto a la tecnología, se concluyó que el proceso de producción no es muy complicado y no requiere de mucha especialización; sin embargo, es necesario contar con maquinaria adecuada para garantizar la preservación del producto final. Además, fue necesario conocer las diferentes tecnologías con el que se realiza la producción de la bebida y de esta forma se eligió la más adecuada y rentable para el proyecto.

- A través del análisis de flujo de fondos económico y financiero, se determinó que resulta más rentable incurrir en un financiamiento para cubrir parte de la inversión. Esto contribuye a obtener un mejor VAN y una TIR mayor que si se cubriera la inversión solo con capital propio.

- Se concluye que la ejecución del proyecto presenta una viabilidad social pues los indicadores demuestran un impacto social favorable en la zona donde se prevé instalar la planta de producción.

- Se puede desarrollar el presente proyecto realizando la compra directa de las materias primas además de buscar alianzas estratégicas con los mismos productores y así asegurar.

- La disponibilidad de las materias no es un problema debido a que el Perú es un país rico en producción de hierbas medicinales. 


\section{RECOMENDACIONES}

A continuación, se detallarán las recomendaciones:

- Es necesario evaluar la posibilidad de incursionar en otros sectores para poder ampliar la cobertura del mercado

- Evaluar las diferencias en la demanda al presentar el producto en distinto volumen, por ejemplo, en una presentación más pequeña.

- Ratificar mediante un estudio de factibilidad los resultados obtenidos en el presente proyecto.

- Evaluar la posibilidad de la existencia del producto fuera de lima, así como a nivel internacional.

- Analizar la introducción de nuevas hierbas medicinales que tengan otras características curativas.

- La empresa debe de contar con procedimientos y manual de funciones para los operarios, para poder estandarizar los procesos y conseguir mejores resultados en el producto.

- Como estrategia de marketing, realizar ofertas con otros productos complementarios para incrementar las ventas

- Se recomienda que para garantizar una mejor calidad en el producto se establezcan relaciones con los proveedores de la materia prima como brindar asesoramiento a los agricultores para el mejoramiento de los cultivos. De esta manera, se garantizaría la calidad y también se reduciría el número de mermas que se pueda generar durante la operación de selección. 


\section{REFERENCIAS}

Adondevivir. (Junio de 2019). Recuperado de www.adondevivir.com

Aguasistec. (Junio de 2019). Recuperado de http://www.aguasistec.com/filtro-de-carbonactivado.php

Aliaga Paredes, Elio. (2017). Estudio de prefactibilidad para la instalación de una planta de producción de bolsas de manzanilla común. Lima, Perú: Universidad de Lima.

Apeim. (2016). Recuperado de http://apeim.com.pe/

Araujo, F. (2017). Estudio de prefactibilidad para la instalación de una planta productora de bebida de té verde con aloe vera y miel dirigido al mercado de Lima Metropolitana. Lima.

Banco Central de Reserva del Perú. (14 de Junio de 2019). Recuperado de https://estadisticas.bcrp.gob.pe/estadisticas/series/diarias/resultados/PD04709XD/ht $\mathrm{ml}$

Bloomberg. (Junio de 2019). Recuperado de https://www.bloomberg.com/

Celiz Castillo, Hernán. (1991). Estudio de prefactibilidad para la instalación de una fáfrica de bolsitas filtrantes de plantas medicinales. Lima, Perú: Universidad de Lima.

Collazos Acosta, Daniel. (2018). Estudio de prefactibilidad para la implementación de una fáfrica para la elaboración de bebida de Aloe Vera. Lima, Perú: Universidad de Lima.

Colliers International. (2017). Recuperado de https://www2.colliers.com/es-pe

Comek. (Mayo de 2019). Recuperado de http://www.comek.com.co/

Consejo Nacional de Ciencia, Tecnología e Innovación Tecnológica. (2019). CONCYTEC Publicaciones. Recuperado de http://portal.concytec.gob.pe/

Díaz, B., y Teresa, M. (2017). Manual para el diseño de instalaciones manufactureras y de servicios. Lima: Fondo Editorial Universiadad de Lima.

Enel. (2019). Recuperado de https://www.enel.pe/es/ayuda/tarifas.html

Equipment. (Junio de 2019). Recuperado de https://www.equipnet.com/es/category/tanques43161/?https://www.equipnet.com/\&gclid=EAlalQobChMI1MPQ1NbV4gIVBOSGChOM SQ7TEAAYAiAAEgI45_D_BwE

Estadístico, P. c. (Junio de 2019). Perú compendio estadístico. 
Euromonitor International. (Mayo de 2019). Euromonitor International. Recuperado de http://www.portal.euromonitor.com/

Franco López, A. (2009). Estudio Preliminar para la instalación de una planta procesadora de conserva de mango. Lima, Perú: Universidad de Lima.

Gallardo Barzola, Cynthia. (2014). Estudio de prefactibilidad para la instalación de una planta productora de jugo bebible de verduras. Lima, Perú: Universidad de Lima.

Google Maps. (2019). Recuperado de https://www.google.com.pe/maps/

Incalfer. (Junio de 2019). Recuperado de https://www.incalfer.com/lavadoras/

Instituto Nacional de Estadística e Informática. (Diciembre de 2018). Recuperado el 05 de Mayo de 2015, de http://www.inei.gob.pe/biblioteca-virtual/boletines/pbitrimestral/1/

Instituto Nacional de Estadística e Informática. (2019). INEI - Perú en cifras. Recuperado de http://www.inei.gob.pe/

Ipsos. (2019). Recuperado de https://www.ipsos.com/es-pe

Joy light industry. (2018). Recuperado de https://shchenghuan.en.alibaba.com/

kyansac. (Junio de 2019). Recuperado de http://kyansac.com/2017/10/19/tanques-de-aceroinoxidable-lima-peru/

Lindley. (2018). Recuperado de https://www.arcacontinentallindley.pe/

Lipton. (2018). Recuperado de https://www.lipton.com/us/en/home.html

Luz del Sur. (2019). Luz del Sur. Recuperado de https://www.luzdelsur.com.pe/media/pdf/tarifas/TARIFAS.pdf

Maquinova. (Junio de 2019). Recuperado de http://maquinova.es/reprensentacionsuministros-industrial-construccion-seguridad-laboral-ferreteria/

Ministerio de Agricultura y Riego. (2019).MINAGRI. Recuperado de https://www.minagri.gob.pe/portal/inicio

Ministerio de energía y minas. (2018). MINEM - Publicaciones. Recuperado de http://www.minem.gob.pe/

Ministerio de la Producción. (2018). Ministerio de la Producción. Recuperado de http://www.produce.gob.pe/

Ministerio de Trabajo. (2018). Recuperado de https://www.gob.pe/mtpe

Ministerio de transporte y comunicaciones. (2018). MTC - Estadísticas y mapas. Recuperado de http://www.mtc.gob.pe/portal/inicio.html 
Ocpuritech. (Junio de 2019). Recuperado de https://www.ocpuritech.com/product

Organismo supervisorde la inversión en energía y minería. (Mayo de 2019). Osinergmin. Recuperado de http://www.osinergmin.gob.pe/

Owens Illinois. (2018). Recuperado de https://www.o-i.com/es/

Pedro, A. (2016). Ingeniería Econónmica: ¿Cómo medir la rentabilidad de un proyecto? Lima: Universidad de Lima.

Pesatec. (Junio de 2019). Recuperado de https://pesatec.com/product-category/balanzaspara-estoca/

Saravia Quispe, Diego. (2014). Estudio de prefactibilidad para la producción y comercialización de néctar de ajonjolí en Lima metropolitana. Lima, Perú: Universidad de Lima.

Servicio de agua potable y alcantarillado. (Mayo de 2019). Recuperado de http://www.sedapal.com.pe/

Servinox. (Junio de 2019). Recuperado de http://www.servinox.com.mx/catalogo/aceroinoxidable/mesas-de-trabajo/

Spanish Alibaba. (Junio de 2019). Recuperado de http://spanish.alibaba.com/Favorite/bandastransportadoras-para-alimentos.html

SUNAT. (2019). Superintencia Nacional de Aduana y Administración Tribtaria. Recuperado de http://www.sunat.gob.pe/

Superintendencia de banca y seguros. (Junio de 2019). Recuperado de http://www.sbs.gob.pe/app/pp/EstadisticasSAEEPortal/Paginas/TIActivaTipoCreditoE mpresa.aspx?tip $=$ B

Superintendencia nacional de servicios de saneamiento. (Junio de 2019). SUNASS. Recuperado de http://www.sunass.gob.pe/

Transhuamali. (2019). Recuperado de http://transhuamalieirl.com/

Unimaq. (Junio de 2019). Recuperado de http://www.unimaq.com.pe/equipos-nuevos

Valencia, R. (2018). Estudio de prefactibilidad para la implementación de una fábrica para la elaboración de bebida de ale vera. Lima.

Veritrade. (Junio de 2019). Recuperado el 15 de Abril de 2015, de http://business.veritrade.info/Veritrade/MyVeritrade.aspx 


\section{BIBLIOGRAFÍA}

Adondevivir. (Junio de 2019). Recuperado de www.adondevivir.com

Aguasistec. (Junio de 2019). Recuperado de http://www.aguasistec.com/filtro-de-carbonactivado.php

Apeim. (2016). Recuperado de http://apeim.com.pe/

Araujo, F. (2017). Estudio de prefactibilidad para la instalación de una planta productora de bebida de té verde con aloe vera y miel dirigido al mercado de Lima Metropolitana. Lima.

ASEMA. (2019). Sistema de Lavado. Recuperado de http://www.asema.com.ar/FOLLETOS/Asema\%20SA\%20Lavado\%20Frutas\%20y\%20Ho rtalizas.pdf

Astimec. (Junio de 2019). Recuperado de https://astimec.net/

Bandas transportadoras. (Junio de 2019). Recuperado de http://www.ropim.com/bandas_transportadoras.php

Basa. (Junio de 2019). Recuperado de http://www.basa.com.pe/agr\%C3\%ADcola/283-jabacosechera-ultra.html

Banco Central de Reserva del Perú. (14 de Junio de 2019). Recuperado de https://estadisticas.bcrp.gob.pe/estadisticas/series/diarias/resultados/PD04709XD/ht $\mathrm{ml}$

Banco Central de Reserva del Perú. (14 de Junio de 2019). Recuperado de http://www.bcrp.gob.pe/docs/Publicaciones/Revista-Moneda/moneda-151/moneda151-04.pdf

Bloomberg. (Junio de 2019). Recuperado de https://www.bloomberg.com/

Botanical. (Junio de 2019). Recuperado de http://www.botanicalonline.com/medicinalsmatricariacastella.htm

Calgoncarbon. (Junio de 2019). Recuperado de https://www.calgoncarbon.com/products/

CITALSA - Equipos y servicios de calidad. (Junio de 2019). Productos - Línea Agroindustrial. Recuperado de http://www.citalsa.com/ciproducts/5/338\#firstproduct

Colliers International. (2017). Recuperado de https://www2.colliers.com/es-pe

Comek. (Mayo de 2019). Recuperado de http://www.comek.com.co/ 
Consejo Nacional de Ciencia, Tecnología e Innovación Tecnológica. (2019). CONCYTEC -

Publicaciones. Recuperado de http://portal.concytec.gob.pe/

Crecemype. (Junio de 2019). Recuperado de http://www.crecemype.pe/

Díaz, B., y Teresa, M. (2017). Manual para el diseño de instalaciones manufactureras y de servicios. Lima: Fondo Editorial Universiadad de Lima.

Direct Industry. (Mayo de 2019). Recuperado de

http://www.directindustry.es/prod/smi/product-15003-382347.html

Emerging Market. (Junio de 2019). Recuperado de

https://www.google.com/search?q=beta+damodaran+emerging+market\&rlz=1C1CHB F_enPE789PE789\&oq=beta+damodaran+emerging+market\&aqs=chrome..69i57j0.481 7j0j3\&sourceid=chrome \&ie=UTF-8

Emprendedor.pe. (Mayo de 2019). Recuperado de http://emprendedor.pe/finanzas/490-tiposde-empresas-en-el-peru.html/

Enel. (2019). Recuperado de https://www.enel.pe/es/ayuda/tarifas.html

Equipment. (Junio de 2019). Recuperado de https://www.equipnet.com/es/category/tanques43161/?https://www.equipnet.com/\&gclid=EAlalQobChMI1MPQ1NbV4gIVBOSGChOM SQ7TEAAYAiAAEgI45_D_BwE

Estadístico, P. c. (Junio de 2019). Perú compendio estadístico.

Euromonitor International. (Mayo de 2019). Euromonitor International. Recuperado de http://www.portal.euromonitor.com/

Franco Lopez, A. (2009). Estudio Preliminar para la instalación de una planta procesadora de conserva de mango. Lima, Perú: Universidad de Lima.

Gedar. (Junio de 2019). Recuperado de https://www.gedar.com/industriales/osmosisinversas.htm

Google Maps. (2019). Recuperado de https://www.google.com.pe/maps/

Guiaenvase. (Junio de 2019). Recuperado de http://www.guiaenvase.com/bases/guiaenvase.nsf/V02wp/D24C96B9564E2A4EC1256 F250063FAA3?Opendocument

Hello Pro. (Junio de 2019). Recuperado de http://www.hellopro.es/Okata_Equipamiento_Industrial_S_A_-8876-noprofil1002148-10850-0-1-1-fr-societe.html

Hidroled. (Junio de 2019). Recuperado de http://hidroled.com/

Icbindustrial. (Junio de 2019). Recuperado de http://www.icbindustrial.com.pe/ Incalfer. (Junio de 2019). Recuperado de https://www.incalfer.com/lavadoras/ 
Instituto Nacional de Estadística e Informática. (Diciembre de 2018). Recuperado el 05 de Mayo de 2015, de http://www.inei.gob.pe/biblioteca-virtual/boletines/pbitrimestral/1/

Inkanal. (Junio de 2019). Recuperado de http://www.inkanat.com/es/infosalud/matecoca.html

Instituto nacional de estadistica e informática. (2019). INEI - Perú en cifras. Recuperado de http://www.inei.gob.pe/

Ipsos. (2019). Recuperado de https://www.ipsos.com/es-pe

Joy light industry. (2018). Recuperado de https://shchenghuan.en.alibaba.com/

kyansac. (Junio de 2019). Recuperado de http://kyansac.com/2017/10/19/tanques-de-aceroinoxidable-lima-peru/

Limtek. (Junio de 2019). Recuperado de www.limtek.com.pe

Lindley. (2018). Recuperado de https://www.arcacontinentallindley.pe/

Lipton. (2018). Recuperado de https://www.lipton.com/us/en/home.html

Luz del Sur. (2019). Luz del Sur. Recuperado de

https://www.luzdelsur.com.pe/media/pdf/tarifas/TARIFAS.pdf

Maprotec Perú. (Junio de 2019). Recuperado de http://www.maprotecperu.com.pe/

Maquinaria Workers. (Junio de 2019). Recuperado de http://www.maquinariaworkers.com/productos

Maquinova. (Junio de 2019). Recuperado de http://maquinova.es/reprensentacionsuministros-industrial-construccion-seguridad-laboral-ferreteria/

Mercado Libre Perú. (Junio de 2019). Recuperado de http://articulo.mercadolibre.com.pe/MPE-416407035-grupo-electrogeno-100kwiveco-italiano-231-horas-de-uso-_JM

Mercado Libre Perú. (Junio de 2019). Recuperado de http://articulo.mercadolibre.com.pe/MPE-416398654-transformadores-electricostrifasicos-_JM

Mercado Libre Perú. (Mayo de 2019). Recuperado de http://listado.mercadolibre.com.pe/salud-y-belleza/stevia-edulcorante-natural

MINAGRI. (2019). Ministerio de Agricultura y Riego. Recuperado de https://www.minagri.gob.pe/portal/inicio

Ministerio de energía y minas. (2018). MINEM - Publicaciones. Recuperado de http://www.minem.gob.pe/ 
Ministerio de la Producción. (2018). Ministerio de la Producción. Recuperado de http://www.produce.gob.pe/

Ministerio de Trabajo. (2018). Recuperado de https://www.gob.pe/mtpe

Ministerio de transporte y comunicaciones. (2018). MTC - Estadísticas y mapas. Recuperado de http://www.mtc.gob.pe/portal/inicio.html

Ocpuritech. (Junio de 2019). Recuperado de https://www.ocpuritech.com/product

Ordessa. (Junio de 2019). Recuperado de http://www.ordessa.es/tipos-de-membranas-deosmosis-inversa/

Organismo supervisorde la inversión en energía y minería. (Mayo de 2019). Osinergmin. Recuperado de http://www.osinergmin.gob.pe/

Osinerg. (Mayo de 2019). Recuperado de http://www.osinergmin.gob.pe/

Owens Illinois. (2018). Recuperado de https://www.o-i.com/es/

Pedro, A. (2016). Ingeniería Econónmica: ¿Cómo medir la rentabilidad de un proyecto? Lima: Universidad de Lima.

Pesatec. (Junio de 2019). Recuperado de https://pesatec.com/product-category/balanzaspara-estoca/

Ponticificia Universidad Católica del Perú. (Junio de 2019). Recuperado de http://www.pucp.edu.pe/climadecambios/index.php?tmpl=articulo\&id=1746

Precintadora. (Junio de 2019). Recuperado de https://www.interempresas.net/Envase/FeriaVirtual/Producto-Precintadora-rotativaAuxiemba-Premat-10-10-55816.html

Prosegur. (Mayo de 2019). Recuperado de www.seguridadprosegur.pe

Salud, M. (2019). Recuperado de http://www.imujer.com/salud/4947/usos-medicinales-de-lahoja-de-coca

Salud, M. d. (2019). Tablas peruanas de omposición de alimentos. Lima.

Servicio de agua potable y alcantarillado. (Mayo de 2019). Recuperado de http://www.sedapal.com.pe/

Servinox. (Junio de 2019). Recuperado de http://www.servinox.com.mx/catalogo/aceroinoxidable/mesas-de-trabajo/

Spanish Alibaba. (Junio de 2019). Recuperado de http://spanish.alibaba.com/Favorite/bandastransportadoras-para-alimentos.html

SUNAT. (2019). Superintencia Nacional de Aduana y Administración Tribtaria. Recuperado de http://www.sunat.gob.pe/ 
Superintendencia de banca y seguros. (Junio de 2019). Recuperado de http://www.sbs.gob.pe/app/pp/EstadisticasSAEEPortal/Paginas/TIActivaTipoCreditoE mpresa.aspx?tip=B

Superintendencia nacional de servicios de saneamiento. (Junio de 2019). SUNASS. Recuperado de http://www.sunass.gob.pe/

TerraTrans. (Junio de 2019). Recuperado de www.logisnet.com

Transhuamali. (2019). Recuperado de http://transhuamalieirl.com/

Unimaq. (Junio de 2019). Recuperado de http://www.unimaq.com.pe/equipos-nuevos

Valencia, R. (2018). Estudio de prefactibilidad para la implementación de una fábrica para la elaboración de bebida de ale vera. Lima.

Veritrade. (Junio de 2019). Recuperado el 15 de Abril de 2015, de http://business.veritrade.info/Veritrade/MyVeritrade.aspx

Zonadiel. (2019). Zonadiet. Recuperado de http://www.zonadiet.com/bebidas/te.htm 
ANEXOS 


\section{Anexo 1: Encuesta}

\section{ENCUESTA SOBRE BEBIDAS EN BASE A HIERBAS MEDICINALES}

La siguiente encuesta tiene objetivo conocer las características del mercado consumidor de bebidas a base de hierbas medicinales, por favor sírvase de contestar todas las preguntas, marcando con un aspa (x) las respuestas / en caso de redactar, letra legible.

1. ¿Cuál es su edad?

2. ¿Consume usted algún tipo de bebida natural?

$$
\text { Si ( ) } \quad 2 \text { No ( ) }
$$

3. ¿Con que frecuencia consume este tipo de bebida? (marcar solo una)
1 Diariamente ( )
3 Quincenalmente ( )
5 Ocasionalmente ( )
2 Semanalmente ( )
4 Mensualmente ( )

4. ¿Dónde acostumbra comprar este tipo de bebida? (marcar solo uno)
1 Supermercado ( )
3 Mercado ( )
2 Bodega ( )
4 Mayorista ( )

5 Otro:

5. ¿Cuánto paga generalmente por este tipo de producto?

$\mathrm{S} /$.

6. ¿Compraría una bebida a base de hierbas medicinales como la manzanilla, muña, romero y matico lista para beber?

$1 \mathrm{Si}() \quad 2 \mathrm{No}()$

7. ¿Hasta cuanto estaría dispuesto a pagar por una presentación de $475 \mathrm{ml}$. en envase de vidrio?

$$
\begin{aligned}
& 1[\mathrm{~S} / .1,50-\mathrm{S} / .2,00](\mathrm{)}) 2[\mathrm{~S} / .2,10-\mathrm{S} / .2,50](\mathrm{)}) 3[\mathrm{~S} / .2,60-\mathrm{S} / .3,00](\text { ) } \\
& 4[\mathrm{~S} / .3,10-\mathrm{S} / .4,00](\mathrm{)}
\end{aligned}
$$


8. Clasifique los siguientes atributos según su importancia en la compra de una bebida a base de hierbas medicinales, asignando un 5 al más importante, 4 al siguiente y así hasta asignar un 1 al menos importante.

$\begin{array}{ll}\text { Precio } & (\text { ) } \\ \text { Marca } & (\text { ) } \\ \text { Sabor } & (\text { ) } \\ \text { Envase } & (\text { ) } \\ \text { Promociones } & (\text { ) }\end{array}$

9. ¿Cuál es su grado de aceptación por este producto? (Siendo 10 el de mayor aceptación y 1 el de menor aceptación)

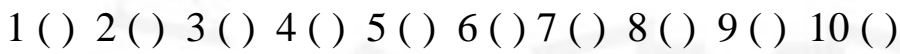

10. ¿En qué presentación y capacidad le gustaría adquirir el producto? (En caso de otro, especificar presentación y capacidad)

Vidrio de $1000 \mathrm{ml} \mathrm{(} \mathrm{)} \quad$ Tetra pack de $750 \mathrm{ml} \mathrm{(} \mathrm{)} \mathrm{Vidrio} \mathrm{de} 475 \mathrm{ml}$ ()

Plástico de $500 \mathrm{ml} \mathrm{(} \mathrm{)} \mathrm{Otro:}$

11. ¿Por cuales medios le sería más factible enterarse de este nuevo producto?

(Puede marcar más de uno) (En caso otro, especificar medio)

Periódico ( ) Televisión ( ) Radio ( ) Redes Sociales ( )

A. Publicitarios ( ) Otros:

Muchas gracias por tu tiempo, pronto tendrás en tus manos la nueva bebida Chachakuma 


\section{Anexo 2: Resultados de encuesta}

Tabulación de datos para el cálculo del K

Intención de compra

¿Compraría una bebida a base de hierbas medicinales como la manzanilla, muña, matico y romero?

\begin{tabular}{|c|c|}
\hline Respuesta & Frecuencia \\
\hline $\mathrm{Si}$ & 347 \\
\hline No & 37 \\
\hline Total de encuestados & 384 \\
\hline
\end{tabular}

Intención de compra $=347 / 384=90,36 \%$

Intensidad de compra

¿Cuál es su grado de aceptación por este producto? (Siendo 10 el de mayor aceptación y 1 el de menor aceptación)

\begin{tabular}{cccc}
\hline $\begin{array}{c}\text { Grado de } \\
\text { Intención }\end{array}$ & Frecuencia & Porcentaje & Total \\
\hline 1 & 5 & $1 \%$ & 0,07 \\
2 & 4 & $1 \%$ & 0,05 \\
3 & 8 & $2 \%$ & 0,18 \\
4 & 17 & $5 \%$ & 0,83 \\
5 & 26 & $7 \%$ & 1,95 \\
6 & 22 & $6 \%$ & 1,39 \\
7 & 85 & $24 \%$ & 20,82 \\
8 & 71 & $20 \%$ & 14,53 \\
9 & 63 & $18 \%$ & 11,44 \\
10 & 46 & $13 \%$ & 6,10 \\
\hline Total & 347 & $100 \%$ & \\
\hline
\end{tabular}

Cálculo del $\mathrm{K}=\mathbf{5 2 , 8 9 \%}$ 


\section{Anexo 3: Producción de las materias primas por departamento (2018)}

\begin{tabular}{c|ccc}
\cline { 2 - 4 } Kg & Ancash & Junín & Huánuco \\
\hline Manzanilla & 4821 & 7237 & 4956 \\
Matico & 2650 & 3171 & 2382 \\
Muña & 2067 & 2982 & 2157 \\
Romero & 2974 & 2861 & 1823 \\
\hline
\end{tabular}

Anexo 4: Muña

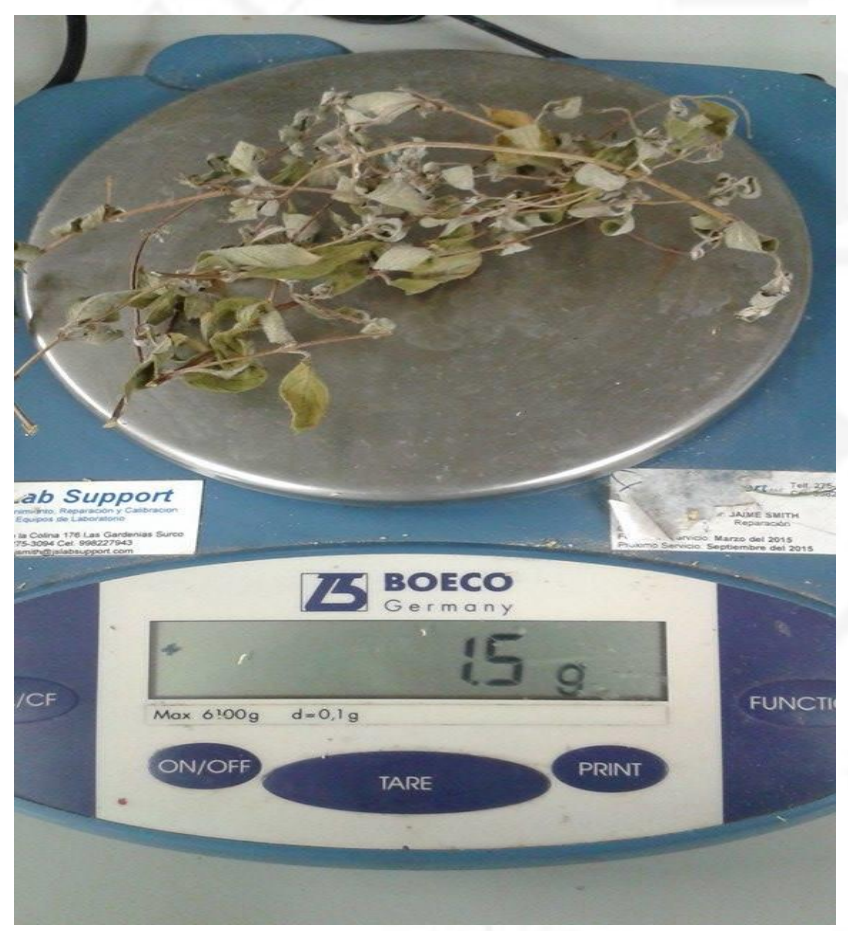




\section{Anexo 5: Manzanilla}

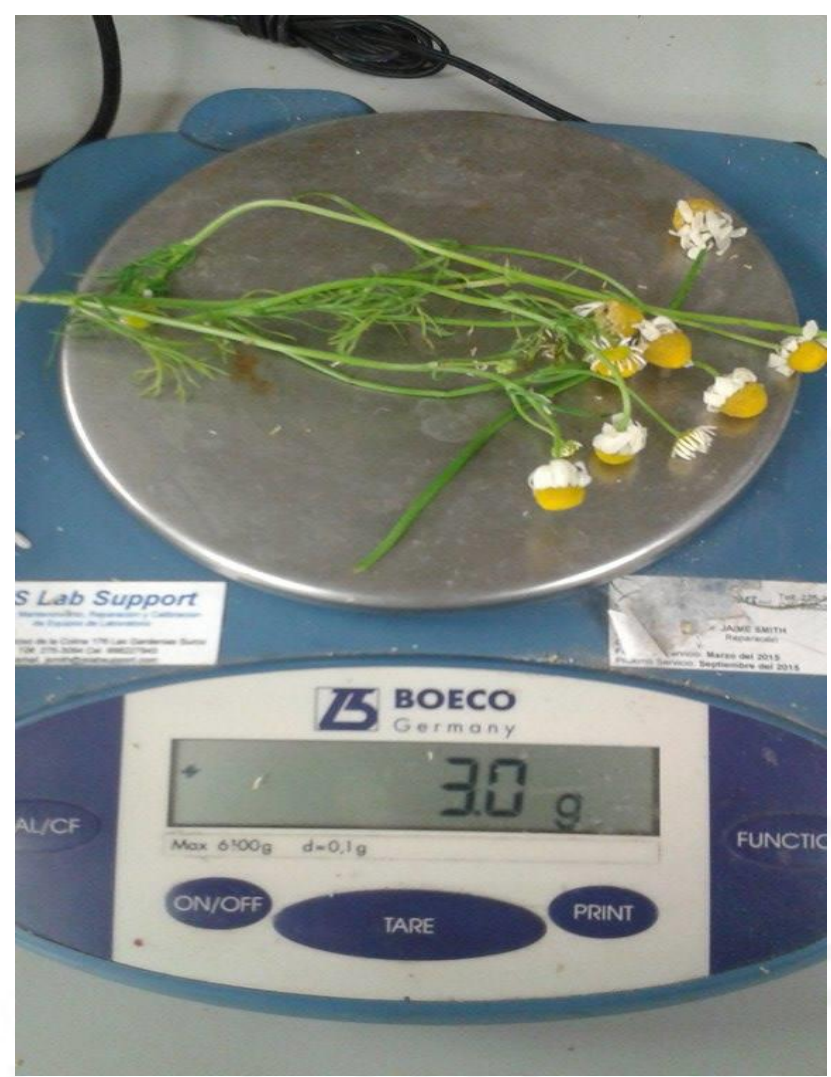

Anexo 6: Romero

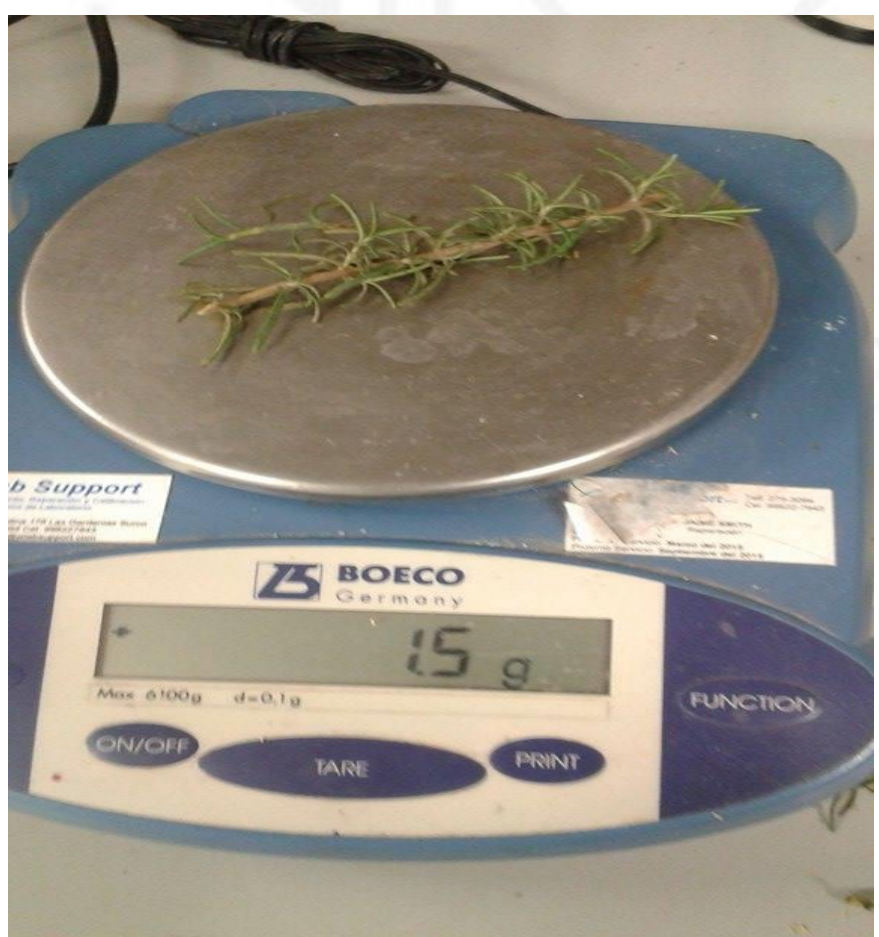




\section{Anexo 7: Matico}

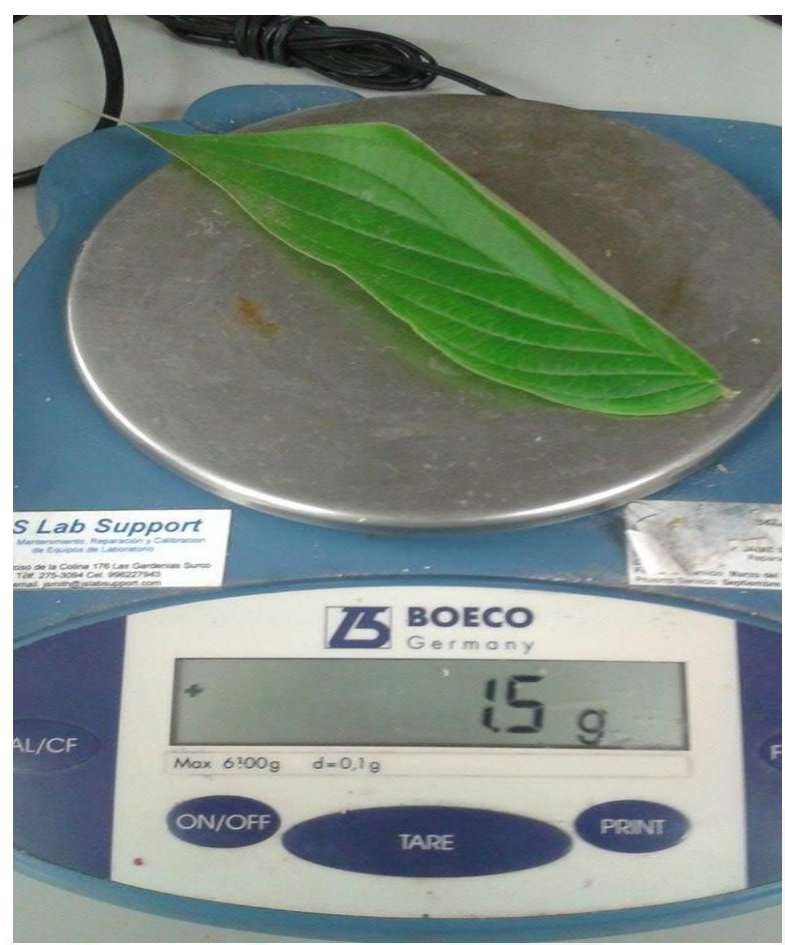

Anexo 8: Las hierbas medicinales listas para mezclarlas

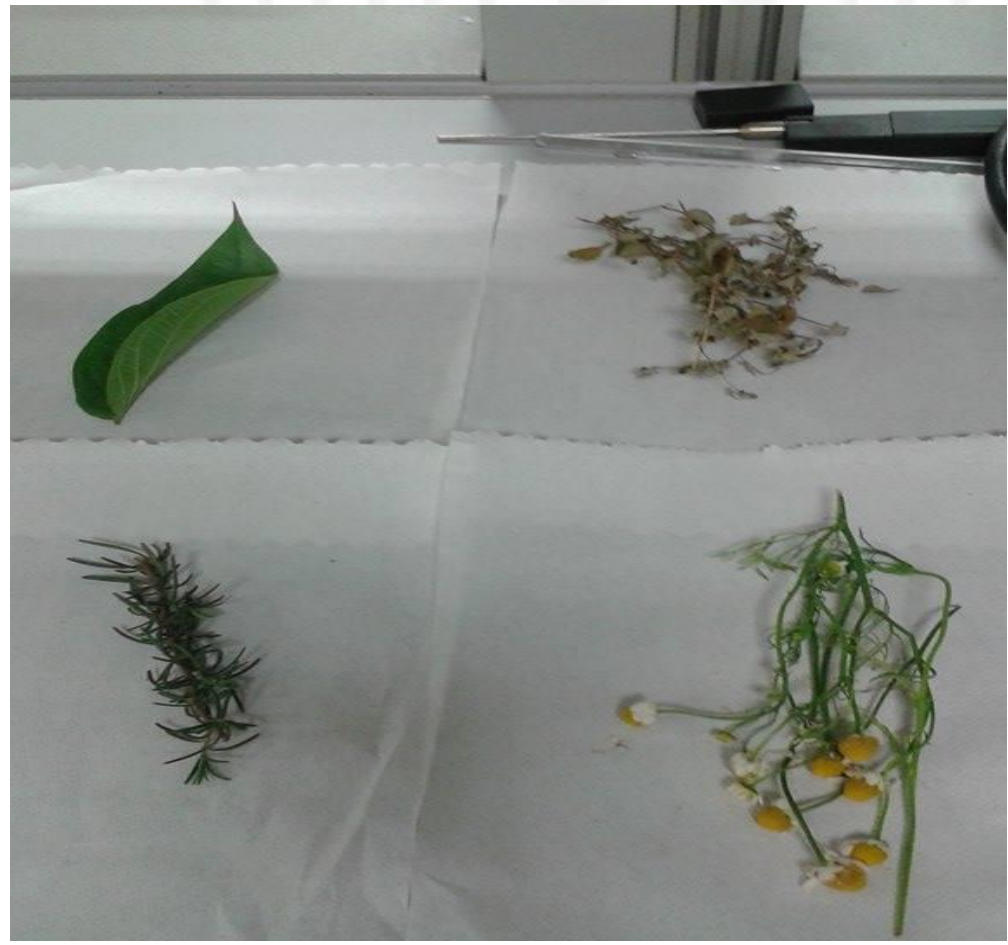


Anexo 9: Las hierbas medicinales en el proceso de cocción

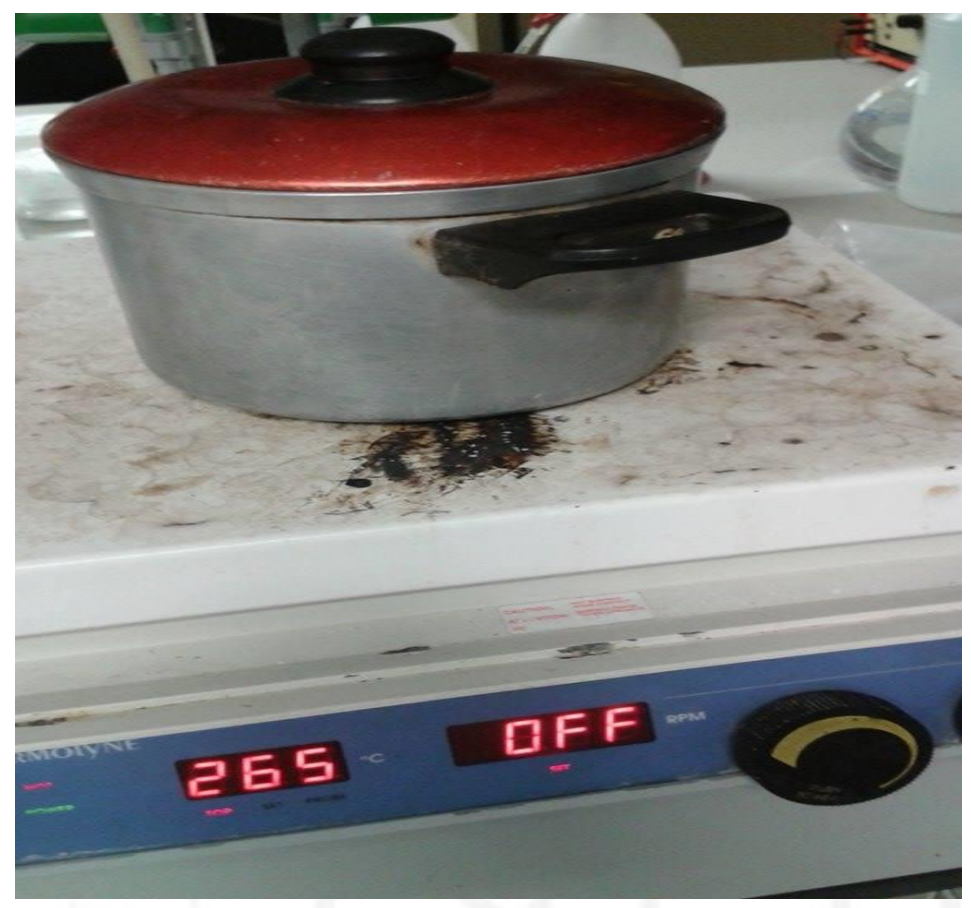

Anexo 10: Esencia de las distintas hierbas medicinales

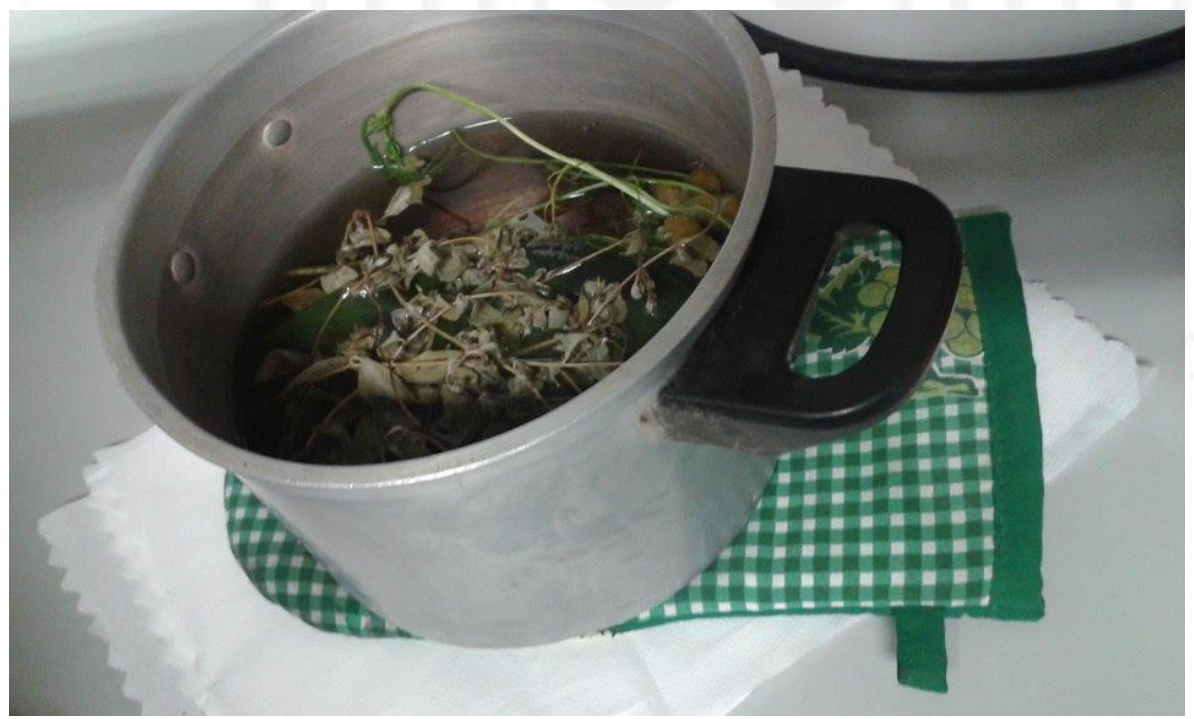


Anexo 11: Residuos que se obtienen en el filtrado

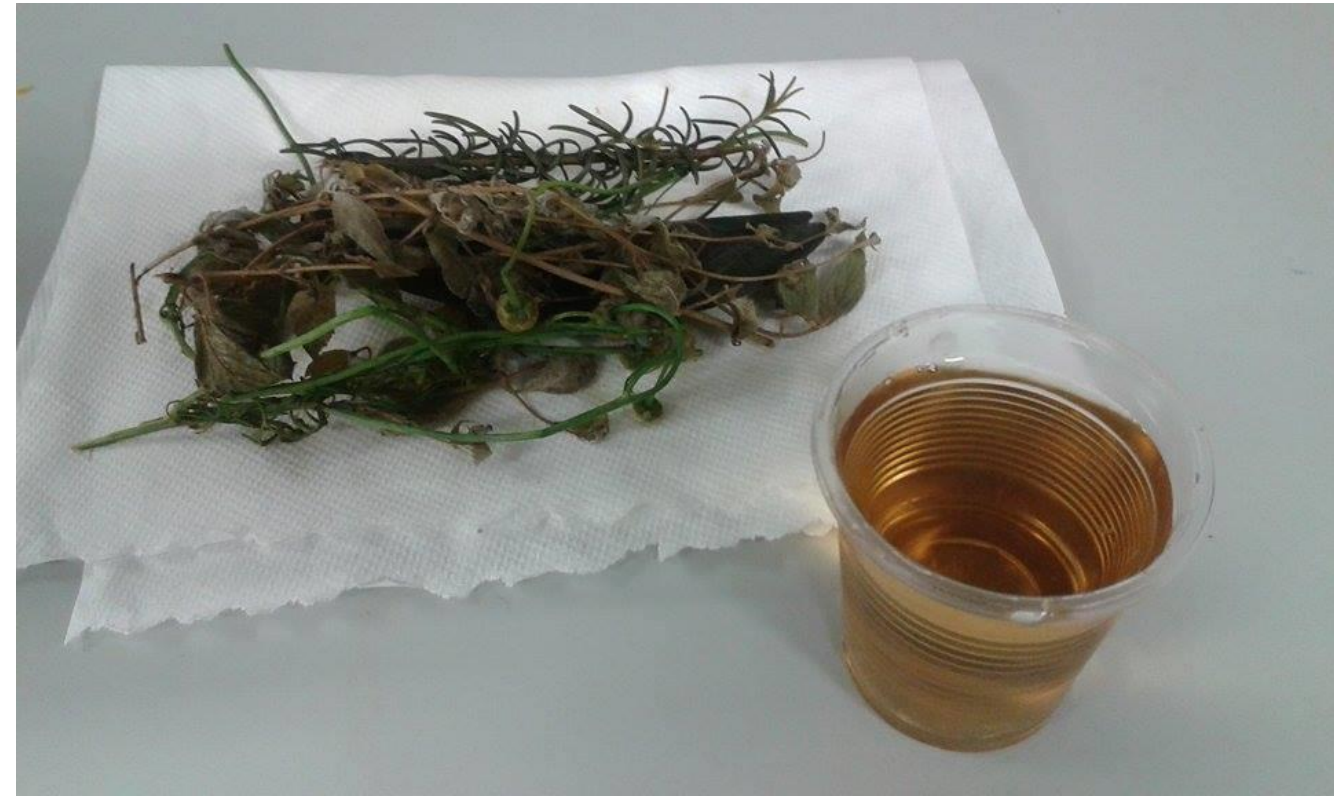

